\title{
THE ASSOCIATION BETWEEN NUTRITIONAL ADEQUACY AND LONG-TERM OUTCOMES IN CRITICALLY ILL PATIENTS REQUIRING PROLONGED MECHANICAL VENTILATION
}

by

Xuejiao (Shelly) Wei

A thesis submitted to the graduate program in Epidemiology

In conformity with the requirements for

the degree of Master of Science

Queen's University

Kingston, Ontario, Canada

(September, 2013)

Copyright @Xuejiao Wei, 2013 


\begin{abstract}
Background: While the provision of adequate nutrition support in critically ill patients has been shown to have an impact on short-term clinical outcomes, relatively little is known about subsequent long-term outcomes. We aimed to examine the association between nutritional adequacy and long-term outcomes including survival and health-related quality of life (HRQoL) in critically ill patients requiring prolonged mechanical ventilation.

Methods: The study was conducted as a retrospective cohort study on data collected prospectively in the context of a multicenter randomized controlled trial (RCT) in critically ill patients. Randomized patients who stayed in the intensive care unit (ICU) and were mechanically ventilated for $>8$ days were eligible for the study, but only six-month survivors were considered for the assessment of HRQoL. Nutritional adequacy was obtained from the average proportion of prescribed calories received during the first eight days of mechanical ventilation in the ICU. Survival status and HRQoL as assessed using Short-Form 36 Health Survey (SF-36) were obtained prospectively as part of the RCT protocol at three-months and six-months post ICU admission.
\end{abstract}

Results: Of the 1223 patients enrolled in the randomized controlled trial, 475 met the inclusion criteria for this study. At six-month follow-up, 302 of the 475 patients were alive. Among critically ill patients with $>8$ days of mechanical ventilation in the ICU, survival time in those who received low nutritional adequacy was significantly shorter than for those who received high nutritional adequacy after adjusting for important covariates. Among six-month survivors, clinically meaningful and statistical significant associations between increase in scores of Physical Functioning (PF) and Role Physical domains (RP) of the SF-36 and 25\% increase in 
nutritional adequacy were observed at three-months follow-up. No significant associations were observed at six-months.

Conclusions: Our findings suggest that nutritional adequacy received as early as the first week in the ICU seems beneficial to longer survival time and faster physical recovery post ICU discharge in critically ill patients requiring prolonged mechanical ventilation in the ICU. Well-designed randomized controlled trials are needed to provide stronger assessment of the causal impact of nutrition therapy on long-term outcomes. 


\section{Co-Authorship}

This thesis was the work of Xuejiao Wei in collaboration with her supervisors Dr. Daren Heyland, Dr. Hélène Ouellette-Kuntz, and Mr. Andrew Day. Data management and statistical analyses for the thesis were performed by Xuejiao Wei, with insight and guidance from Mr. Andrew Day. Interpretation of results and writing of the thesis was performed by Xuejiao Wei, with editorial feedback from Dr. Daren Heyland, Dr. Hélène Ouellette-Kuntz, and Mr. Andrew Day. 


\section{Acknowledgements}

I wish to express my gratitude to all those who contributed to the completion of this thesis. First and foremost, I would like to thank my supervisors, Dr. Daren Heyland, Dr. Hélène Ouellette-Kuntz, and Mr. Andrew Day, for their exceptional guidance, encouragement, and the tremendous amount of time they invested in this project. To Dr. Heyland, thank you for your clinical insight, and providing me with the opportunity to be involved with this project. To Dr. Ouellette-Kuntz, thank you for your invaluable input, and the constant support whenever I popped into your office. I am extremely grateful that you are my mentor. To Andrew, thank you for all your statistical expertise and your patience. This project would not have been possible without your support.

I would also like to thank the faculty, students, and staff in the Department of Public Health Sciences for a friendly and supportive learning environment during my Master's degree. Additionally, thank you to the research team at the Clinical Evaluation Research Unit, particularly Ms. Rupinder Dhaliwal, for sharing her expertise. Thanks also to Ms. Xuran Jiang for her work in preparing the data.

I would like to acknowledge the funding support from Dr. Daren Heyland and the Department of Public Health Sciences at Queen's University.

Last but not least, I would like to thank my fiancé, Jimmy Shi, for his continuous love and support. To Jimmy, thank you for always being there whenever I struggled to find the inspiration and motivation needed to complete this dissertation. I would also like to thank my parents for their unconditional love; and they have been a constant source of encouragement and strength for me. 


\section{Table of Contents}

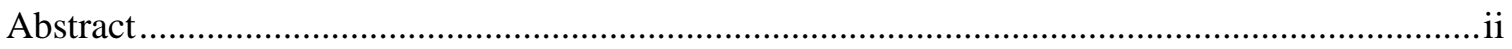

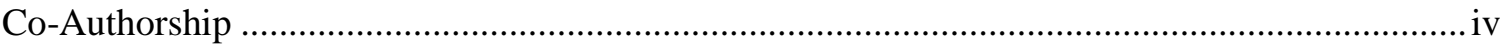

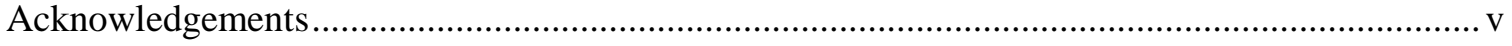

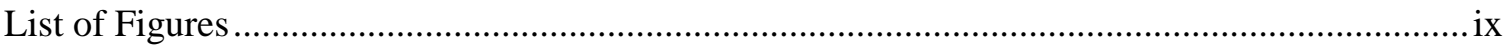

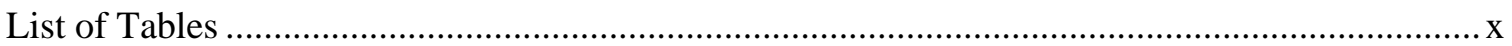

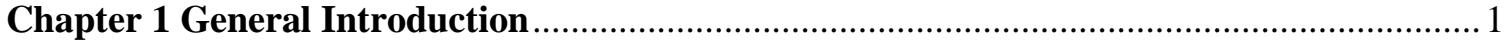

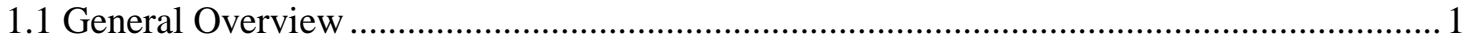

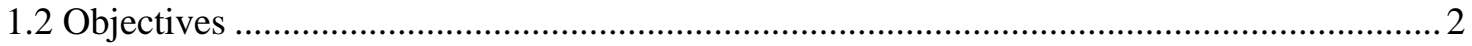

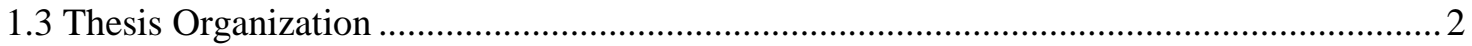

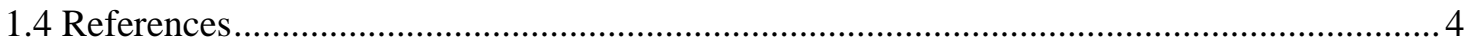

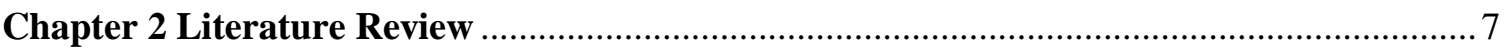

2.1 Malnutrition in Critically Ill Patients ............................................................................ 7

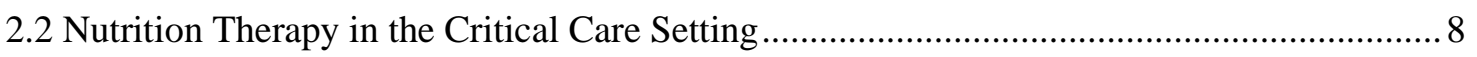

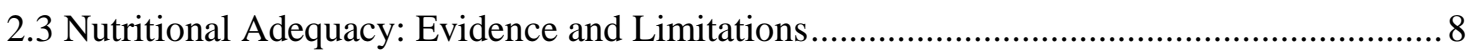

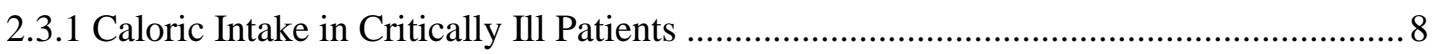

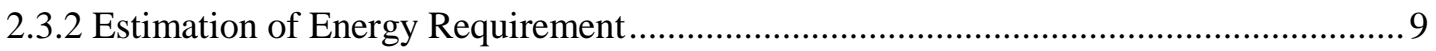

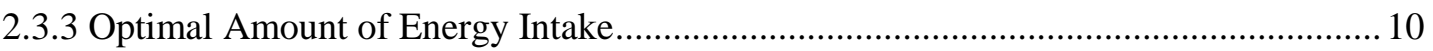

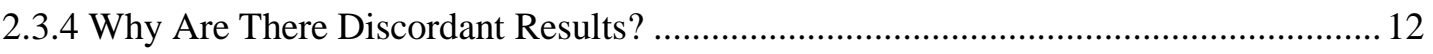

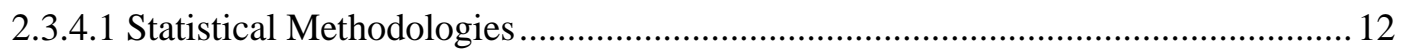

2.3.4.2 Target the 'High Risk' Patient Population ........................................................... 13

2.3.5 Lack of Evidence of the Effect on Long-term Outcomes ............................................ 14

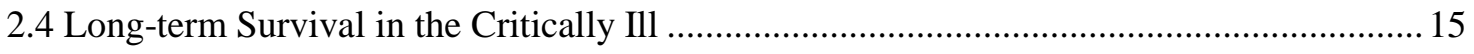

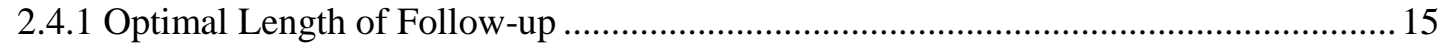

2.4.2 Predictors of Long-term Survival in the Critically Ill ................................................ 16

2.4.3 Nutritional Adequacy and Long-term Survival......................................................... 16

2.5 Health-related Quality of Life in Survivors of Critical Illness ........................................... 18

2.5.1 Definition of Health-related Quality of Life ............................................................... 18

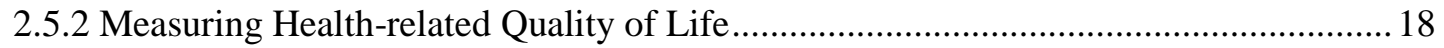

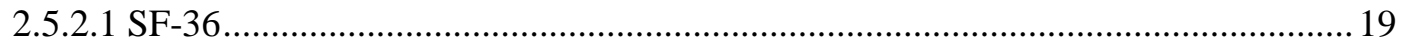

2.5.3 Changes in Health-related Quality of Life over Time …............................................20 


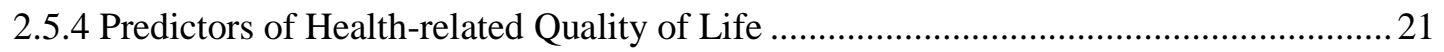

2.5.5 Nutritional Adequacy and Health-related Quality of Life .........................................22

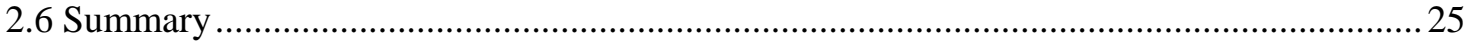

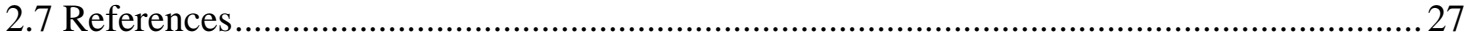

Chapter 3: Nutritional Adequacy and Long-term Survival in Critically Ill Patients

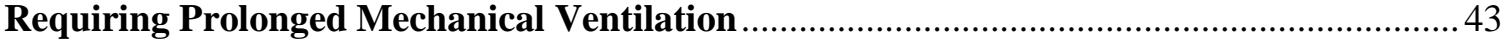

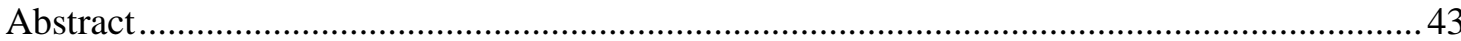

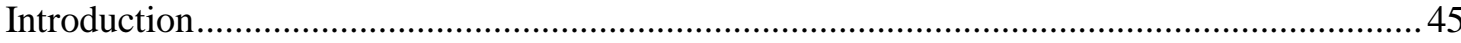

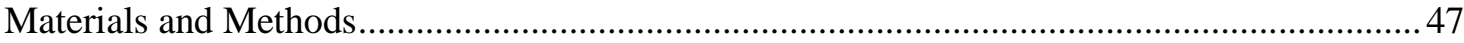

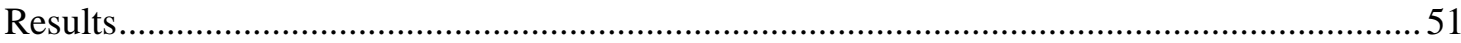

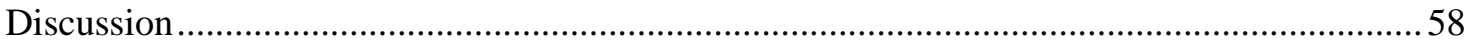

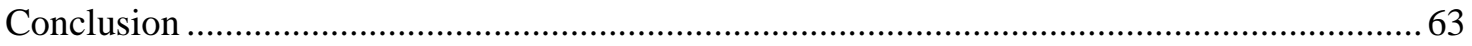

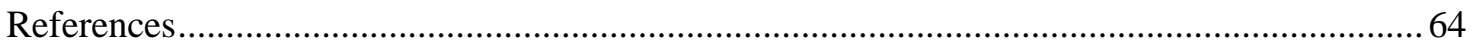

Chapter 4: Nutritional Adequacy and Health-related Quality of Life in Critically III

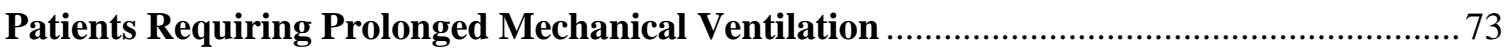

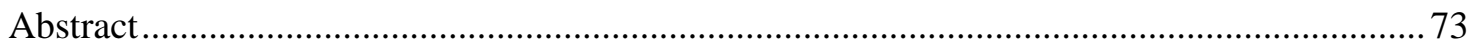

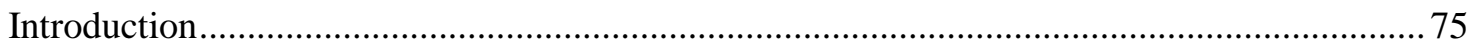

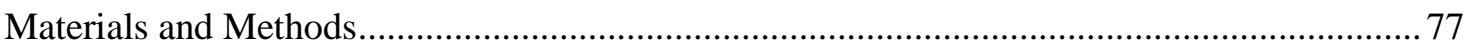

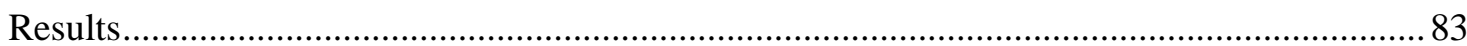

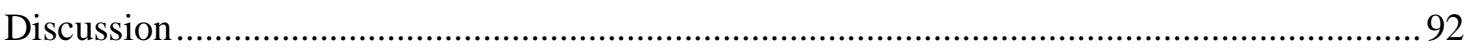

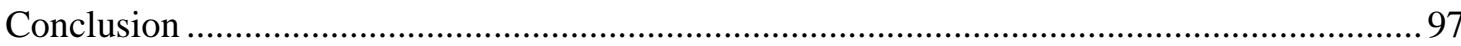

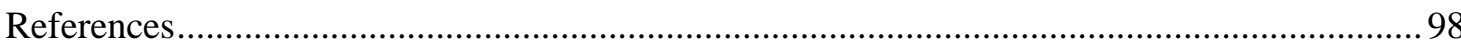

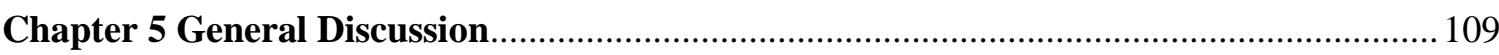

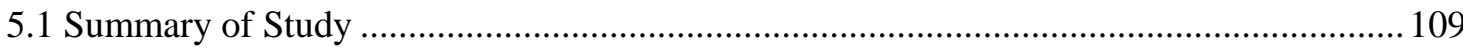

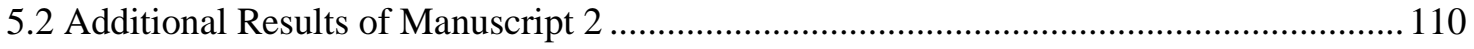

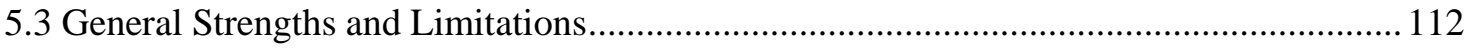

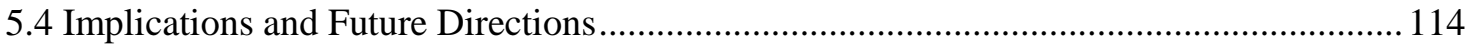

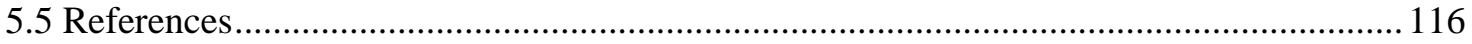

Appendix A Short-Form 36 Health Survey (SF-36) ................................................................. 119

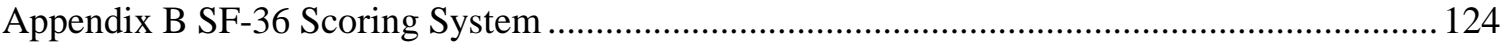

Appendix C Inclusion and Exclusion Criteria for the RCT …................................................ 125

Appendix D Results of Multiple Imputation for Manuscript 2 ................................................. 126 
Appendix E Additional Results for Manuscript 2 …......................................................... 128

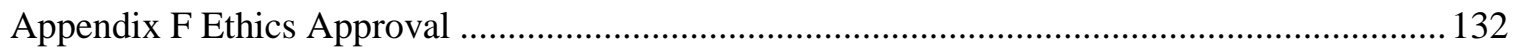




\section{List of Figures}

\section{Chapter 2}

Figure 2.1 Conceptual framework

\section{Chapter 3}

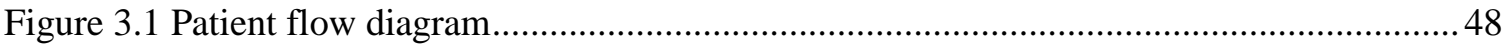

Figure 3.2 Crude Kaplan-Meier survival curves stratified by nutritional adequacy groups ...........55

Figure 3.3 Adjusted Kaplan-Meier survival curves stratified by nutritional adequacy groups .....57

\section{Chapter 4}

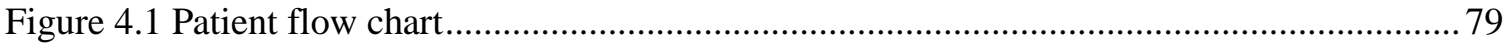

Figure 4.2 Three-month and six-month mean scores for PF, RP, and PCS of SF-36.................. 86

Figure 4.3 Unadjusted relationship between nutritional adequacy and SF-36 scores................... 88 


\section{List of Tables}

\section{Chapter 3}

Table 3.1 Characteristics of participating ICU sites

Table 3.2 Patient baseline characteristics

Table 3.3 Short-term clinical outcomes according to nutritional adequacy groups

Table 3.4 Hazard ratio estimates of the effect of nutritional adequacy on 6-months survival.......56

\section{Chapter 4}

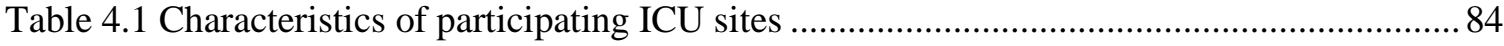

Table 4.2 Patient baseline and clinical characteristics in 6-month survivors ............................... 85

Table 4.3 Parameter estimates of the effect of nutritional adequacy on SF-36 scores ..................89

Table 4.4 Subgroup analysis of the effect of nutritional adequacy on SF-36 scores by admission

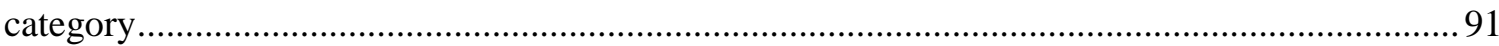




\section{Chapter 1}

\section{General Introduction}

\subsection{General Overview}

The aim of critical care medicine is to diagnose and treat patients with acute life threatening illness, and to restore their previous health condition and quality of life [1]. Advances in critical care service and modern technology have led to increased survival of critically ill patients [2]. Utilization of critical care has increased over the past two decades [3]. The expansion of critical care services comes at significant monetary cost, accounting for $20 \%$ of all inpatient costs [3]. Given that critical care has a significant impact on national health care both clinically and economically, knowledge of outcomes in patients admitted to intensive care units (ICU) and factors that may influence those outcomes are necessary to inform the most effective utilization of critical care.

Nutrition support has shifted from adjunctive care toward an active therapeutic strategy with high-quality evidence to support the concept that nutrients and nutritional interventions modulate the underlying disease process and affect clinical outcomes [4]. Nutrition therapy is now considered an integral part of standard care in the ICU [5]. Although nutrition therapy has been perceived as essential for improved short-term outcomes including morbidity and mortality in critically ill patients [6], the optimal amount of nutritional intake and its relative importance in long-term outcomes such as post ICU survival and health-related quality of life remain unknown.

As the number of ICU survivors increases, long-term outcomes in critically ill patients have become more and more important $[7,8]$. Survival alone is not the only important outcome after ICU discharge [9]. The true value of critical care should be determined by both survival and health-related quality of life [10]. There is emerging evidence suggesting that nutritional intake may affect muscle mass and muscle function, which may predict physical recovery and mortality 
in ICU patients [11-16] . Many critically ill patients have a poor nutritional status upon admission to ICU and their nutritional status often becomes further compromised during their ICU stay [17, 18]. More than half of all ICU patients worldwide are significantly underfed [19], and are thus likely to experience loss of muscle mass and impaired muscle function. As such, it is hypothesized that adequate nutritional intake may be associated with improved long-term survival and health-related quality of life (HRQoL) in critically ill patients.

\subsection{Objectives}

This thesis involves the secondary analysis of data from a large multi-centre randomized controlled trial in critically ill patients. The objectives of this thesis are as follows:

1) To examine the association between nutritional adequacy and 6-month survival in patients with prolonged mechanical ventilation in the intensive care unit.

2) To describe HRQoL at 3 and 6 months in 6-month survivors with prolonged mechanical ventilation in the intensive care unit.

3) To examine the association between nutritional adequacy and physical components of HRQoL at 3 and 6 months in 6-month survivors with prolonged mechanical ventilation in the intensive care unit.

\subsection{Thesis Organization}

This thesis is organized according to the framework provided by the "General Form of Theses" as outlined by the School of Graduate Studies at Queen's University [20]. The remainder of this thesis is organized into four sections. Chapter two presents a review of the literature on the epidemiology of malnutrition in critically ill patients, background and current state of knowledge on nutrition therapy and nutritional adequacy in the critical care setting, the importance and predictors of long-term survival and health-related quality of life in critically ill patients, as well 
as the biological plausibility for the relationship between nutritional adequacy and long-term outcomes in the critically ill.

The third chapter is the first manuscript, which presents the findings of the analyses examining the association between nutritional adequacy and six-month survival in critically ill patients requiring prolonged mechanical ventilation (Objective 1). To help facilitate interpretation and comparisons to previous research, in the main analysis of this manuscript, nutritional adequacy was treated as categorical based on the existing clinically meaningful cut-points. This manuscript has been prepared for submission to Critical Care.

Chapter four is the second manuscript, which presents the findings of the analyses examining the associations between nutritional adequacy and physical components of healthrelated quality of life in six-month survivors with prolonged mechanical ventilation in the intensive care unit (Objectives 2 and 3). Because the study was in survivors only and had a large amount of missing data and hence a much smaller sample size, nutritional adequacy was treated as continuous in the main analysis of Manuscript 2 to ensure adequate power. However, an exploratory analysis was performed by categorizing nutritional adequacy to examine the relationship of interest (additional results are presented in Appendix 5 and discussed in Chapter five). This manuscript has been prepared for submission to Critical Care Medicine.

Chapter five provides a general discussion of the thesis, including a summary of the key findings, the strength and limitations of the research, as well as implications and future research directions in the topic area. Additional material may be found in appendices at the end. 


\subsection{References}

1. Suter P, Armaganidis A, Beaufils F, Bonfill X, Burchardi H, Cook D: Predicting outcome in ICU patients. Intensive Care Medicine 1994, 20:390-397.

2. Khouli H, Astua A, Dombrowski W, Ahmad F, Homel P, Shapiro J, Singh J, Nallamothu R, Mahbub H, Eden E, Delfiner J: Changes in health-related quality of life and factors predicting long-term outcomes in older adults admitted to intensive care units. Critical Care Medicine 2011, 39:731-7.

3. Needham DM, Bronskill SE, Sibbald WJ, Pronovost PJ, Laupacis A: Mechanical ventilation in Ontario, 1992-2000: Incidence, survival, and hospital bed utilization of noncardiac surgery adult patients. Critical Care Medicine 2004, 32:1504-1509.

4. Jones N, Heyland D: Pharmaconutrition: a new emerging paradigm. Current Opinion in Gastroenterology 2008, 24:215.

5. Jones NE, Dhaliwal R, Day AG, Ouellette-Kuntz H, Heyland DK: Factors predicting adherence to the Canadian Clinical Practice Guidelines for nutrition support in mechanically ventilated, critically ill adult patients. Journal of Critical Care 2008, 23:301-7.

6. Heyland D, Dhaliwal R, Drover J, Gramlich L, Dodek P: Canadian clinical practice guidelines for nutrition support in mechanically ventilated, critically ill adult patients. Journal of Parenteral and Enteral Nutrition 2003, 27:355-373. 
7. Needham DM, Bronskill SE, Calinawan JR, Sibbald WJ, Pronovost PJ, Laupacis A: Projected incidence of mechanical ventilation in Ontario to 2026: Preparing for the aging baby boomers. Critical Care Medicine 2005, 33:574-579.

8. Spragg RG, Bernard GR, Checkley W, Curtis JR, Gajic O, Guyatt G, Hall J, Israel E, Jain M, Needham DM, Randolph AG, Rubenfeld GD, Schoenfeld D, Thompson BT, Ware LB, Young D, Harabin AL: Beyond mortality: future clinical research in acute lung injury. American Journal of Respiratory and Critical Care Medicine 2010, 181:1121-7.

9. Needham DM, Davidson J, Cohen H, Hopkins RO, Weinert C, Wunsch H, Zawistowski C, Bemis-Dougherty A, Berney SC, Bienvenu OJ, Brady SL, Brodsky MB, Denehy L, Elliott D, Flatley C, Harabin AL, Jones C, Louis D, Meltzer W, Muldoon SR, Palmer JB, Perme C, Robinson M, Schmidt DM, Scruth E, Spill GR, Storey CP, Render M, Votto J, Harvey MA: Improving long-term outcomes after discharge from intensive care unit: report from a stakeholders' conference. Critical Care Medicine 2012, 40:502-9.

10. Flaatten H, Kvåle R: Survival and quality of life 12 years after ICU. A comparison with the general Norwegian population. Intensive Care Medicine 2001, 27:1005-1011.

11. Volkert D: The role of nutrition in the prevention of sarcopenia. Wiener Medizinische Wochenschrift 2011, 161:409-15.

12. Kasper CE, Talbot LA, Gaines JM: Skeletal muscle damage and recovery. AACN Clinical Issues 2002, 13:237-47.

13. Puthucheary Z, Montgomery H, Moxham J, Harridge S, Hart N: Structure to function: muscle failure in critically ill patients. The Journal of Physiology 2010, 588:4641-8. 
14. Hickson M, Frost G: An investigation into the relationships between quality of life, nutritional status and physical function. Clinical Nutrition 2004, 23:213-21.

15. Faisy C, Rabbat A, Kouchakji B, Laaban JP: Bioelectrical impedance analysis in estimating nutritional status and outcome of patients with chronic obstructive pulmonary disease and acute respiratory failure. Intensive Care Medicine 2000, 26:518-25.

16. Gruther W, Benesch T, Zorn C, Paternostro-Sluga T, Quittan M, Fialka-Moser V, Spiss C, Kainberger F, Crevenna R: Muscle wasting in intensive care patients: ultrasound observation of the M. quadriceps femoris muscle layer. Journal of Rehabilitation Medicine 2008, 40:185-9.

17. Cerra FB, Benitez MR, Blackburn GL, Irwin RS, Jeejeebhoy K, Katz DP, Pingleton SK, Pomposelli J, Rombeau L, Shronts E, Robert R, Zaloga GP: Applied Nutrition in ICU Patients. A Consensus Statement of the American of Chest Physicians. Chest 1997, 111:769-778.

18. Quirk J: Malnutrition in critically ill patients in intensive care units. British Journal of Nursing 2000, 9:537-41.

19. Cahill NE, Dhaliwal R, Day AG, Jiang X, Heyland DK: Nutrition therapy in the critical care setting: what is "best achievable" practice? An international multicenter observational study. Critical Care Medicine 2010, 38:395-401.

20. General Forms of Theses. In School of Graduate Studies. Kingston, ON: Queen's University; 2011. 


\section{Chapter 2}

\section{Literature Review}

\subsection{Malnutrition in Critically Ill Patients}

Malnutrition is a disorder of body composition in which deficiencies of macronutrients and micronutrients occur due to inadequate nutritional intake which results in reduced body cell mass, organ dysfunction, and abnormal blood chemistry [1]. Pre-existing malnutrition is common in hospitalized patients, with as many as $40 \%$ of adult patients malnourished at the time of hospital admission [2]. Iatrogenic malnutrition is a hospital-acquired malnutrition that is induced inadvertently by medical treatments or diagnostic procedures. Two thirds of all patients experience deterioration of nutritional status during their hospital stay [2]. A review of 20 studies worldwide since 1990 found that the average malnutrition rate in the hospital was $41.7 \%$ [3]. Critically ill patients, often treated in the intensive care unit (ICU) environment, are those who sustained or were at risk of acute, life-threatening, single or multiple organ failure due to disease or injury (i.e. respiratory failure, post-operative care and major trauma such as head injury, motor vehicle accident, burns) [4]. Nutritional status of critically ill patients often becomes significantly more compromised during their ICU stay, due to factors that may be intrinsic to the patient or iatrogenic [1]. Malnutrition is particularly prevalent in critically ill patients, with an overall incidence as high as $50 \%[5,6]$. Consequences related to malnutrition in critically ill patients include impaired immunological function, impaired ventilator drive, and weakened respiratory muscles, leading to prolonged ventilator dependence and increased infectious morbidity and mortality [7-9]. 


\subsection{Nutrition Therapy in the Critical Care Setting}

The key objective of nutrition support is to supply the nutritional substrates necessary to meet the metabolic needs when oral feeding is not possible [6]. Better understanding of metabolic response to critical illness and effects of nutrients in maintaining homeostasis in the critically ill patient has led to advances with nutrition support [10]. Nutrition support used to be regarded as adjunctive care to preserve lean body mass, to maintain immune function, and to prevent metabolic complication [10]. Nutrition support has shifted to nutrition therapy and is now considered as a first-line therapy to prevent oxidative cellular injury, to enhance immune function, and to attenuate metabolic response to critical illness [10].

Nutrition therapy is most often provided as nutritional supplementation in the form of enteral (i.e. feeding via tube into the gut) or parenteral (i.e. intravenous feeding) nutrition [11]. Clinical practice guidelines in the area of critical care nutrition have been published in Canada, Europe, and the US $[10,12,13]$. Key considerations in nutrition therapy include: route of feeding, when to feed, and what to feed $[10,12,13]$. Although high-quality evidence on nutrition therapy in the critically ill has been published, many controversies still exist.

\subsection{Nutritional Adequacy: Evidence and Limitations}

\subsubsection{Caloric Intake in Critically Ill Patients}

Nutritional adequacy is often defined as energy provision divided by energy requirement as determined by indirect calorimetry or a formula that estimates energy requirement [14-16]. Critical illness often further worsens a patient's poor nutritional status by increasing their metabolic rate and by impairing their utilization of nutritional substrates $[1,17]$. Adequate nutritional intake is essential in the prevention and treatment of malnutrition in critically ill patients. However, critically ill patients frequently receive inadequate nutritional support. 
Consistently, studies have reported that, on average, critically ill patients only receive caloric intake between $40 \%$ and $50 \%$ of their prescribed requirements [18-22]. A more recent international multicenter study showed that more than half of all ICU patients worldwide are significantly underfed based on the proportion of prescribed energy received for the first 12 days of ICU stay [16]. Patients who require prolonged mechanical ventilation are at particular risk for underfeeding because they are susceptible to the wasting effects of illness [23].

Some factors that may limit nutritional intake in critically ill patients, include gastrointestinal intolerance of enteral tube feedings, repeated interruptions in feedings for tests and procedures, and delayed initiation of nutritional support [15, 24]. Accurately assessing caloric requirements and closely monitoring the delivery of nutrition can help to prevent underfeeding or overfeeding patients [15].

\subsubsection{Estimation of Energy Requirement}

Although there are various methods available for estimating energy needs, there are no prospective, randomized studies to support the use of any single method. Energy requirements vary based on age, activity level, nutritional status, severity of illness, need for wound healing, and a variety of other factors [15]. The most common method for determining caloric needs of critically ill patients is the Harris-Benedict Equation (HBE) [15]. The HBE is based on regression equations that calculate resting energy expenditure for healthy persons based on their body weight, age, sex, and height [15]. Disease-specific equations or stress factors that account for activity and injury are then multiplied by the resting energy expenditure to account for the increased energy expenditure during acute illness and injury [15]. Although HBE is easy to use, inexpensive, and universally available, its accuracy is limited in particular patient groups, such as ventilator-dependent patients and patients who are either morbidly obese or severely malnourished $[15,25]$. 
Another common method to estimate energy requirements is indirect calorimetry. The resting energy expenditure for this method is calculated by measuring pulmonary gas exchange. Although this method is more accurate, it is technically demanding, expensive, time consuming, and requires trained personnel to perform it [25].

\subsubsection{Optimal Amount of Energy Intake}

The optimal amount of energy intake in the critically ill remains controversial. Studies exploring the association between optimal caloric intake and clinical outcome have yielded conflicting results. Several studies have shown better clinical outcomes in patients receiving low caloric intake [26-32]. A prospective cohort study by Krishnan et al. $(\mathrm{n}=187)$ showed that patients receiving moderate caloric intake (33\%-65\% of total recommended caloric amount) had better clinical outcomes including reduced mechanical ventilation duration, ICU length of stay (LOS), and hospital mortality than those receiving higher caloric intake [26]. A cohort study nested with a randomized controlled trial (RCT) by Arabi et al. $(\mathrm{n}=523)$ suggested that receiving near target caloric intake (>64.6\% of their goal calories) was associated with higher hospital mortality [27]. Dickerson et al. studied 40 critically ill, obese patients and found that receiving fewer calories $(<20 \mathrm{kcal} / \mathrm{kg})$ was associated with decreased ICU LOS [28]. A single-center RCT on 150 mechanically ventilated medical patients also suggested that patients receiving fewer calories had lower incidence of ventilator-associated pneumonia and shorter ICU LOS [29]. Two recent RCTs on patients with acute lung injury ( $n=200$ and $n=1,000)$ compared trophic feeding ( $25 \%$ of goal calories) vs. full enteral feeding ( $80 \%$ of goal calories) for the first six days of ICU stay. Both studies reported that there were differences favoring trophic feeding in ventilator-free days, infections, and 60-day mortality between trophic and full feed patients [30, 31]. Another RCT of general medical-surgical ventilated patients $(n=240)$ compared permissive feeding $(60-$ $70 \%$ of caloric requirement) vs. full feeding (90\% to $100 \%)$. There were no differences found in 
28-day and 90-day mortality between permissive and full feed patients. However, hospital mortality and ICU LOS were reduced in the permissive feeding group [32].

In contrast, other studies have shown underfeeding or caloric debt was associated with adverse clinical outcomes, including increased infection, metabolic complications, prolonged mechanical ventilation, and increased ICU and hospital mortality [24, 33-42]. A large scale multicenter observational study with 2,772 mechanically ventilated patients and another multicenter observational study with 207 patients showed that increased intake of energy was associated with lower 60 -day mortality and reduced infection [33, 34]. A prospective observational study of 48 surgical patients with $\geq 5$ days of ICU stay suggested that cumulative energy deficit or hypocaloric feeding was associated with longer ICU LOS, more days on mechanical ventilation, and increased complications [24]. The largest multicenter observational study to date by Heyland et al., including 7,872 mechanically ventilated patients suggested that providing at least $80 \%$ of prescribed calories was associated with improved clinical outcomes [35]. A prospective cohort study by Rubinson et al. $(\mathrm{n}=138)$ found that low caloric intake $(<25 \%$ of prescribed calories) was associated with an increased risk of nosocomial bloodstream infection in critically ill patients [36]. Other observational studies consistently showed that underfeeding was associated with increased infection, prolonged mechanical ventilation, and higher ICU mortality [37-39]. A single-center RCT of 82 head-injured patients demonstrated that an enhanced nutrition group (59.2\% of caloric goal) had better neurological outcome and fewer overall complications compared to the standard group (36.8\% of caloric goal) [40]. A multicenter cluster-randomized clinical trial of algorithms for critical-care enteral and parenteral therapy (ACCEPT) (499 patients at 14 sites) reported that patients who received more calories per day (1,264 kcal vs. $998 \mathrm{kcal})$, had shorter hospital LOS, and a trend toward reduced mortality [41]. A single-center RCT $(n=130)$ of a tight caloric control strategy showed that the group receiving 
higher caloric intake $(2,086 \pm 460 \mathrm{kcal}$ vs. $1,480 \pm 468 \mathrm{kcal})$ had lower hospital mortality [42]. Review studies have documented substantial evidence showing that adequate nutritional support is crucial to improving wound healing, decreasing catabolic response to injury, improving gastrointestinal structure and function, reducing length of stay, lowering complication rates, and decreasing morbidity and mortality [43-45].

As demonstrated in studies cited above, there is no consensus on a standard definition of trophic feeding or permissive underfeeding. Although there is lack of agreement, trophic feeding or permissive underfeeding have been most widely defined as providing approximately $25 \%$ of estimated total caloric needs $[30,31,36]$. Full feeding or target feeding have been commonly defined as providing $80 \%$ to $100 \%$ of prescribed caloric needs [30-32, 35].

Although the optimal amount of nutritional intake continues to be controversial, there is general agreement that excessive hypercaloric feeding should be avoided. Studies have suggested that hypercaloric or overfeeding (>110\% of prescribed calories) is associated with hyperglycemia, hypercapnia, and gastric feeding intolerance, which can lead to overall detrimental clinical outcomes [14, 15, 46-49].

\subsubsection{Why Are There Discordant Results?}

\subsubsection{Statistical Methodologies}

The inconsistency in the estimated association between amount of caloric intake and clinical outcomes reported in the studies is significantly influenced by the statistical methodology used. A recent large observational study by Heyland et al. shows that the discordant results in the association between the amount of energy intake and clinical outcomes is highly dependent on the statistical method used, particularly the method of accounting for duration of exposure to nutrition or length of stay in the ICU [35]. Since most feeding protocols recommend gradually 
increasing nutrition intake over the first several days of ICU stay, meaning that often little or none is given on the first few days, the daily average amount of calories received would be lower for patients with shorter stays in the ICU. Therefore, the duration of exposure to nutrition as measured by length of stay in the ICU may be a confounder in evaluating the relationship between nutrition intake and clinical outcomes because short-term ICU patients who have a good outcome often receive little calories.

Heyland et al. evaluated the relationship between the amount of calories intake and mortality using various sample restriction (i.e. only including patients with a minimum or the same lengths of stay) and/or statistical adjustment through regression models [35]. They demonstrated that the most robust approach to avoid this confounding problem is to only include patients with a minimum stay (i.e. at least 12 days) in the ICU, but this method requires excluding many patients and limits inference to those staying longer in the ICU. The study found that excluding patients whose ICU length of stay or duration of exposure to nutrition is less than 12 days suggested that increased caloric intake was associated with lower 60-day mortality. Similar results were obtained using four-day restriction while adjusting for number of days in the ICU before progressing to permanent exclusive oral feeding. The study also showed analyses that do not exclude patients who have very short durations of exposure to nutrition, or that do not adjust for the number of days of exposure to nutrition suggest that increased caloric intake is associated with increased mortality. Therefore, it is especially important to consider the most appropriate statistical method to account for duration of exposure to nutrition and ICU length of stay in studying the relationship between nutrition intake and clinical outcomes.

\subsubsection{Target the 'High Risk' Patient Population}

Another factor that may lead to discordant results is that many studies fail to consider that not all critically ill patients are the same in terms of their nutrition risk [50, 51]. The patients at 
high nutrition risk are more likely to benefit from nutrition therapy than others [52]. This assertion is based on the evidence from studies that showed a differential treatment effect of artificial nutrition in different subgroups of ICU patients. Alberda et al. found that the beneficial treatment effect of increased calories intake on 60-day mortality was observed only in critically ill patients whose body mass index (BMI) was under 25 or at least 35 with no effect on patients with a BMI $>25$ and <35 [33]. A study by Faisy et al. demonstrated that in a small group ( $n=38)$ of critically ill patients requiring prolonged mechanical ventilation ( $>7$ days), an energy deficit of approximately $1200 \mathrm{kcal} /$ day was independently associated with ICU mortality [38]. In summary, studies have shown that critically ill patients with low BMI, high BMI, or with prolonged stays in the ICU may benefit the most from nutrition therapy. Hence, future studies of critical care nutrition should consider patients at high nutrition risk, such as those who require prolonged mechanical ventilation or who have extreme BMI.

\subsubsection{Lack of Evidence of the Effect on Long-term Outcomes}

While many studies have documented the impacts of nutritional intervention on shortterm outcomes such as ICU-acquired infection and ICU and hospital mortality, relatively little is known about subsequent longer-term outcomes. Nutritional interventions might have an effect on longer-term outcomes [53]. An emerging body of evidence suggests muscle mass and muscle function predict mortality in ICU patients after prolonged critical illness [54, 55]. Previous studies also suggested that longer-term outcomes in ICU patients might be different from their short-term outcomes [56]. As the outcomes of nutritional interventions in the ICU are evaluated, there is need to move beyond focusing on short-term outcomes.

Needham et al. proposed that by 2026 , the proportion of the population $\geq 65$ years old in North America would increase from $13 \%$ to $21 \%$ [57]. This demographic trend is expected to have a great impact on critical care medicine, increasing the incidence of mechanical ventilation 
by $31 \%$ between 2000 and 2026 . As critical care advances, the number of ICU survivors is growing and expected to further increase with the aging baby boomer population and improved short-term mortality $[57,58]$.

Although critical care improves short-term outcomes for most patients admitted to an ICU, the high resources consumed and cost of critical care above that of general hospital care may be considered excessive if long-term outcome is poor [59]. Thus, as the number of ICU survivors increases, information on how ICU interventions impact the patients in the long run and more importantly, in the long-term health-related quality of life (HRQoL) is needed.

Understanding long-term outcomes among ICU patients is essential for making decisions about the efficacy and efficiency of ICU interventions. This thesis examines long-term survival and HRQoL as the indicators of outcome in critically ill patients.

\subsection{Long-term Survival in the Critically III}

\subsubsection{Optimal Length of Follow-up}

Historically, most studies have focused on survival to 28 days after admission, or to either ICU or hospital discharge as the primary end-point when studying ICU patients [56]. As critical care advances, more studies have shifted to examining 60-day mortality, 90-day mortality, and 6-month mortality. Many studies have challenged the use of short-term survival as a valid measure of intensive care outcome [56]. A study emphasized that only assessing short-term outcomes is not appropriate for ICU patients with sustained severe illness because mortality continues after hospital with most occurring within six months [53]. Moreover, based on survival curves from prior studies, a roundtable conference in 2002 recommended that all ICU interventional trials designed to test efficacy include survival follow-up to at least six months $[60]$. 


\subsubsection{Predictors of Long-term Survival in the Critically Ill}

Cumulative mortality over the six months after ICU admission ranges from $22 \%$ to $39 \%$, with five studies providing important data regarding long-term mortality [32, 61-64]. Multiple risk factors that determine long-term survival post ICU discharge have been reported, including age, comorbidity (estimated using Charlson Comorbidity Index), severity of illness (determined with the acute physiology and chronic health evaluation (APACHE) II score), number of organ failures (determined with sequential organ failure assessment (SOFA) score), primary diagnosis group (i.e. cardiac surgery, sepsis, and trauma), and admission category (surgical or medical) [56, $63,65]$. Among all the risk factors, age, comorbidity, and primary diagnosis group were most strongly associated with long-term survival [65].

\subsubsection{Nutritional Adequacy and Long-term Survival}

Griffiths proposed that nutritional interventions have potential positive effect on longerterm survival [53]. He suggested that early deaths in ICU depend on the ability of the patients to cope with the stress, thus are minimally affected by a nutritional intervention. However, longerterm survival depends on the physical reserve and ability to repair, which is related to nutritional intake. Patients who survive the initial illness but have a poor nutritional state or physical reserve may die later from a relatively minor problem.

The biological plausibility in the relationship between nutritional adequacy and long-term survival can be predicted based on the evidence that nutritional intake impacts muscle mass and muscle function which in turn predicts mortality. Loss of some muscle mass is due to catabolism, hypermetabolism, and disuse in the ICU [66]. More importantly, amino acids released from muscles are crucial for synthesis of acute phase proteins and other inflammatory mediators. Although the effect of loss of muscle mass on clinical outcomes is not well understood in the 
critically ill population, it has been related to poor clinical outcomes including mortality in other clinical populations such as cancer, chronic renal failure, and liver disease [51]. Furthermore, there is emerging evidence suggesting that the loss of muscle mass may affect clinical outcomes differently depending on the length of ICU stay [66]. For ICU patients who are 'short-stayers' (24-48 hours length of ICU stay), loss of lean body mass may not significantly modify the outcome. However, for patients who are 'long-stayers' (more than 7-10 days), cumulative energy and protein balance may become quite severe and have been shown to effect morbidity and mortality [33].

Despite the understanding that nutritional interventions have the potential to effect longterm survival in the critically ill, there is little research investigating the long-term outcomes of nutritional intake in the ICU. A recently published prospective study of patients enrolled in a randomized controlled trial compared the effect of trophic feeds (for the first 6 days, received $25 \%$ of goal calories) with full feeding (received about $80 \%$ of goal calories) on survival and quality of life at 6 and 12 months in 525 patients with acute lung injury [64]. The study found no difference in survival at 6 and 12 months follow-up after initial trophic or full enteral feeding. No specific insights were drawn from the finding due to limited research on investigating the effect of nutritional intake on long-term outcomes; hence, highlighting the importance of further investigation on this issue. However, it is important to note that the patients studied in this trial were at low nutrition risk. They were young for ICU patients (average 52 years), well nourished (average BMI 30), and had a relatively short stay in the ICU (average duration of mechanical ventilation of 5 day). Thus, it is not surprising that the trial found no difference in clinical outcomes between trophic and full feeding. 


\subsection{Health-related Quality of Life in Survivors of Critical Illness}

\subsubsection{Definition of Health-related Quality of Life}

The World Health Organization (WHO) defines quality of life (QoL) as individuals' perceptions of their position in life in the context of the culture and value systems in which they live and in relation to their goals, expectations, standards and concerns [67]. QoL is a multidimensional concept comprised of five major domains: 1) physical status and functional abilities, 2) psychological status and well-being, 3) social interactions, 4) economic and vocational status and factors, and 5) religious and spiritual status [68].

HRQoL is determined primarily by the person's health and can be influenced by clinical interventions. Environmental, economic, social, spiritual, and political variables often influence a person's QoL, but these factors are not expected to be directly affected by most health care interventions [68]. However, despite the distinction between QoL and HRQoL, the two terms are often used interchangeably in the literature [69]. Conceptually, HRQoL includes the domains of physical, psychological, social, spiritual, and role functioning, as well as general well-being, which are seen as distinct areas that are influenced by a person's experience, beliefs, expectations, and perceptions [68].

\subsubsection{Measuring Health-related Quality of Life}

HRQoL has been assessed by questionnaires that are regarded as measurement instruments. Instruments for measuring HRQoL can be divided into two groups: generic or disease specific [70]. Generic instruments measure all important aspects of HRQoL and are designed to be applicable to a range of populations and interventions irrespective of the type or number of illness [70]. This enables the comparison between clinical groups and the general population. Instruments specific to a particular disease are more specific and sensitive but they 
make comparison between different patient groups difficult [70]. Well-established instruments for generic measures that are commonly used in critical care research include the Short-Form 36

Health Survey (SF-36), Sickness Impact Profile (SIP), the EuroQol five-dimension (EQ-5D), and the Nottingham Health Profile (NHP) [71, 72]. SF-36 and SIP have been validated in critically ill patients [73-75].

As for the optimal follow-up period for HRQoL in critically ill patients, Heyland et al. justified that following patients for six months is adequate because most of the improvements in HRQoL will have occurred by then [76]. However, it is important to note that this recommended follow-up period is an average estimate based on a heterogeneous patient group. A longer followup period may be needed for older populations because they do not have the same pattern of response to treatment and recovery as younger patients.

\subsubsection{SF-36}

The SF-36 is one of the most widely used generic questionnaires in critical care and may be appropriate for critical care patients $[73,74,77]$. The SF-36, a short-form HRQoL scoring system, is a questionnaire with 36 questions that comprise eight domains: 1) physical functioning, a ten-question scale that captures abilities to deal with the physical requirement of life; 2) rolephysical, a four-question scale that evaluates the extent to which physical capabilities limit activity; 3 ) bodily pain, a two-item scale that evaluates the perceived amount of pain experienced during the previous four weeks and the extent to which that pain interfered with normal work activities; 4) general health, a five-item scale that evaluates general health in terms of personal perception; 5) vitality, a four-item scale that evaluates feelings of energy and fatigue; 6) social functioning, a two-item scale that evaluates the extent and amount of time, if any, that physical health or emotional problems interfered with family, friends, and other social interactions during 
the previous four weeks; 7) role-emotional, a three-item scale that evaluates the extent, if any, to which emotional factors interfere with work or other activities; 8) mental health is a five-item scale that evaluates feelings principally of anxiety and depression [78] (See Appendix A for SF36 Questionnaire).

The domains of the SF-36 are summarized into two higher-order scales: physical and mental health summary score [79] (See Appendix B for SF-36 Scoring System). In the SF-36 scoring system, the domains are assessed quantitatively, each on the basis of answers to two to ten multiple choice questions, and a score between 0 to 100 is calculated for each domain, with a higher score indicating a better state of health [74]. The score of the summary components of the SF-36 are weighted averages of the domains based on a factor analysis with orthogonal rotation [80]. A minimum change of five points in the eight domains and two points in the two summary scales are considered clinically important [79].

The SF-36 has been shown to have the required acceptability, reliability, and validity in the ICU population and it is one of the recommended outcome measurements [73, 74]. Heyland et $a l$. assessed the validity of the SF-36 in a representative sample of the survivors of sepsis and demonstrated that the SF-36 has high internal consistency (Cronbach's alpha: 0.65-0.94) and excellent test-retest stability (intraclass correlation coefficient: 0.75-0.97) [74].

\subsubsection{Changes in Health-related Quality of Life over Time}

A systematic review of 21 studies with 7,320 patients found that ICU survivors had significantly lower HRQoL prior to ICU admission than matched general population samples [72]. Existing research indicates that HRQoL in ICU survivors is worse post ICU discharge ranging from 1 month to 5 years compared to gender and age matched general population 
samples [81-87]. Furthermore, studies suggest that HRQoL of ICU survivors is generally poorer following discharge than prior to their ICU admission [72].

HRQoL in ICU survivors improves with time after discharge but this improvement is not uniform across domains. In an observational study of ICU survivors staying for more than 24 hours in the ICU, Graf et al. used the SF-36 and found that physical and emotional role scores deteriorated one month after ICU discharge but returned to baseline nine months thereafter [85]. Herridge et al. evaluated survivors of acute respiratory distress syndrome (ARDS) and found that they have persistent functional limitations one year after discharge from the ICU [88]. Wehler et al. found that patients with multiple organ failure (MOF) had regained HRQoL at six months after ICU discharge, although persistent deterioration was especially noted in the physical health domains [89]. In summary, studies found clinically meaningful improvements in the SF-36 domains except mental health and general health perceptions over one to twelve months of follow-up [72]. Impaired HRQoL in ICU survivors is most commonly found in the domains related to physical health and it generally improves, to some degree, within six to twelve months after discharge [72, 76, 90-92].

\subsubsection{Predictors of Health-related Quality of Life}

A variety of factors have been associated with worse HRQoL, including age, severity of illness, admission category, ICU length of stay, and functional comorbidity [72, 76, 93]. Age and severity of illness were found to be strong predictors of HRQoL. Studies found lower physical functioning or overall HRQoL in older versus younger ICU survivors [82, 85, 89, 94]. Studies also demonstrated a significant association between increased severity of illness (APACHE II) and lower physical functioning or general health perceptions $[84,89,95]$. The functional comorbidity index was found to be highly correlated with SF-36 scores [76, 96]. In addition, 
lower scores related to physical HRQoL were specifically associated with critical illness polyneuropathy, the loss of muscle mass, and impaired pulmonary function [76, 91, 97].

\subsubsection{Nutritional Adequacy and Health-related Quality of Life}

There has been little work done to investigate the effect of nutrition therapy on HRQoL in survivors of critical illness. Despite the lack of documentation in the literature, the biological plausibility in the relationship between nutritional adequacy and HRQoL is hypothesized based on the evidence of nutrition's impact on muscle mass and muscle function which in term facilitates better physical recovery. A conceptual framework of this study is shown in Figure 2.1. 


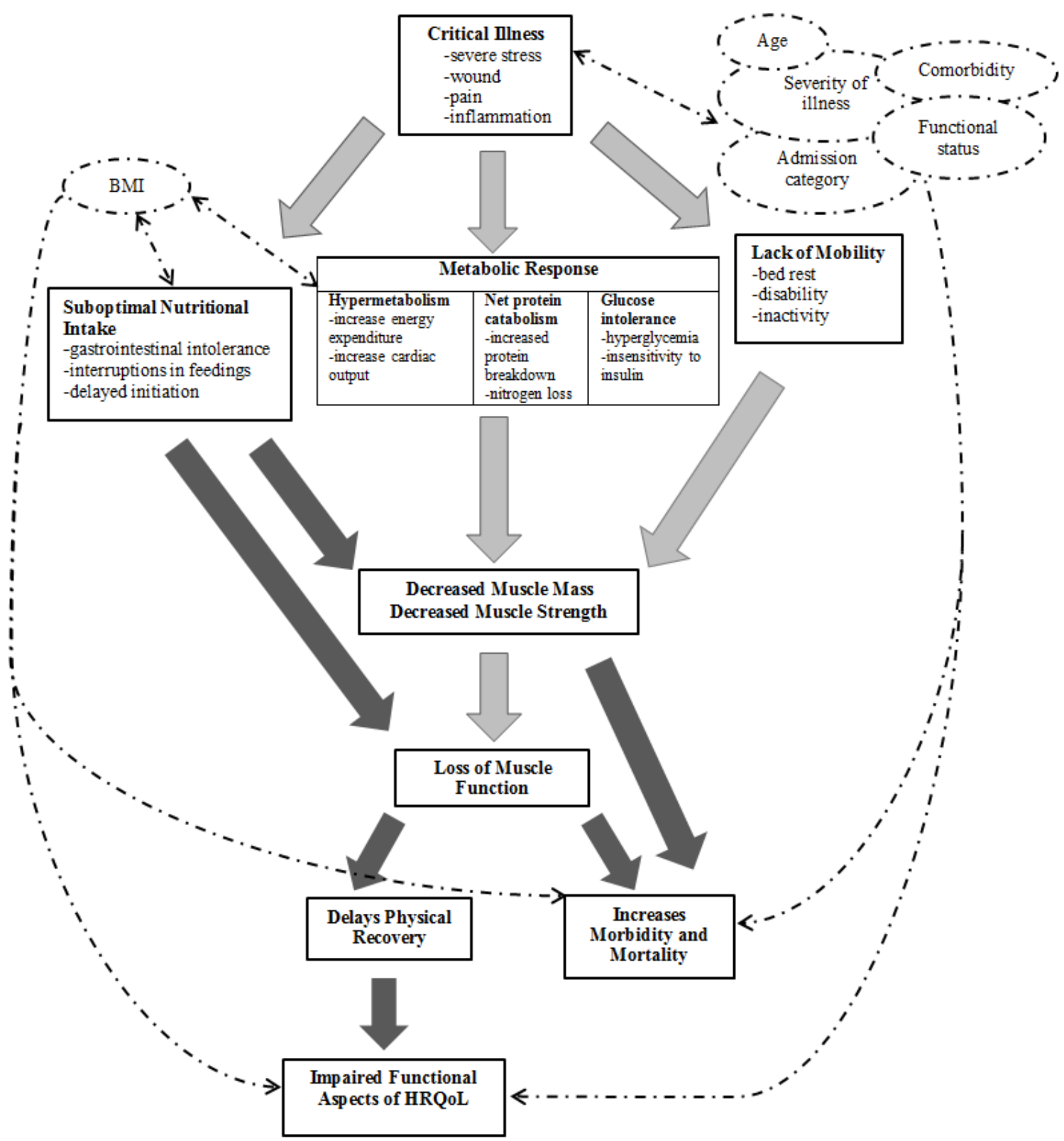

\section{Figure 2.1 Conceptual framework}

(Black thick arrows: the roles of nutritional intake and long-term outcomes in the relationship of interest; grey thick arrows: the biological plausibility in the relationship between nutritional intake and long-term outcomes; dotted line arrows: the role of the possible risk factors in our relationship of interest) 
The metabolic response to critical illness is characterized by hypermetabolism, hyperglycemia, increased lipolysis, and net protein metabolism [98]. The metabolic response may be seen as an adaptation to severe stress or injury to ensure optimal supply of amino acids to organs to serve as substrate for gluconeogenesis and synthesis of various proteins [99]. One of the metabolic features in critically ill patients is the catabolic response to skeletal muscle [98].

Skeletal muscle protein is broken down and the amino acids are used for gluconeogenesis and protein synthesis [98]. These metabolic changes, along with bed rest and suboptimal nutrient intake, often result in depletion of lean body mass. Nutritional support has been shown to be one of the effective treatments to reduce or prevent the catabolic response in critical illness $[98,100]$.

In recent years, a growing numbers of studies have confirmed the relationship between protein-energy nutrition and muscle mass, strength, function and physical performance [101108]. Castanda et al. reported the relation between protein intake and muscle mass and function [101]. Low protein intake resulted in significant loss of lean body mass, especially muscle mass, and muscle strength, whereas muscle mass and function were maintained at higher intake levels. More recently, an epidemiologic study found loss of lean muscle mass was about $40 \%$ less in participants who had higher protein intake than those who had lower protein intake [102]. Another study reported an increased risk of frailty in healthy elderly with low protein intake [103]. A study on supplementation of essential amino acids showed promising results with respect to muscle strength and physical performance [104]. It is important to note that the studies mentioned above are not on critical illness, however, they demonstrate that protein and amino acids play an important role in muscle protein metabolism, and presumably muscle mass and function.

Energy demands in critically ill patients increase as a result of increased energy expenditure [105]. For the maintenance of muscle mass and function, the amount of energy intake 
is also important. Skeletal muscles need energy for their own metabolism and maintenance in addition to the energy required for motor activity and contractions [106]. When total daily energy expenditure is not compromised by nutritional intake, catabolism of body energy store starts, and may further breakdown proteins [105]. A lack of energy may compromise energy metabolism of muscle fibers and lead to muscle weakness and fatigue [106].

Research suggests loss of muscle mass may be a causal factor of impairment in physical function [107]. Muscle wasting and weakness often delays physical recovery in ICU patients [109]. In the critical care setting, muscle function is often indicated by muscle movement and muscle strength [109]. Research has shown that muscle strength and movement are essential for physical recovery after critical illness [108]. Thus, providing a composition of nutrient to maintain muscle function and enhance protein synthesis could help accelerate recovery.

A study of the relationship between quality of life, nutritional status and physical function in hospitalized elderly patients indicated nutritional status may influence quality of life through the consequences of reduced physical function [110]. Other studies have indicated physical function as an important variable that may play a part in any link between malnutrition and quality of life $[111,112]$. Overall, nutritional support is provided in an effort to minimize the wasting of muscle mass to support muscle function, and to facilitate physical recovery, which may directly impact physical components of HRQoL.

\subsection{Summary}

Malnutrition is common in hospitalized patients [2], especially in critically ill patients requiring mechanical ventilation $[113,114]$. Malnutrition has been associated with prolonged mechanical ventilation, increased risk of infection, and higher mortality[8]. Adequate nutrition 
support is essential in prevention and treatment of malnutrition in critically ill patients. However, the optimal amount of nutritional intake remains controversial.

While many studies have documented the impacts of nutrition intake on short-term outcomes such as ICU-acquired infection, and ICU and hospital mortality [12], relatively little is known about subsequent long-term outcomes. Long-term outcomes in critically ill patients have grown in importance as the number of ICU survivors increases as a result of aging baby boomer population and improvements in intensive care medicine. Although critical care improves shortterm outcomes for many ICU patients, the high resource consumption and cost of critical care above that of general care may be considered excessive if the long-term outcome is poor [59]. The goal of intensive care medicine is quality patient survival, thus the true value of critical care should be determined by both survival and quality of life $[59,115]$.

Nutrition therapy may be related to long-term outcomes such as long-term survival and HRQoL, as the evidence has shown that energy intake may reduce the loss of muscle mass and improve muscle function which may predict physical recovery, morbidity and mortality in ICU patients $[54,55,101,106-110]$. An investigation of the relationship between nutritional adequacy and long-term outcomes would be important for making decisions and policies about the most effective utilization of critical care nutrition. 


\subsection{References}

1. Cerra FB, Benitez MR, Blackburn GL, Irwin RS, Jeejeebhoy K, Katz DP, Pingleton SK, Pomposelli J, Rombeau L, Shronts E, Robert R, Zaloga GP: Applied Nutrition in ICU Patients. A Consensus Statement of the American of Chest Physicians. Chest 1997, 111:769-778.

2. McWhirter JP, Pennington CR: Incidence and recognition of malnutrition in hospital. $B M J$ 1994, 308:945-8.

3. Norman K, Pichard C, Lochs H, Pirlich M: Prognostic impact of disease-related malnutrition. Clinical Nutrition 2008, 27:5-15.

4. Martin CM, Hill AD, Burns K, Chen LM: Characteristics and outcomes for critically ill patients with prolonged intensive care unit stays. Critical Care Medicine 2005, 33:1922-1927.

5. Giner M, Laviano A, Meguid MM, Gleason JR: In 1995 a correlation between malnutrition and poor outcome in critically ill patients still exists. Nutrition 1996, 12:23-9.

6. Quirk J: Malnutrition in critically ill patients in intensive care units. British Journal of Nursing 2000, 9:537-41.

7. Dark D, Pingleton S: Nutrition and nutritional support in critically ill patients. Journal of Intensive Care Medicine 1993, 8:16-33.

8. Dardaine V, Dequin PF, Ripault H, Constans T, Giniès G: Outcome of older patients requiring ventilatory support in intensive care: impact of nutritional status. Journal of the American Geriatrics Society 2001, 49:564-70. 
9. Dempsey, DT Mullen, JL Buzby G: The link be- tween nutritional status and clinical outcome: can nutritional intervention modify it? American Journal of Clinical Nutritrion $1988,47: 352-356$.

10. Martindale RG, Mcclave SA, Vanek VW, Mccarthy M, Roberts P, Taylor B, Ochoa JB, Napolitano L, Cresci G, College A, Medicine C, Board ASPEN: Guidelines for the provision and assessment of nutrition support therapy in the adult critically ill patient : Society of Critical Care Medicine and American Society for Parenteral and Enteral Nutrition. Critical Care Medicine 2009, 37:1-30.

11. Jones NE, Dhaliwal R, Day AG, Ouellette-Kuntz H, Heyland DK: Factors predicting adherence to the Canadian Clinical Practice Guidelines for nutrition support in mechanically ventilated, critically ill adult patients. Journal of Critical Care 2008, 23:301-7.

12. Heyland D, Dhaliwal R, Drover J, Gramlich L, Dodek P: Canadian clinical practice guidelines for nutrition support in mechanically ventilated, critically ill adult patients. Journal of Parenteral and Enteral Nutrition 2003, 27:355-373.

13. Kreymann KG, Berger MM, Deutz NEP, Hiesmayr M, Jolliet P, Kazandjiev G, Nitenberg G, van den Berghe G, Wernerman J, Ebner C, Hartl W, Heymann C, Spies C: ESPEN Guidelines on Enteral Nutrition: Intensive care. Clinical Nutrition 2006, 25:210-23.

14. McClave S, Lowen C, Kleber M, Nicholson J, Jimmerson S, McConnell J, Jung L: Are patients fed appropriately according to their caloric requirements? Journal of Parenteral and Enteral Nutrition 1998, 22:375-381. 
15. O’Leary-Kelley C, Puntillo K, Barr J, Stotts N, Douglas M: Nutritional adequacy in patients receiving mechanical ventilation who are fed enterally. The American Journal of Critical Care 2005, 14:222-31.

16. Cahill NE, Dhaliwal R, Day AG, Jiang X, Heyland DK: Nutrition therapy in the critical care setting: what is "best achievable" practice? An international multicenter observational study. Critical Care Medicine 2010, 38:395-401.

17. Stroud M: Protein and the critically ill; do we know what to give? The Proceedings of the Nutrition Society 2007, 66:378-83.

18. Barr J, Hecht M, Flavin KE, Khorana A, Gould MK: Outcomes in critically ill patients before and after the implementation of an evidence-based nutritional management protocol. Chest 2004, 125:1446-57.

19. Binnekade JM, Tepaske R, Bruynzeel P, Mathus-Vliegen EMH, de Hann RJ: Daily enteral feeding practice on the ICU: attainment of goals and interfering factors. Critical Care 2005, 9:R218-25.

20. De Jonghe B, Appere-De-Vechi C, Fournier M, Tran B, Merrer J, Melchior JC, Outin H: A prospective survey of nutritional support practices in intensive care unit patients: what is prescribed? What is delivered? Critical Care Medicine 2001, 29:8-12.

21. Heyland D, Schroter-Noppe D, Drover J, Jain M, Keefe L, Dhaliwal R, Day a: Nutrition support in the critical care setting: current practice in canadian ICUs--opportunities for improvement? Journal of Parenteral and Enteral Nutrition 2003, 27:74-83. 
22. McClave S, Sexton L, Spain D: Enteral tube feeding in the intensive care unit: factors impeding adequate delivery. Critical Care Medicine 1999, 27:1252-1256.

23. Shikora S, Benotti P: Nutritional support of the mechanically ventilated patient. Respiratory Care Clinics of North America 1997, 3:69-90.

24. Villet S, Chiolero RL, Bollmann MD, Revelly J-P, Cayeux R N M-C, Delarue J, Berger MM: Negative impact of hypocaloric feeding and energy balance on clinical outcome in ICU patients. Clinical Nutrition Edinburgh Scotland 2005, 24:502-9.

25. Flancbaum L, Choban PS, Sambucco S, Verducci J, Burge JC: Comparison of indirect calorimetry, the Fick method, and prediction equations in estimating the energy requirements of critically ill patients. The American Journal of Clinical Nutrition 1999, 69:461-6.

26. Krishnan JA, Parce PB, Martinez A, Diette GB, Brower RG: Caloric intake in medical ICU patients: consistency of care with guidelines and relationship to clinical outcomes. Chest 2003, 124:297-305.

27. Arabi YM, Haddad SH, Tamim HM, Rishu AH, Sakkijha MH, Kahoul SH, Britts RJ: Neartarget caloric intake in critically ill medical-surgical patients is associated with adverse outcomes. Journal of Parenteral and Enteral Nutrition 2010, 34:280-8.

28. Dickerson RN, Boschert KJ, Kudsk KA, Brown RO: Hypocaloric enteral tube feeding in critically ill obese patients. Nutrition 2002, 18:241-6. 
29. Ibrahim E, Mehringer L, Prentice D, Sherman G, Schaiff R, Fraser V, Kollef M: Early versus late enteral feeding of mechanically ventilated patients: results of a clinical trial. Journal of Parenteral and Enteral Nutrition 2002, 26:174-181.

30. Rice TW, Mogan S, Hays MA, Bernard GR, Jensen GL, Wheeler AP: Randomized trial of initial trophic versus full-energy enteral nutrition in mechanically ventilated patients with acute respiratory failure. Critical Care Medicine 2011, 39:967-74.

31. Rice TW, Wheeler AP, Thompson BT, Steingrub J, Hite RD, Moss M, Morris A, Dong N, Rock P: Initial trophic vs full enteral feeding in patients with acute lung injury: the EDEN randomized trial. JAMA 2012, 307:795-803.

32. Arabi YM, Tamim HM, Dhar GS, Al-dawood A, Al-sultan M, Sakkijha MH, Kahoul SH, Brits R: Permissive underfeeding and intensive insulin therapy in critically ill patients : a randomized controlled trial. The American Journal of Clinical Nutritrion 2011, 93:569-77.

33. Alberda C, Gramlich L, Jones N, Jeejeebhoy K, Day AG, Dhaliwal R, Heyland DK: The relationship between nutritional intake and clinical outcomes in critically ill patients: results of an international multicenter observational study. Intensive Care Medicine 2009, 35:1728-37.

34. Heyland DK, Stephens KE, Day AG, McClave SA: The success of enteral nutrition and ICU-acquired infections: a multicenter observational study. Clinical Nutrition 2011, 30:14855.

35. Heyland DK, Cahill N, Day AG: Optimal amount of calories for critically ill patients: depends on how you slice the cake! Critical Care Medicine 2011, 39:2619-26. 
36. Rubinson L, Diette GB, Song X, Brower RG, Krishnan JA: Low caloric intake is associated with nosocomial bloodstream infections in patients in the medical intensive care unit. Critical Care Medicine 2004, 32:350-7.

37. Strack Van Schijndel RJ, Weijs PJ, Koopmans RH, Sauerwein HP, Beishuizen A, Girbes AR: Optimal nutrition during the period of mechanical ventilation decreases mortality in critically ill, long-term acute female patients: a prospective observational cohort study. Critical Care 2009, 13:R132.

38. Faisy C, Lerolle N, Dachraoui F, Savard J-F, Abboud I, Tadie J-M, Fagon J-Y: Impact of energy deficit calculated by a predictive method on outcome in medical patients requiring prolonged acute mechanical ventilation. The British Journal of Nutrition 2009, 101:1079-87.

39. Huang YC, Yen CE, Cheng CH, Jih KS, Kan MN: Nutritional status of mechanically ventilated critically ill patients: comparison of different types of nutritional support. Clinical Nutrition 2000, 19:101-7.

40. Taylor S, Fettes S, Jewkes C, Nelson RJ: Prospective, randomized, controlled trial to determine the effect of early enhanced enteral nutrition on clinical outcome in mechanically ventilated patients suffering head injury. Critical Care Medicine 1999, 27:2525-2531.

41. Martin CM, Doig GS, Heyland DK, Morrison T, Sibbald WJ: Multicentre, clusterrandomized clinical trial of algorithms for critical-care enteral and parenteral therapy (ACCEPT). CMAJ 2004, 170:197-204.

42. Singer P, Anbar R, Cohen J, Shapiro H, Shalita-Chesner M, Lev S, Grozovski E, Theilla M, Frishman S, Madar Z: The tight calorie control study (TICACOS): a prospective, 
randomized, controlled pilot study of nutritional support in critically ill patients. Intensive Care Medicine 2011, 37:601-9.

43. Heyland DK: Nutritional support in the critically ill patient: A critical review of the evidence. Critical Care Clinics 1998, 14:423-440.

44. Dhaliwal R, Heyland DK: Nutrition and infection in the intensive care unit: what does the evidence show? Current Opinion in Critical Care 2005, 11:461-7.

45. Heyland, DK Novak, F Drover, JW Jain, M Su, X Suchner U: Should Immunonutrition Become Routine A Systematic Review of the Evidence. JAMA 2001, 286:944-53.

46. Klein, CJ Stanek, GS Wiles C: Overfeeding macronutrients to critically ill adults:: Metabolic complications. Journal of the American Dietetic Association 1998, 98:795-806.

47. Dickerson RN: Optimal caloric intake for critically ill patients: first, do no harm. Nutrition in Clinical Practice 2011, 26:48-54.

48. Ahrens CL, Barletta JF, Kanji S, Tyburski JG, Wilson RF, Janisse JJ, Devlin JW: Effect of low-calorie parenteral nutrition on the incidence and severity of hyperglycemia in surgical patients: A randomized, controlled trial. Critical Care Medicine 2005, 33:2507-2512.

49. Alberda C, Snowden L, McCargar L, Gramlich L: Energy Requirements in Critically Ill Patients: How Close Are Our Estimates? Nutrition in Clinical Practice 2002, 17:38-42.

50. Heyland DK, Dhaliwal R, Jiang X, Day AG: Identifying critically ill patients who benefit the most from nutrition therapy: the development and initial validation of a novel risk assessment tool. Critical Care 2011, 15:R268. 
51. Heyland DK: Critical care nutrition support research: lessons learned from recent trials. Current Opinion in Clinical Nutrition and Metabolic Care 2013, 16:176-81.

52. Kondrup J: Nutritional risk screening (NRS 2002): a new method based on an analysis of controlled clinical trials. Clinical Nutrition 2003, 22:321-336.

53. Griffiths RD: Nutrition and survival in intensive care. Intensivmedizin und Notfallmedizin 1998, 35:3-9.

54. Gruther W, Benesch T, Zorn C, Paternostro-Sluga T, Quittan M, Fialka-Moser V, Spiss C, Kainberger F, Crevenna R: Muscle wasting in intensive care patients: ultrasound observation of the M. quadriceps femoris muscle layer. Journal of Rehabilitation Medicine 2008, 40:185-9.

55. Faisy C, Rabbat a, Kouchakji B, Laaban JP: Bioelectrical impedance analysis in estimating nutritional status and outcome of patients with chronic obstructive pulmonary disease and acute respiratory failure. Intensive Care Medicine 2000, 26:518-25.

56. Williams T a, Dobb GJ, Finn JC, Webb S a R: Long-term survival from intensive care: a review. Intensive Care Medicine 2005, 31:1306-15.

57. Needham DM, Bronskill SE, Calinawan JR, Sibbald WJ, Pronovost PJ, Laupacis A:

Projected incidence of mechanical ventilation in Ontario to 2026: Preparing for the aging baby boomers. Critical Care Medicine 2005, 33:574-579.

58. Spragg RG, Bernard GR, Checkley W, Curtis JR, Gajic O, Guyatt G, Hall J, Israel E, Jain M, Needham DM, Randolph AG, Rubenfeld GD, Schoenfeld D, Thompson BT, Ware LB, Young D, 
Harabin AL: Beyond mortality: future clinical research in acute lung injury. American Journal of Respiratory and Critical Care Medicine 2010, 181:1121-7.

59. Keenan SP, Dodek P, Chan K, Hogg RS, Craib KJP, Anis AH, Spinelli JJ: Intensive care unit admission has minimal impact on long-term mortality. Critical Care Medicine 2002, 30:501-7.

60. Angus DC, Carlet J: Surviving intensive care: a report from the 2002 Brussels Roundtable. Intensive Care Medicine 2003, 29:368-77.

61. Jacobs C, Van der Vliet J, Van Roozendaal M, Van der Linden C: Mortality and quality of life after intensive care for critical illness. Intensive Care Medicine 1988, 14:217-220.

62. Zaren B, Bergstrom R: Survival compared to the general population and changes in health status among intensive care patients. Acta Anaesthesiologica Scandinavica 1989, 33:612.

63. Wunsch H, Guerra C, Barnato AE, Angus DC, Li G, Linde-Zwirble WT: Three-year outcomes for Medicare beneficiaries who survive intensive care. JAMA 2010, 303:849-56.

64. Needham DM, Dinglas VD, Bienvenu OJ, Colantuoni E, Wozniak a. W, Rice TW, Hopkins RO: One year outcomes in patients with acute lung injury randomised to initial trophic or full enteral feeding: prospective follow-up of EDEN randomised trial. BMJ 2013, 346:f1532f1532. 
65. Williams T a, Dobb GJ, Finn JC, Knuiman MW, Geelhoed E, Lee KY, Webb S a R:

Determinants of long-term survival after intensive care. Critical Care Medicine 2008, 36:1523-30.

66. Weijs PJM, Wischmeyer PE: Optimizing energy and protein balance in the ICU. Current Opinion in Clinical Nutrition and Metabolic Care 2013, 16:194-201.

67. Saxena S, Orley J: Quality of life assessment: The world health organization perspective. The Journal of the Association of European Psychiatrists 1997, 12(Suppl 3):263s-6s.

68. Spilker B: Taxonomy of quality of life. In Quality of Life and Pharmacoeconomics in Clinical Trials. 2nd edition. Edited by Spilker B. Philadelphia: Lippincott-Raven; 1996:25-36.

69. Chaboyer W, Elliott D: Health-related quality of life of ICU survivors: review of the literature. Intensive \& Critical Care Nursing : the Official Journal of the British Association of Critical Care Nurses 2000, 16:88-97.

70. Hofhuis JGM, van Stel HF, Schrijvers AJP, Rommes JH, Bakker J, Spronk PE: Healthrelated quality of life in critically ill patients: how to score and what is the clinical impact? Current Opinion in Critical Care 2009, 15:425-30.

71. Coons SJ, Rao S, Keininger DL, Hays RD: A comparative review of generic quality-of-life instruments. PharmacoEconomics 2000, 17:13-35.

72. Dowdy DW, Eid MP, Sedrakyan A, Mendez-Tellez PA, Pronovost PJ, Herridge MS, Needham DM: Quality of life in adult survivors of critical illness: a systematic review of the literature. Intensive Care Medicine 2005, 31:611-20. 
73. Chrispin PS, Scotton H, Rogers J, Lloyd D, Ridley S a: Short Form 36 in the intensive care unit: assessment of acceptability, reliability and validity of the questionnaire. Anaesthesia 1997, 52:15-23.

74. Heyland D, Hopman W, Coo H: Long-term health-related quality of life in survivors of sepsis. Short Form 36: a valid and reliable measure of health-related quality of life. Critical Care Medicine 2000, 28:3599-3605.

75. Tian ZM, Miranda DR: Quality of life after intensive care with the sickness impact profile. Intensive Care Medicine 1995, 21:422-8.

76. Heyland DK, Groll D, Caeser M: Survivors of acute respiratory distress syndrome: Relationship between pulmonary dysfunction and long-term health-related quality of life. Critical Care Medicine 2005, 33:1549-1556.

77. Khoudri I, Ali Zeggwagh a, Abidi K, Madani N, Abouqal R: Measurement properties of the short form 36 and health-related quality of life after intensive care in Morocco. Acta Anaesthesiologica Scandinavica 2007, 51:189-97.

78. McHorney CA, Ware JE, Raczek AE: The MOS 36-Item Short-Form Health Survey (SF36): II. Psychometric and clinical tests of validity in measuring physical and mental health constructs. Medical Care 1993, 31:247-63.

79. Ware J, Kosinski M, Dewey J, Gandek B: SF-36 Health Survey: Manual and Interpretation Guide. Boston: The Health Institute, New England Medical Center; 2000. 
80. Ware J, Kosinski M: SF-36 physical \& mental health summary scales: a manual for users of version 1; 2001.

81. Kvåle R, Ulvik A, Flaatten H: Follow-up after intensive care: a single center study. Intensive Care Medicine 2003, 29:2149-56.

82. Eddleston JM, White P, Guthrie E: Survival, morbidity, and quality of life after discharge from intensive care. Critical Care Medicine 2000, 28:2293-9.

83. Orwelius L, Nordlund A, Edell-Gustafsson U, Simonsson E, Nordlund P, Kristenson M, Bendtsen P, Sjoberg F: Role of preexisting disease in patients' perceptions of health-related quality of life after intensive care. Critical Care Medicine 2005, 33:1557-1564.

84. Pettilä V, Kaarlola A, Mäkeläinen A: Health-related quality of life of multiple organ dysfunction patients one year after intensive care. Intensive Care Medicine 2000, 26:14731479.

85. Graf J, Koch M, Dujardin R, Kersten A, Janssens U: Health-related quality of life before, 1 month after, and 9 months after intensive care in medical cardiovascular and pulmonary patients. Critical Care Medicine 2003, 31:2163-9.

86. Kaarlola A, Pettilä V, Kekki P: Quality of life six years after intensive care. Intensive Care Medicine 2003, 29:1294-9.

87. Ridley SA, Chrispin PS, Scotton H, Rogers J, Lloyd D: Changes in quality of life after intensive care: comparison with normal data. Anaesthesia 1997, 52:195-202. 
88. Herridge MS, Cheung AM, Tansey CM, Matte-Martyn A, Diaz-Granados N, Al-Saidi F, Cooper AB, Guest CB, Mazer CD, Mehta S, Stewart TE, Barr A, Cook D, Slutsky AS: One-year outcomes in survivors of the acute respiratory distress syndrome. The New England Journal of Medicine 2003, 348:683-93.

89. Wehler M, Geise A, Hadzionerovic D, Aljukic E, Reulbach U, Hahn EG, Strauss R: Healthrelated quality of life of patients with multiple organ dysfunction: individual changes and comparison with normative population. Critical Care Medicine 2003, 31:1094-101.

90. Winters BD, Eberlein M, Leung J, Needham DM, Pronovost PJ, Sevransky JE: Long-term mortality and quality of life in sepsis: a systematic review. Critical Care Medicine 2010, 38: $1276-83$.

91. Van der Schaaf M, Beelen A, Dongelmans DA, Vroom MB, Nollet F: Functional status after intensive care: a challenge for rehabilitation professionals to improve outcome. Journal of Rehabilitation Medicine 2009, 41:360-6.

92. Sukantarat K, Greer S, Brett S, Williamson R: Physical and psychological sequelae of critical illness. British Journal of Health Psychology 2007, 12:65-74.

93. Orwelius L, Nordlund A, Nordlund P, Simonsson E, Bäckman C, Samuelsson A, Sjöberg F: Pre-existing disease: the most important factor for health related quality of life long-term after critical illness: a prospective, longitudinal, multicentre trial. Critical Care 2010, 14:R67. 
94. Chelluri L, Im KA, Belle SH, Schulz R, Rotondi AJ, Donahoe MP, Sirio C a, Mendelsohn $\mathrm{AB}$, Pinsky MR: Long-term mortality and quality of life after prolonged mechanical ventilation. Critical Care Medicine 2004, 32:61-9.

95. Kleinpell RM: Exploring outcomes after critical illness in the elderly. Outcomes Management 2003, 7:159-69.

96. Parker CM, Heyland DK, Groll D, Caeser M: Mechanism of injury influences quality of life in survivors of acute respiratory distress syndrome. Intensive Care Medicine 2006, 32:1895-900.

97. Poulsen JB, Møller K, Kehlet H, Perner a: Long-term physical outcome in patients with septic shock. Acta Anaesthesiologica Scandinavica 2009, 53:724-30.

98. Wray CJ, Mammen JM V, Hasselgren P-O: Catabolic response to stress and potential benefits of nutrition support. Nutrition 2002, 18:971-7.

99. Rosenblatt S, Clowes GH, George BC, Hirsch E, Lindberg B: Exchange of amino acids by muscle and liver in sepsis. Archives of Surgery 1983, 118:167-75.

100. Ziegler T, MD, Gatzen C: Strategies for attenuating protein-catabolic responses in the critically ill. Annual Review of Medicine 1994, 1:459-80.

101. Castaneda C, Charnley JM, Evans WJ, Crim MC: Elderly women accommodate to a lowprotein diet with losses of body cell mass, muscle function, and immune response. The American Journal of Clinical Nutrition 1995, 62:30-9. 
102. Houston DK, Nicklas BJ, Ding J, Harris TB, Tylavsky F a, Newman AB, Lee JS, Sahyoun NR, Visser M, Kritchevsky SB: Dietary protein intake is associated with lean mass change in older, community-dwelling adults: the Health, Aging, and Body Composition (Health ABC) Study. The American Journal of Clinical Nutrition 2008, 87:150-5.

103. Bartali B, Frongillo EA, Bandinelli S, Lauretani F, Semba RD, Fried LP, Ferrucci L: Low nutrient intake is an essential component of frailty in older persons. The Journal of Gerontology 2006, 61:589-93.

104. Børsheim E, Bui Q-UT, Tissier S, Kobayashi H, Ferrando A a, Wolfe RR: Effect of amino acid supplementation on muscle mass, strength and physical function in elderly. Clinical Nutrition 2008, 27:189-95.

105. Plank L, Hill G: Energy balance in critical illness. Proceedings of the Nutrition Society 2003, 62:545-52.

106. Volkert D: The role of nutrition in the prevention of sarcopenia. Wiener Medizinische Wochenschrift 2011, 161:409-15.

107. Griffiths RD, Hall JB: Exploring intensive care unit-acquired weakness. Preface. Critical Care Medicine 2009, 37(10 Suppl):S295.

108. Puthucheary Z, Montgomery H, Moxham J, Harridge S, Hart N: Structure to function: muscle failure in critically ill patients. The Journal of Physiology 2010, 588:4641-8.

109. Kasper CE, Talbot LA, Gaines JM: Skeletal muscle damage and recovery. AACN Clinical Issues 2002, 13:237-47. 
110. Hickson M, Frost G: An investigation into the relationships between quality of life, nutritional status and physical function. Clinical Nutrition 2004, 23:213-21.

111. Tidermark J, Zethraeus N, Svensson O, Törnkvist H, Ponzer S: Femoral neck fractures in the elderly: functional outcome and quality of life according to EuroQol. Quality of Life research : an International Journal of Quality of Life Aspects of Treatment, Care and Rehabilitation 2002, 11:473-81.

112. Mackenzie A, Chang A: Predictors of quality of life following stroke. Disability and Rehabilitation 2002, 24:259-65.

113. Driver AG, Lebrun M: latrogenic Malnutrition in Patients Receiving Ventilatory Support. JAMA 1980, 244:2195-2196.

114. Bassili H, Deitel M: Effect of nutritional support on weaning patients off mechanical ventilators. Journal of Parenteral and Enteral Nutrition 1981, 5:161-163.

115. Flaatten H, Kvåle R: Survival and quality of life 12 years after ICU. A comparison with the general Norwegian population. Intensive Care Medicine 2001, 27:1005-1011. 


\title{
Chapter 3
}

\section{Nutritional Adequacy and Long-term Survival in Critically Ill Patients Requiring Prolonged Mechanical Ventilation}

\begin{abstract}
Introduction: While the provision of adequate nutrition support in critically ill patients has been shown to have an impact on short-term outcomes, such as intensive care unit (ICU) and hospital mortality, relatively little is known about subsequent long-term outcomes. The objective of this study was to examine the association between short-term nutritional adequacy received while in the ICU and six-months survival in critically ill patients with prolonged mechanical ventilation. Methods: The study was conducted as a retrospective cohort study on data collected prospectively in the context of a multicenter randomized controlled trial in critically ill patients. Randomized patients who stayed in ICU and were mechanically ventilated for more than eight days were included. Nutritional adequacy was obtained from the average proportion of prescribed calories received during the first eight days where the patients were mechanically ventilated in the ICU. Patients were categorized into three groups according to nutritional adequacy: low, $<50 \%$; moderate, $\geq 50$ and $<80 \%$; and high, $\geq 80 \%$. Patients were followed prospectively to determine the survival at six months. Kaplan-Meier survival curves and Cox proportional hazards regression modeling were used to analyze group differences in survival.

Results: Of the 1223 patients enrolled in the randomized controlled trial, 475 met the inclusion criteria for this study. For critically ill patients with $>8$ days of ICU stay and mechanical ventilation, survival time in those who received low nutritional adequacy was significantly shorter than those who received high nutritional adequacy while adjusting for important
\end{abstract}


covariates $($ adjusted hazard ratio $(\mathrm{HR})=1.67 ; 95 \%$ confidence interval $(\mathrm{CI}), 1.06-2.64 ; P=0.03)$. When restricting the analysis to patients who were mechanically ventilated and in ICU for $>12$ days, the association between nutritional adequacy and six-month survival remained statistically significant (adjusted $\mathrm{HR}=1.91 ; 95 \% \mathrm{CI}, 1.23-2.95 ; P=0.004)$ comparing low nutritional adequacy group to high nutritional adequacy group). Consistent results were obtained when treating nutritional adequacy as a continuous predictor.

Conclusions: Higher nutritional adequacy (receiving $>80 \%$ prescribed energy) is associated with longer survival time in critically ill patients requiring prolonged mechanical ventilation. 


\section{Introduction}

Malnutrition is a common problem in hospitalized patients [1], especially in critically ill patients requiring mechanical ventilation $[2,3]$. Nutritional status of critically ill patients is often further compromised during their intensive care unit (ICU) stay, due to factors that may be intrinsic to the patient or iatrogenic [4]. In mechanically ventilated patients, nutritional status often becomes deteriorated because of inability of these patients to express hunger and feed orally, or because of the complexity of intensive medical care [2]. Consequences related to malnutrition in critically ill patients include impaired immunological function, impaired ventilator drive, and weakened respiratory muscles, leading to prolonged ventilator dependence and increased infectious morbidity and mortality $[5,6]$. Providing adequate artificial nutrition is essential to the prevention and treatment of malnutrition in critically ill patients. However, critically ill patients frequently receive inadequate nutritional support $[7,8]$.

Despite clinical practice guidelines in the area of critical care nutrition published worldwide, the optimal amount of nutritional intake in critically ill remains controversial. Some studies have shown that underfeeding or caloric debt is associated with adverse clinical outcomes [8-16]. In contrast, other studies have suggested better clinical outcomes in patients receiving low caloric intake [17-22]. Inconsistent findings could be due to the use of different statistical methodology to account for duration of exposure to nutrition, and failure to consider which patients may benefit the most from artificial nutrition support [23-25]. The duration of exposure to nutrition may be a confounder in evaluating the relationship between nutrition intake and clinical outcomes because short-term ICU patients who have a good outcome often receive few calories while in ICU [23]. Thus, taking a robust approach to account for the duration of exposure to nutrition is important in studies of nutrition support in the critical care setting. 
There is emerging evidence that not all critically ill patients are the same in terms of their nutrition risk or the benefit they receive from artificial nutrition. The patients at high nutrition risk are more likely to benefit from nutrition therapy than those at low risk [25]. It is recognized that nutrition risk depends on degrees of severity of disease as well as degrees of undernutrition. This concept was illustrated in studies that showed differential treatment effects of artificial nutrition in different subgroups of ICU patients. Alberda et al. found that the beneficial treatment effects of increased caloric intake on 60-day mortality were observed only in critically ill patients whose BMI was under 25 or at least 35 [9]. A study by Faisy el al. demonstrated that in a small group of critically ill patients requiring prolonged mechanical ventilation ( $>7$ days), an energy deficit of approximately $1200 \mathrm{kcal} /$ day was independently associated with ICU mortality [12]. Therefore, consideration of ICU patients at high nutrition risk, potentially those who require prolonged mechanical ventilation or have extreme BMI is needed in future studies of critical care nutrition.

While many studies have documented the impacts of nutritional intake on short-term outcomes, such as ICU-acquired infection, and ICU and hospital mortality, relatively little is known about subsequent long-term outcomes. Furthermore, studies have suggested that muscle mass and muscle function predict mortality in ICU patients after prolonged critical illness [26, 27]. Hence, it is hypothesized that nutrition support may effect long-term survival [28]. As critical care advances, the number of ICU survivors is growing and expected to further increase with the aging baby boomer population and improved short-term mortality [29, 30]. Understanding how ICU interventions may impact the patients in the long run is essential for making decisions and policies about the most effective utilization of critical care.

The purpose of this study was to examine the relationship between nutritional adequacy and long-term (six-month) survival in critically ill patients requiring prolonged mechanical ventilation (>8 days). Our a priori hypothesis was that in critically ill patients at high nutrition 
risk, particularly those who were mechanically ventilated for a long period of time, increasing nutritional adequacy is associated with better long-term survival.

\section{Materials and Methods}

\section{Study design}

This is a retrospective cohort study on data collected prospectively in the context of a randomized controlled trial (RCT) of glutamine and antioxidants supplementation in critically ill patients. The trial was conducted between May 2007 and December 2011 in 40 ICU sites across Canada, the United States, and Europe. Details of the RCT are described elsewhere [31]. This study involved secondary analysis of data collected for the RCT as well as additional data collected on the characteristics of ICU sites.

\section{Study population}

Mechanically-ventilated adult patients 18 years of age and older admitted to ICU who had two or more organ failures related to their acute illness were eligible for the parent clinical trial (see Appendix $\mathrm{C}$ for a complete list of the eligibility criteria for the RCT). In the current study, eligible patients were randomized critically ill patients who were mechanically ventilated and remained in ICU for $>8$ days, and were not overfed (received $<110 \%$ of prescribed energy) (Figure 3.1). The duration of mechanical ventilation allowed selection of patients requiring prolonged mechanical ventilation $[12,32,33]$. 


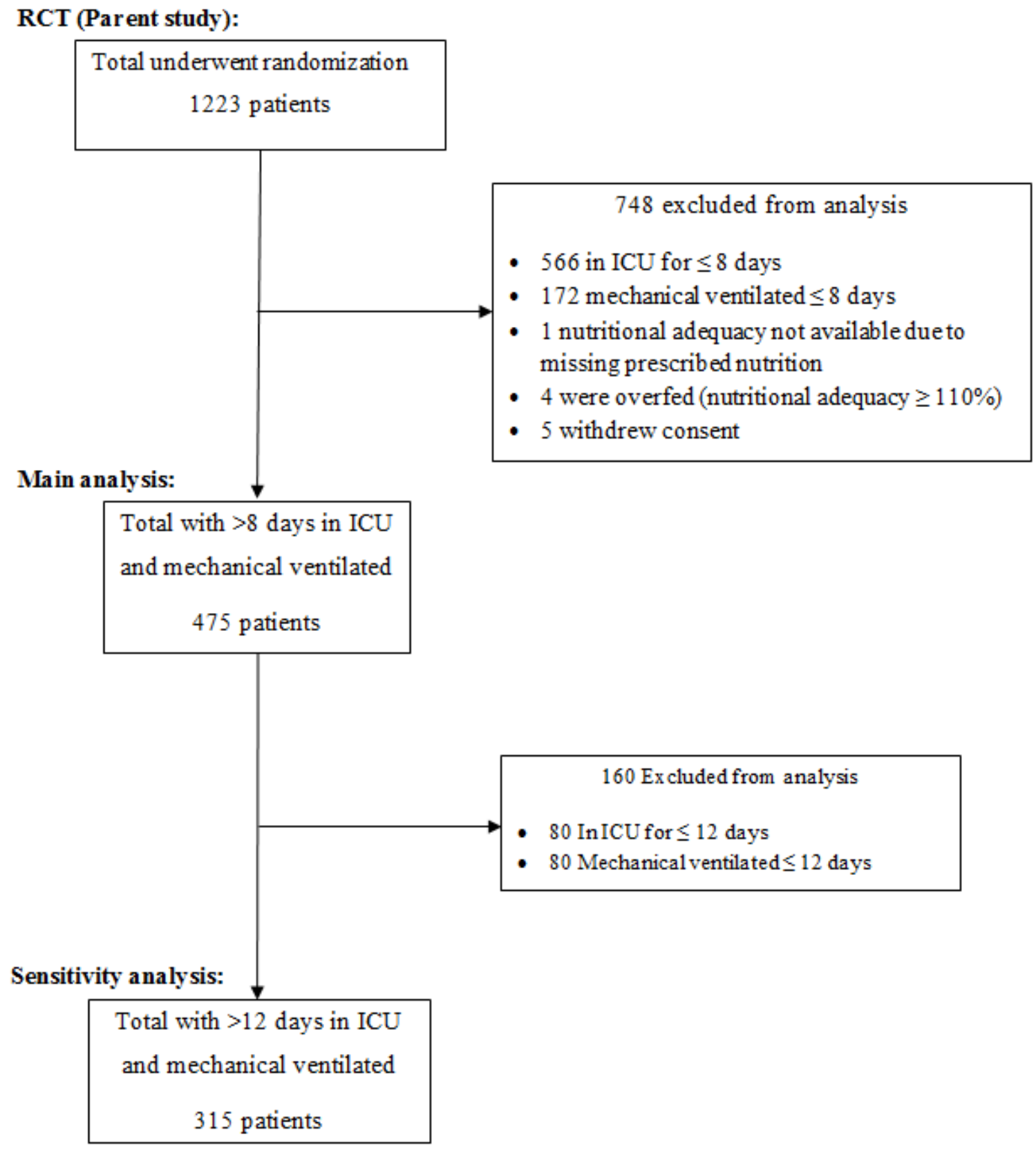

Figure 3.1 Patient flow diagram 


\section{Data collection and measurements}

The following data collected at ICU admission were extracted from the database of the RCT: age, sex, admission category (medical or surgical), primary admission diagnosis (cardiovascular, respiratory, gastrointestinal, sepsis, and other), body mass index (BMI), comorbidities, Acute Physiology and Chronic Health Evaluation (APACHE) II score to assess severity of illness [34], and Sequential Organ Failure Assessment (SOFA) score to determine organ dysfunction [35]. The Charlson Comorbidity Index was used to describe patient comorbidities [36]. A survey of ICU characteristics was conducted at each participating site retrospectively. The ICU characteristics included: ICU type (open or closed), ICU size (number of beds), case mix, region, presence of a medical director, and presence of a dietitian.

The daily total caloric intake from enteral nutrition $(\mathrm{EN})$ and parenteral nutrition $(\mathrm{PN})$ was collected from ICU admission for a maximum of 28 days, unless ICU discharge or death occurred sooner. The optimal amount of energy prescription was determined by indirect calorimetry or a formula that estimates energy requirements. Nutritional adequacy per day was calculated as the amount of calories received from enteral nutrition (EN) or parenteral nutrition (PN) divided by the amount prescribed, and expressed as a percentage. The average nutritional adequacy is then calculated as overall average percentage of prescribed calories received during the pre-specified duration of mechanical ventilation. Clinically meaningful cut-points at $50 \%$ and $80 \%$ were selected to categorize nutritional adequacy into three groups: low, $<50 \%$; moderate, $\geq 50 \%$ and $<80 \%$; and high, $\geq 80 \%[23,37,38]$

Study patients were followed for a maximum of six months from the date of ICU admission. At three and six months post ICU admission, patients or next of kin were contacted by telephone to record vital status as well as the last date that the patients were known to be alive or their date of death. 


\section{Statistical analysis}

Patients and selected ICU characteristics were described using means with standard deviations for continuous variables and counts with percentages for categorical variables. The characteristics were compared between the three nutritional adequacy groups using the Rao-Scott adjusted chi-squared method for categorical variables and the generalized estimating equation model for continuous variables to account for the ICU-level clustering.

Survival analyses were used to examine the association between nutritional adequacy and time to death in $>8$ days stayers. Nutritional adequacy was averaged over the first 8 days of mechanical ventilation and ICU stay. The starting point for all survival analyses was date of ICU admission. Survival time was measured from ICU admission to date of death. Patients who did not die by six months were censored at six months. Patients who were lost to follow-up prior to six months were censored at the last time they were known to be alive. The Kaplan-Meier method was used to estimate the survival functions of three nutritional adequacy groups. A score test with robust sandwich estimate was used to test for a statistically significant difference between any of the three groups. This test is similar to the log-rank test except it accounts for potential between ICU heterogeneity. To adjust for confounders, the Cox proportional hazard (PH) regression model was used to estimate the hazard ratio (HR) and 95\% confidence intervals (CIs). A marginal Cox model with robust standard error approach was taken to account for ICU-level clustering [39]. The proportional hazard assumptions were evaluated using the observed score process component, and the functional form was assessed using the observed cumulative martingale residuals [40]. Age, Charlson Comorbidity Index, APACHE II score, baseline SOFA, primary admission diagnosis group, and admission category were adjusted for in the model based on evidence from previous research [41-43]. In addition to these pre-specified covariates, the final model included site and patient characteristics from Table 3.1 and 3.2 that were selected by 
backward selection based on a significance of 0.1. Subgroup analyses by admission category (medical vs. surgical) were performed to explore the interactions between admission category and nutritional adequacy. The significance of the interaction term was tested in the final model.

Because of different definitions of prolonged mechanical ventilation in the literature [12, 44-46], a sensitivity analysis was conducted in $>12$ days stayers to explore the effect of feeding experience in even longer stayers. In this restricted sample, nutritional adequacy was averaged over the first 12 days of mechanical ventilation and ICU stay. To further validate our observations, we performed a sensitivity analysis by repeating the Cox PH model described previously except we treated nutritional adequacy as a continuous variable. Linearity assumptions were checked for the Cox PH model. All statistical analyses were performed using SAS version 9.3 (SAS Institute Inc., Cary, NC, USA). Unless otherwise specified, statistical significance was set at $P=0.05$ (two-sided) for all tests.

Research ethics approval was obtained from the Health Sciences Research Ethics Board at Queen's University in Kingston, Ontario, Canada. The need for informed patient consent was waived given the observational nature and deidentified data capture of this study.

\section{Results}

Of the 1223 patients enrolled in the randomized clinical trial, 475 patients who were mechanically ventilated and remained in ICU for $>8$ days were included in the main analysis. 315 patients who were mechanically ventilated and remained in ICU for $>12$ days were included in the sensitivity analysis (Figure 3.1). Patients included were from 35 ICU sites across Canada, Europe, and the US. Table 3.1 shows characteristics of participating ICU sites. 
Table 3.1 Characteristics of participating ICU sites

\begin{tabular}{lr}
\hline Site characteristics & All sites (n=35) \\
\hline Region & $22(62.9 \%)$ \\
Canada & $5(14.3 \%)$ \\
Europe & $8(22.9 \%)$ \\
USA & $27.0(8.0,62.0)$ \\
Size of ICU (beds) & \\
ICU type & $25(71.4 \%)$ \\
Closed & $5(14.3 \%)$ \\
Open & $4(11.4 \%)$ \\
Open/Closed & $1(2.9 \%)$ \\
Other & \\
Case type & $31(88.6 \%)$ \\
Medical & $34(97.1 \%)$ \\
Surgical & $22(62.9 \%)$ \\
Trauma & $1(2.9 \%)$ \\
Pediatrics & $22(62.9 \%)$ \\
Neurological & $11(31.4 \%)$ \\
Cardiac surgery & $9(25.7 \%)$ \\
Burns & $6(17.1 \%)$ \\
Others & \\
Presence of medical director & $32(91.4 \%)$ \\
Yes & $3(8.6 \%)$ \\
Yresence of dietitian & $35(100 \%)$ \\
No & \\
\hline Des & \\
\hline
\end{tabular}

Data are reported as number (\%) or median (range).

\section{Patient characteristics}

Table 3.2 describes the baseline characteristics of patients included in the main analysis.

The patient cohort had a mean age of 62 years, $39.5 \%$ were female, $78.3 \%$ were admitted for medical indications, and had a mean BMI of 30 and an average APACHE II score of 26.9. Patient characteristics were compared between the three nutritional adequacy groups as shown in Table 
3.2. The baseline characteristic did not differ significantly between the three nutritional adequacy

groups except for sex, admission category, and primary ICU diagnosis.

Table 3.2 Patient baseline characteristics

\begin{tabular}{|c|c|c|c|c|c|}
\hline \multirow[b]{2}{*}{ Variable } & \multirow[b]{2}{*}{ Overall } & \multicolumn{3}{|c|}{ Nutritional Adequacy $^{a}$} & \multirow[b]{2}{*}{$p^{\mathbf{b}}$} \\
\hline & & $\begin{array}{c}\text { Low } \\
(0=<50 \%)\end{array}$ & $\begin{array}{l}\text { Moderate } \\
(\mathbf{5 0}=<\mathbf{8 0 \%})\end{array}$ & $\begin{array}{c}\text { High } \\
(>=80 \%)\end{array}$ & \\
\hline Number of patients & 475 & 182 & 231 & 62 & \\
\hline Age, yrs & $62.3 \pm 14.5$ & $61.5 \pm 14.6$ & $62.2 \pm 14.6$ & $65.2 \pm 13.8$ & 0.53 \\
\hline Female & $187(39.5 \%)$ & $55(30.2 \%)$ & $102(44.1 \%)$ & $30(48.4 \%)$ & 0.001 \\
\hline APACHE II score & $26.9 \pm 7.1$ & $27.2 \pm 7.4$ & $26.8 \pm 7.0$ & $26.6 \pm 7.1$ & 0.94 \\
\hline Charlson Comorbidity Index & $1.5 \pm 1.7$ & $1.4 \pm 1.8$ & $1.6 \pm 1.7$ & $1.7 \pm 1.9$ & 0.44 \\
\hline Baseline SOFA & $8.6 \pm 2.8$ & $8.6 \pm 3.1$ & $8.5 \pm 2.8$ & $8.5 \pm 2.4$ & 0.91 \\
\hline Admission Category & & & & & $<0.0001$ \\
\hline Medical & $372(78.3 \%)$ & $116(63.7 \%)$ & $203(87.9 \%)$ & $53(85.5 \%)$ & \\
\hline Surgical & $103(21.7 \%)$ & $66(36.2 \%)$ & $28(12.2 \%)$ & $9(13.6 \%)$ & \\
\hline Primary ICU Diagnosis & & & & & $<0.0001$ \\
\hline Cardiovascular & $78(16.4 \%)$ & $44(24.2 \%)$ & $24(10.4 \%)$ & $10(15.2 \%)$ & \\
\hline Respiratory & $154(32.4 \%)$ & $35(19.2 \%)$ & $90(39.0 \%)$ & $29(46.8 \%)$ & \\
\hline Gastrointestinal & $44(9.3 \%)$ & $25(13.7 \%)$ & $12(5.2 \%)$ & $7(10.6 \%)$ & \\
\hline Sepsis & $149(30.9 \%)$ & $58(31.9 \%)$ & $75(32.5 \%)$ & $16(24.2 \%)$ & \\
\hline Other & $52(10.9 \%)$ & $20(11.0 \%)$ & $30(13.0 \%)$ & $2(3.0 \%)$ & \\
\hline Treatment Arm & & & & & 0.07 \\
\hline Antioxidants & $114(24.0 \%)$ & $32(17.6 \%)$ & $65(28.1 \%)$ & $19(27.4 \%)$ & \\
\hline Glutamine & $124(25.9 \%)$ & $46(25.3 \%)$ & $66(28.6 \%)$ & $12(19.4 \%)$ & \\
\hline Glutamine + Antioxidants & $120(25.3 \%)$ & $55(30.2 \%)$ & $52(22.5 \%)$ & $13(21.0 \%)$ & \\
\hline Placebo & $117(24.6 \%)$ & $49(26.9 \%)$ & $48(20.8 \%)$ & $20(32.3 \%)$ & \\
\hline Body Mass Index, $\mathrm{kg} / \mathrm{m}^{2}$ & & & & & 0.31 \\
\hline Overall mean & $30.0 \pm 8.7$ & $29.7 \pm 7.9$ & $30.4 \pm 9.1$ & $29.3 \pm 9.4$ & \\
\hline Underweight $(<18.5)$ & $9(1.9 \%)$ & $3(1.6 \%)$ & $4(1.7 \%)$ & $2(3.2 \%)$ & \\
\hline Normal weight (18.5-24) & $139(29.3 \%)$ & $48(26.4 \%)$ & $73(31.6 \%)$ & $18(29.0 \%)$ & \\
\hline Overweight (25-29) & $145(30.5 \%)$ & $64(35.2 \%)$ & $58(25.1 \%)$ & $23(37.1 \%)$ & \\
\hline Obese I (30-34) & $82(17.3 \%)$ & $34(18.7 \%)$ & $38(16.5 \%)$ & $10(16.1 \%)$ & \\
\hline Obese II (35-40) & $42(8.8 \%)$ & $15(8.2 \%)$ & $23(9.6 \%)$ & $4(6.5 \%)$ & \\
\hline Obese III (>41) & $58(12.2 \%)$ & $18(9.9 \%)$ & $35(15.2 \%)$ & $5(8.1 \%)$ & \\
\hline Region & & & & & 0.09 \\
\hline Canada & $404(85.1 \%)$ & $144(79.1 \%)$ & $203(87.9 \%)$ & $57(91.9 \%)$ & \\
\hline Europe & $15(3.2 \%)$ & $5(2.7 \%)$ & $8(3.5 \%)$ & $2(3.0 \%)$ & \\
\hline USA & $56(11.8 \%)$ & $33(18.1 \%)$ & $20(8.7 \%)$ & $3(4.5 \%)$ & \\
\hline
\end{tabular}

Data are reported as number $(\%)$ or mean \pm SD.

${ }^{a}$ Proportion of caloric prescription received by enteral nutrition and parenteral nutrition over first 8 days of mechanical ventilation and intensive care unit stay;

${ }^{b}$ to account for intensive care unit level clustering, p-values were calculated by Rao-Scott adjusted chisquared method for categorical variables and the linear generalized estimating equations for continuous variables. 
Table 3.3 shows the short-term clinical outcomes of the patients according to nutritional adequacy groups. The average length of stay and duration of mechanical ventilation were 26.3 and 21.8 days, respectively. Just over a quarter of the patients died in the ICU. Based on the crude comparisons, short-term clinical outcomes did not differ significantly between the three nutritional adequacy groups (Table 3.3).

Table 3.3 Short-term clinical outcomes according to nutritional adequacy groups

\begin{tabular}{lccccc}
\hline & & \multicolumn{3}{c}{ Nutritional Adequacy $^{\mathbf{a}}$} \\
\cline { 3 - 5 } \multicolumn{1}{c}{ Variable } & Overall & $\begin{array}{c}\text { Low } \\
(\mathbf{0 =}=<\mathbf{5 0 \% )}\end{array}$ & $\begin{array}{c}\text { Moderate } \\
\mathbf{( 5 0 = < 8 0 \% )}\end{array}$ & $\begin{array}{c}\text { High } \\
(>=\mathbf{8 0 \%})\end{array}$ & $\boldsymbol{p}^{\mathbf{b}}$ \\
\hline Number of patients & 475 & 182 & 231 & 62 & \\
ICU length of stay & $26.3 \pm 32.6$ & $28.0 \pm 38.7$ & $26.2 \pm 30.9$ & $22.2 \pm 13.9$ & 0.22 \\
Mechanical ventilation duration & $21.8 \pm 29.5$ & $22.1 \pm 32.7$ & $22.2 \pm 30.2$ & $19.7 \pm 13.5$ & 0.56 \\
ICU mortality $^{\mathrm{c}}$ & $123(25.7 \%)$ & $47(25.8 \%)$ & $62(26.8 \%)$ & $14(21.2 \%)$ & 0.63 \\
\hline
\end{tabular}

Data are reported as number $(\%)$ or mean $\pm \mathrm{SD}$.

${ }^{\mathrm{a}}$ Proportion of caloric prescription received by enteral nutrition and parenteral nutrition over first 8 days of mechanical ventilation and intensive care unit stay;

${ }^{b}$ to account for intensive care unit level clustering, p-values were calculated by Rao-Scott adjusted chisquared method for categorical variables and the linear generalized estimating equations for continuous variables;

${ }^{c} \mathrm{ICU}$ mortality is calculated based on the raw number of deaths prior to ICU discharge.

\section{6-month survival in $>8$ days stayers}

For critically ill patients with $>8$ days of ICU stay and mechanical ventilation, the probability of survival to six months in the low, moderate, and high nutritional adequacy groups were $59.1 \%, 60.5 \%$, and $63.3 \%$, respectively. There were $78(16.4 \%)$ patients censored due to loss to follow-up before three months and $22(4.6 \%)$ additional patients censored due to lost to follow-up prior to six months. The crude Kaplan-Meier survival curves for each nutritional adequacy group are shown in Figure 3.2, with no significant difference in six-month survival observed between the three groups $(P=0.86)$. 


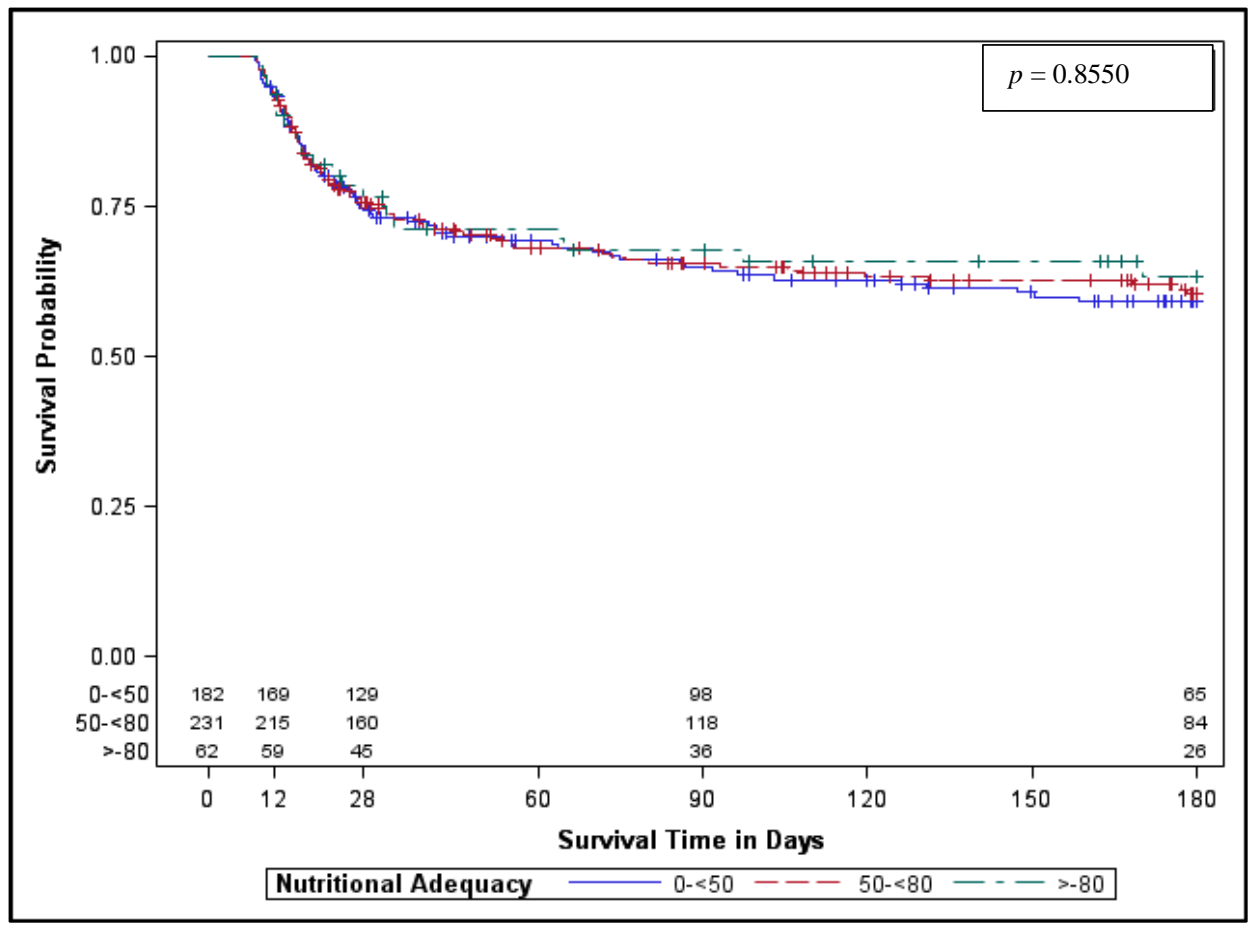

Figure 3.2 Crude Kaplan-Meier survival curves stratified by nutritional adequacy groups

Results of the Cox PH regression model are presented in Table 3.4. In the unadjusted analysis, high nutritional adequacy was not associated with six-month survival (crude HR = 1.13, 95\% CI: $0.73-1.75, P=0.59$ ). When adjusted for baseline characteristics in a multivariate Cox PH model, the low nutritional adequacy group was found to have a shorter survival time (adjusted $\mathrm{HR}=1.67,95 \% \mathrm{CI}: 1.06-2.64, P=0.03)$ compared to the high nutritional adequacy group $(\geq 80 \%)$. No significant difference in survival time was found between moderate and high nutritional adequacy groups (adjusted $\mathrm{HR}=1.30,95 \% \mathrm{CI}$ : $0.74,2.26, P=0.36$ ). Although not statistically significant, the hazard ratio consistently trended toward benefit from high over moderate nutritional adequacy. Figure 3.3 shows the adjusted survival curves stratified by nutritional adequacy group, with significant differences in survival time observed between the three groups $(P=0.04)$. 
Table 3.4 Hazard ratio estimates of the effect of nutritional adequacy on 6-months survival

\begin{tabular}{|c|c|c|c|c|c|c|}
\hline \multirow[t]{2}{*}{ Model } & \multicolumn{2}{|l|}{ Low vs. High } & \multicolumn{2}{|c|}{ Moderate vs. High } & \multicolumn{2}{|c|}{ Continuous per $25 \%$ decrease } \\
\hline & HR $(95 \% \mathrm{CI})$ & $p$ & HR $(95 \% \mathrm{CI})$ & $p$ & HR $(95 \%$ CI $)$ & $p$ \\
\hline \multicolumn{7}{|c|}{ Main analysis: $>8$ days stayers $(n=475$, deaths $=173)$} \\
\hline Crude & $1.13(0.73,1.75)$ & 0.59 & $1.08(0.66,1.77)$ & 0.75 & $0.98(0.84,1.15)$ & 0.85 \\
\hline Adjusted $^{\mathrm{a}, \mathrm{b}}$ & $1.67(1.06,2.64)$ & 0.03 & $1.30(0.74,2.26)$ & 0.36 & $1.14(0.99,1.33)$ & 0.08 \\
\hline \multicolumn{7}{|c|}{ Sensitivity analysis: $>12$ days stayers $(n=315$, deaths $=120)$} \\
\hline Crude & $1.23(0.85,1.77)$ & 0.28 & $1.07(0.72,1.58)$ & 0.74 & $1.02(0.83,1.24)$ & 0.88 \\
\hline Adjusted $^{\mathrm{a}, \mathrm{b}}$ & $1.91(1.23,2.95)$ & 0.004 & $1.49(0.87,2.52)$ & 0.14 & $1.21(1.01,1.46)$ & 0.04 \\
\hline
\end{tabular}

\section{Subgroup analysis in $>8$ day stayers}

Medical (n=372, deaths=147)

$\begin{array}{lllllll}\text { Crude } & 1.53(0.92,2.52) & 0.10 & 1.26(0.68,2.33) & 0.46 & 1.11(0.93,1.31) & 0.25\end{array}$

$\begin{array}{lllllll}\text { Adjusted }^{\mathrm{a}, \mathrm{c}} \quad 2.09(1.26,3.45) & 0.004 & 1.53(0.75,3.13) & 0.24 & 1.24(1.07,1.44) & 0.004\end{array}$

\begin{tabular}{|c|c|c|c|c|c|c|}
\hline \multicolumn{7}{|c|}{ Surgical $(n=103$, deaths $=26)$} \\
\hline Crude & $0.48(0.16,1.45)$ & 0.19 & $0.32(0.10,1.05)$ & 0.06 & $0.80(0.46,1.40)$ & 0.80 \\
\hline Adjusted $^{\mathrm{a}, \mathrm{c}}$ & $1.32(0.35,5.08)$ & 0.68 & $0.69(0.23,2.05)$ & 0.50 & $1.08(0.59,2.01)$ & 0.80 \\
\hline
\end{tabular}

${ }^{a}$ Adjusted for age, APACHE II score, baseline SOFA, Charlson Comorbidity Index, admission category, primary ICU diagnosis, body mass index, and region;

${ }^{\mathrm{b}}$ The overall model used 19 degrees of freedom;

${ }^{c}$ The medical and surgical subgroup models used 17 and 15 degrees of freedom respectively due to the absence of admission type and differences in the number of admission categories. 


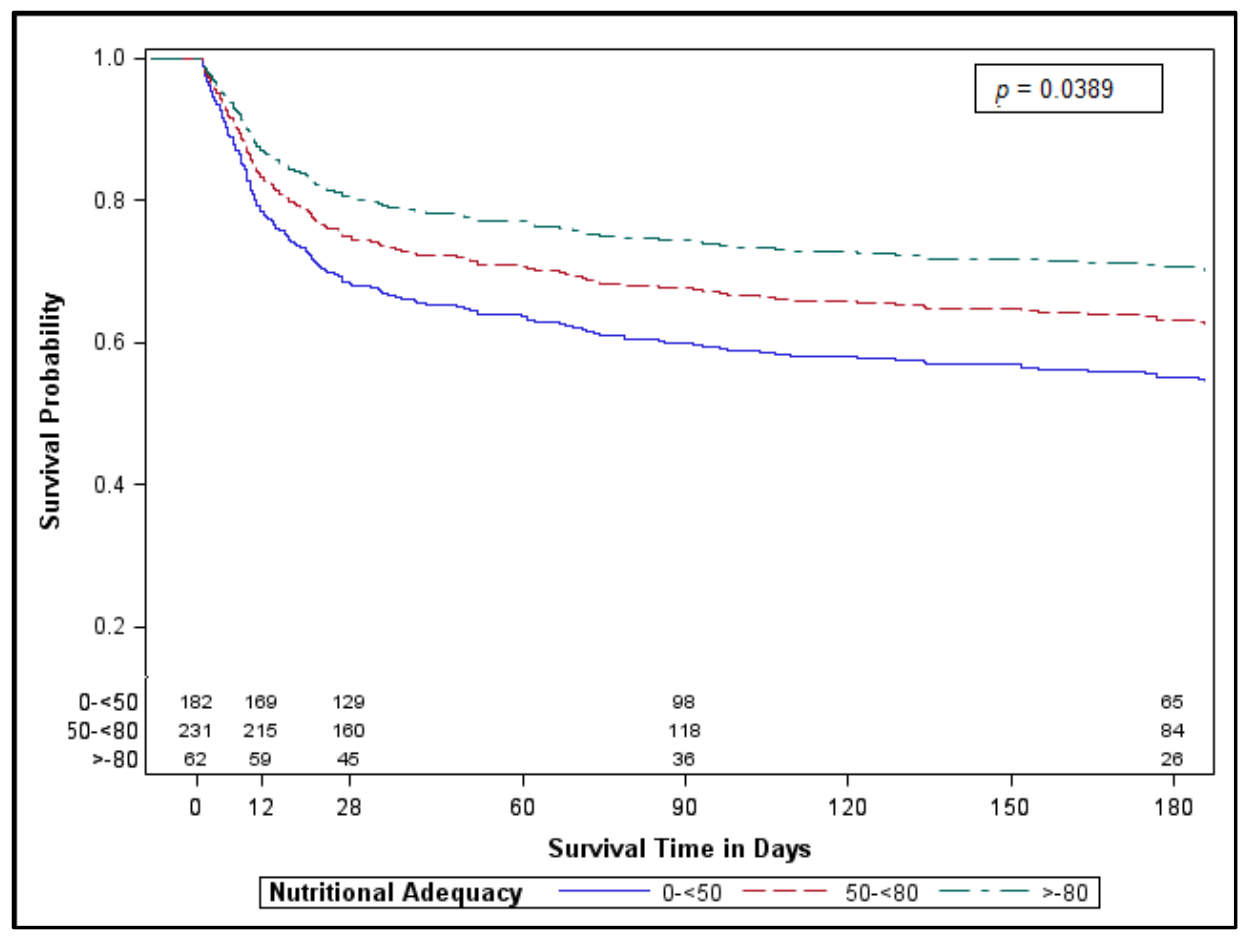

Figure 3.3 Adjusted Kaplan-Meier survival curves stratified by nutritional adequacy groups

\section{6-month survival in >12 days stayers}

A subset analysis of patients who were mechanically ventilated and stayed in ICU for $>12$ days consistently revealed that low nutritional adequacy was associated with shorter survival time (adjusted HR $=1.91,95 \% \mathrm{CI}: 1.23-2.95, P=0.004)$ compared to high nutritional adequacy (Table 3.4). Although no significant difference in survival time was found between moderate and high nutritional adequacy, the hazard ratio consistently trended toward benefit from high over moderate nutritional adequacy (adjusted $\mathrm{HR}=1.49,95 \% \mathrm{CI}: 0.87-2.52, P=0.14$ ).

\section{Subgroup analysis by admission category}

Subgroup analysis by admission category in $>8$ days stayers showed an association between nutritional adequacy and longer survival time only in medical patients with the same consistent trend in favor of high nutritional adequacy (Table 3.4). The interaction between 
admission category and nutritional adequacy was tested and found not to be statistically significant $(P=0.18)$.

\section{Nutritional adequacy as a continuous predictor}

Consistent results were obtained when repeating the analyses by treating nutritional adequacy as a continuous predictor (Table 3.4). After controlling for baseline characteristics, per $25 \%$ decrease in nutritional adequacy had an association of borderline significance with shorter survival time $(\mathrm{HR}=1.14,95 \% \mathrm{CI}=0.99-1.33, P=0.08)$ in $>8$ days stayers. A stronger and more significant association was observed in $>12$ days stayers $(\mathrm{HR}=1.21,95 \% \mathrm{CI}=1.01-1.46, P=$ 0.04). The proportional hazard assumption and the linearity assumption were not violated in the Cox PH models mentioned above.

\section{Discussion}

We hypothesized that critically ill patients at high nutrition risk, particularly those who were mechanically ventilated for a long period of time in the ICU, would benefit from aggressive provision of energy intake. We conducted a cohort study of nutrition therapy to evaluate the impact of nutritional adequacy (percentage of prescribed energy patients received) on six-month survival in 475 critically ill patients with prolonged mechanical ventilation in the ICU. The main finding of our study was that after adjusting for important known confounding variables, higher nutritional adequacy was significantly associated with six-month survival in critically ill patients requiring prolonged mechanical ventilation. More specifically, receiving more than $80 \%$ of prescribed energy seemed to be beneficial.

Although there is a general agreement about the importance of nutrition therapy in critically ill patients, controversy continues to exist over what the optimal amount of energy provision is, as different studies have yielded different results. In addition, there is very little research investigating the long-term effect of nutritional intake in the ICU. Two studies have 
recently examined the long-term effect of underfeeding compared to target feeding. In a single center randomized controlled trial (RCT) of 240 patients, Arabi et al. compared permissive underfeeding (60-70\% of energy target) with target feeding (90-100\% of energy target) [37]. The actual energy intake for the two intervention groups was 59\% versus 71\%. Although not statistically significant, the investigators observed a lower mortality at 180 days (32.8\%) in the permissive underfeeding group compared with the mortality (44.4\%) in the target feeding group $(P=0.07)$. In a recently published follow-up evaluation of a large randomized controlled trial (EDEN trial) [47], Needham et al. compared the long-term effects of trophic feeding (for the first six days, $25 \%$ of energy target) versus full energy feeding ( $80 \%$ of energy target) in 525 patients with acute lung injury. The investigators reported no difference between trophic vs. full feeding in six month and twelve month survival (estimated 12 month survival for trophic vs. full feeding: $65 \%$ vs. $63 \% ; P=0.63)$.

Our study has yielded different results from these two studies. However, it is important to note that our study is different from the two studies in terms of comparison groups and patient population. A major limitation of the study by Arabi et al. was that the difference in energy delivery between the study interventions was only about $10 \%$. The target feeding group did not achieve the $90-100 \%$ caloric goal as the study intended. Thus, its implication on appropriate nutrition provision is less meaningful as most discrepancies in the optimal amount of caloric intake have been whether achieving full feeding (about 70-100\% of caloric goal) is beneficial compared to trophic feeding. In the EDEN trial, it is important to note that all EDEN patients received the benefits of early enteral nutrition and the trophic feeding group eventually received full feeding after the six-day period. It is possible that the overall duration of differences in feeding strategies was not long enough to contribute to differences in long-term outcomes. 
It is also important to recognize that the patients in the EDEN and Arabi trials are different from our patient population. The EDEN patients were younger (average 52 years), had a much shorter duration of mechanical ventilation (average 5 days), and had a smaller proportion of medical patients (62\%). Similarly, patients in the Arabi trial were also younger (51 years) and had a shorter average duration of mechanical ventilation (12 days). Our patient population is relatively older (mean 62 years) and had much longer average duration of mechanical ventilation (21 days). Thus, a key difference between our study and the other two studies is that our study targeted more severely ill patients or 'high-risk' patients. An emerging body of evidence suggests that not all critically ill patients are the same in terms of their nutrition risk [25, 48]. The patients at high nutrition risk are more likely to benefit from nutrition therapy than others. It has been well-recognized that severity of illness can further impair patients' nutritional status, and these patients need more nutritional intake due to their increased stress-metabolism [25]. Thus, our study only focused on the 'high-risk' patients, who are those who were very sick and required prolonged mechanical ventilation.

Our findings are consistent with studies that looked at the effects of caloric intake in 'high-risk' critically ill patients. The studies reported a relationship between lower caloric intake and worse clinical outcomes in patients who had prolonged ICU stay or mechanical ventilation $[12,33]$. Faisy et al. demonstrated that in a small group $(n=38)$ of critically ill patients requiring prolonged mechanical ventilation (>7 days), an energy deficit of approximately $1200 \mathrm{kcal} /$ day is independently associated with ICU mortality [12]. A retrospective study in 295 patients who stayed in ICU for at least seven days, Tsai et al. found that patients receiving low caloric intake $(<60 \%)$ were at greater risk of ICU mortality than the patients receiving higher caloric intake $(\geq 60 \%)$ [33]. However, these studies only examined short-term clinical outcomes. 
Another finding of our study is that the effect of increasing energy intake on six-month survival seemed to be largest in medical patients with little evidence of an effect in surgical patients. Although the interaction between admission category and nutritional adequacy did not reach statistical significance, possibly because of inadequate power, the observed difference in medical and surgical patients is consistent with the findings of previous studies [10, 12, 49]. Compared to surgical patients, medical patients have more underlying comorbidities, suffer from more decompensation of chronic underlying disease, and poor short-term survival [50-52]. One study has confirmed that the difference in survival extends beyond ICU discharge [51]. This finding may again explain the different results we have seen in heterogeneous patient population with different nutrition risk. Medical patients are more severely ill or at higher nutrition risk, thus more likely to benefit from artificial nutrition than surgical patients.

The major strength of this study is the assessment of longer-term outcomes in critically ill patients as compared to previous studies examining the effect of nutrition therapy. The study is novel in that it is the first observational study that evaluated the long-term impacts of nutrition therapy and focused on the 'high risk' patients. Another strength of our study is that we used the most robust sample restriction approach by only including patients with a minimum duration of mechanical ventilation in the ICU, which has been shown to be appropriate to account for the confounding effect of duration of exposure to nutrition in estimating the association between nutritional adequacy and clinical outcomes. In addition, nutritional data were extracted from an original RCT conducted in multiple intensive care units across different countries thus enhancing the generalizability of the findings.

There are several limitations to this study. First, although the study provides evidence for temporality, the causal association between nutritional adequacy and long-term survival cannot be definitively established due to the observational nature of the study and possible remaining 
unknown confounding. However, we did use sample restriction and statistical adjustment techniques to account for variability in duration of exposure to nutrition and key patient demographics that relate to exposure and outcome. Second, many exclusion criteria of the RCT were applied to only include patients who are likely to benefit from the therapeutic intervention for the purpose of the clinical trials. Thus, the generalizability of the study findings is restricted. However, the study targeted the most severely ill ICU patients, which have been projected as the patient population that will benefit the most from artificial nutrition. Third, the method used for caloric prescription for individual patients is not standardized across ICU sites because there is lack of evidence to determine the best method for estimating energy requirements [53]. In the RCT study, the method to estimate energy requirement and hence the prescribed calories, was left to clinical judgment of the unit dietitian. Fourth, there were many patients who were lost to follow-up, with $78(16.4 \%)$ prior to three months and an additional $22(4.6 \%)$ by six months. It is possible that the patients become too sick to follow-up or they may be fully recovered and may no longer feel the need to follow-up. Thus, the reason for lost to follow-up could potentially be informative; the survival time for these patients could be underestimated or overestimated. However, the likelihood of being lost to follow-up would have to be related to both exposure and outcome status to have biased the estimate of effect. Fifth, health-related quality of life (HRQoL) was not considered as one of our study outcomes. There is emerging evidence suggesting that adequate energy intake impact muscle mass and muscle function which in turn predict physical outcomes [48-51]. As the number of ICU survivors increases, it has been recognized that survival alone is not the only important outcome after ICU discharge [58]. HRQoL is especially important to consider in the critical care setting, as the resultant health state may be valued as worse than death [59]. Better understanding of how nutritional adequacy affects both long-term survival as well as HRQoL is essential to the most effective utilization of critical care. 
Our findings have important implications for the planning of nutrition practices as well as future research. From a nutrition practice perspective, more nutritional intake may be associated with better long-term outcome, particularly in the most severely ill medical patients. In the future development of nutrition practices, special attention should be given to the most severely ill patients such as those who require prolonged mechanical ventilation. Clinical trials of nutrition support should evaluate longer-term outcomes. Furthermore, future research in critical care nutrition should recognize that not all patients are the same in terms of the benefit they receive from nutrition therapy. This issue should be taken into consideration in the design of future studies by either including only patients at risk or stratifying by their nutrition risk.

\section{Conclusion}

Our study has suggested an important relationship between higher energy intake (>80\% of prescribed energy) and longer survival time in critically ill patients with prolonged mechanical ventilation. Receiving adequate energy as early as the first week of ICU stay seems beneficial to long-term survival of these patients. We also observed a stronger association in medical patients as opposed to surgical patients. Evidence from well-designed randomized controlled trials is required to provide stronger assessment of the causal impact of nutrition therapy on long-term outcomes. 


\section{References}

1. McWhirter JP, Pennington CR: Incidence and recognition of malnutrition in hospital. $B M J$ 1994, 308:945-8.

2. Driver AG, Lebrun M: latrogenic Malnutrition in Patients Receiving Ventilatory Support. JAMA 1980, 244:2195-2196.

3. Bassili H, Deitel M: Effect of nutritional support on weaning patients off mechanical ventilators. Journal of Parenteral and Enteral Nutrition 1981, 5:161-163.

4. Cerra FB, Benitez MR, Blackburn GL, Irwin RS, Jeejeebhoy K, Katz DP, Pingleton SK, Pomposelli J, Rombeau L, Shronts E, Robert R, Zaloga GP: Applied Nutrition in ICU Patients. A Consensus Statement of the American of Chest Physicians. Chest 1997, 111:769-778.

5. Dardaine V, Dequin PF, Ripault H, Constans T, Giniès G: Outcome of older patients requiring ventilatory support in intensive care: impact of nutritional status. Journal of the American Geriatrics Society 2001, 49:564-70.

6. Dempsey, DT Mullen, JL Buzby G: The link be- tween nutritional status and clinical outcome: can nutritional intervention modify it? The American Journal of Clinical Nutritrion $1988,47: 352-356$.

7. O’Leary-Kelley C, Puntillo K, Barr J, Stotts N, Douglas M: Nutritional adequacy in patients receiving mechanical ventilation who are fed enterally. American Journal of Critical Care 2005, 14:222-31. 
8. Villet S, Chiolero RL, Bollmann MD, Revelly J-P, Cayeux R N M-C, Delarue J, Berger MM: Negative impact of hypocaloric feeding and energy balance on clinical outcome in ICU patients. Clinical Nutrition Edinburgh Scotland 2005, 24:502-9.

9. Alberda C, Gramlich L, Jones N, Jeejeebhoy K, Day AG, Dhaliwal R, Heyland DK: The relationship between nutritional intake and clinical outcomes in critically ill patients: results of an international multicenter observational study. Intensive Care Medicine 2009, 35:1728-37.

10. Rubinson L, Diette GB, Song X, Brower RG, Krishnan JA: Low caloric intake is associated with nosocomial bloodstream infections in patients in the medical intensive care unit. Critical Care Medicine 2004, 32:350-7.

11. Strack Van Schijndel RJ, Weijs PJ, Koopmans RH, Sauerwein HP, Beishuizen A, Girbes AR: Optimal nutrition during the period of mechanical ventilation decreases mortality in critically ill, long-term acute female patients: a prospective observational cohort study. Critical Care 2009, 13:R132.

12. Faisy C, Lerolle N, Dachraoui F, Savard J-F, Abboud I, Tadie J-M, Fagon J-Y: Impact of energy deficit calculated by a predictive method on outcome in medical patients requiring prolonged acute mechanical ventilation. The British Journal of Nutrition 2009, 101:1079-87.

13. Taylor S, Fettes S, Jewkes C, Nelson RJ: Prospective, randomized, controlled trial to determine the effect of early enhanced enteral nutrition on clinical outcome in mechanically ventilated patients suffering head injury. Critical Care Medicine 1999, 27:2525-2531. 
14. Martin CM, Doig GS, Heyland DK, Morrison T, Sibbald WJ: Multicentre, clusterrandomized clinical trial of algorithms for critical-care enteral and parenteral therapy (ACCEPT). CMAJ 2004, 170:197-204.

15. Singer P, Anbar R, Cohen J, Shapiro H, Shalita-Chesner M, Lev S, Grozovski E, Theilla M, Frishman S, Madar Z: The tight calorie control study (TICACOS): a prospective, randomized, controlled pilot study of nutritional support in critically ill patients. Intensive Care Medicine 2011, 37:601-9.

16. Heyland DK, Stephens KE, Day AG, McClave SA: The success of enteral nutrition and ICU-acquired infections: a multicenter observational study. Clinical Nutrition 2011, 30:14855.

17. Krishnan JA, Parce PB, Martinez A, Diette GB, Brower RG: Caloric intake in medical ICU patients: consistency of care with guidelines and relationship to clinical outcomes. Chest 2003, 124:297-305.

18. Arabi YM, Haddad SH, Tamim HM, Rishu AH, Sakkijha MH, Kahoul SH, Britts RJ: Neartarget caloric intake in critically ill medical-surgical patients is associated with adverse outcomes. Journal of Parenteral and Enteral Nutrition 2010, 34:280-8.

19. Dickerson RN, Boschert KJ, Kudsk KA, Brown RO: Hypocaloric enteral tube feeding in critically ill obese patients. Nutrition 2002, 18:241-6.

20. Ibrahim E, Mehringer L, Prentice D, Sherman G, Schaiff R, Fraser V, Kollef M: Early versus late enteral feeding of mechanically ventilated patients: results of a clinical trial. Journal of Parenteral and Enteral Nutrition 2002, 26:174-181. 
21. Rice TW, Mogan S, Hays MA, Bernard GR, Jensen GL, Wheeler AP: Randomized trial of initial trophic versus full-energy enteral nutrition in mechanically ventilated patients with acute respiratory failure. Critical Care Medicine 2011, 39:967-74.

22. Rice TW, Wheeler AP, Thompson BT, Steingrub J, Hite RD, Moss M, Morris A, Dong N, Rock P: Initial trophic vs full enteral feeding in patients with acute lung injury: the EDEN randomized trial. JAMA 2012, 307:795-803.

23. Heyland DK, Cahill N, Day AG: Optimal amount of calories for critically ill patients: depends on how you slice the cake! Critical Care Medicine 2011, 39:2619-26.

24. Heyland DK: Critical care nutrition support research: lessons learned from recent trials. Current Opinion in Clinical Nutrition and Metabolic Care 2013, 16:176-81.

25. Kondrup J: Nutritional risk screening (NRS 2002): a new method based on an analysis of controlled clinical trials. Clinical Nutrition 2003, 22:321-336.

26. Gruther W, Benesch T, Zorn C, Paternostro-Sluga T, Quittan M, Fialka-Moser V, Spiss C, Kainberger F, Crevenna R: Muscle wasting in intensive care patients: ultrasound observation of the M. quadriceps femoris muscle layer. Journal of Rehabilitation Medicine 2008, 40:185-9.

27. Faisy C, Rabbat a, Kouchakji B, Laaban JP: Bioelectrical impedance analysis in estimating nutritional status and outcome of patients with chronic obstructive pulmonary disease and acute respiratory failure. Intensive Care Medicine 2000, 26:518-25.

28. Griffiths RD: Nutrition and survival in intensive care. Intensivmedizin und Notfallmedizin 1998, 35:3-9. 
29. Needham DM, Bronskill SE, Calinawan JR, Sibbald WJ, Pronovost PJ, Laupacis A:

Projected incidence of mechanical ventilation in Ontario to 2026: Preparing for the aging baby boomers. Critical Care Medicine 2005, 33:574-579.

30. Spragg RG, Bernard GR, Checkley W, Curtis JR, Gajic O, Guyatt G, Hall J, Israel E, Jain M, Needham DM, Randolph AG, Rubenfeld GD, Schoenfeld D, Thompson BT, Ware LB, Young D, Harabin AL: Beyond mortality: future clinical research in acute lung injury. American Journal of Respiratory and Critical Care Medicine 2010, 181:1121-7.

31. Heyland DK, Dhaliwal R, Day AG, Muscedere J, Drover J, Suchner U, Cook D: REducing Deaths due to OXidative Stress (The REDOXS@ Study): rationale and study design for a randomized trial of glutamine and antioxidant supplementation in critically-ill patients. Proceedings of the Nutrition Society 2007, 65:250-263.

32. Weijs PJM, Stapel SN, de Groot SDW, Driessen RH, de Jong E, Girbes ARJ, Strack van Schijndel RJM, Beishuizen A: Optimal protein and energy nutrition decreases mortality in mechanically ventilated, critically ill patients: a prospective observational cohort study. Journal of Parenteral and Enteral Nutrition 2012, 36:60-8.

33. Tsai J-R, Chang W-T, Sheu C-C, Wu Y-J, Sheu Y-H, Liu P-L, Ker C-G, Huang M-C: Inadequate energy delivery during early critical illness correlates with increased risk of mortality in patients who survive at least seven days: a retrospective study. Clinical Nutrition 2011, 30:209-14.

34. Knaus W, Draper E: APACHE II: a severity of disease classification system. Critical Care 1985, 13:819-29. 
35. Moreno R, Vincent J, Matos R: The use of maximum SOFA score to quantify organ dysfunction/failure in intensive care. Results of a prospective, multicentre study. Intensive Care Medicine 1999, 25:686-696.

36. Charlson M, Pompei P: A new method of classifying prognostic comorbidity in longitudinal studies: development and validation. Journal of Chronic Disease 1987, 40:373383.

37. Arabi YM, Tamim HM, Dhar GS, Al-dawood A, Al-sultan M, Sakkijha MH, Kahoul SH, Brits R: Permissive underfeeding and intensive insulin therapy in critically ill patients : a randomized controlled trial. The American Journal of Clinical Nutritrion 2011, 93:569-77.

38. Casaer MP, Mesotten D, Hermans G, Wouters PJ, Schetz M, Meyfroidt G, Van Cromphaut S, Ingels C, Meersseman P, Muller J, Vlasselaers D, Debaveye Y, Desmet L, Dubois J, Van Assche A, Vanderheyden S, Wilmer A, Van den Berghe G: Early versus late parenteral nutrition in critically ill adults. The New England Journal of Medicine 2011, 365:506-17.

39. Lin D: Cox regression analysis of multivariate failure time data: the marginal approach. Statistics in Medicine 1994, 13:2233-2247.

40. Lin D, Wei L, Ying Z: Checking the Cox model with cumulative sums of martingalebased residuals. Biometrika 1993, 80:557-572.

41. Williams TA, Dobb GJ, Finn JC, Knuiman MW, Geelhoed E, Lee KY, Webb SA:

Determinants of long-term survival after intensive care. Critical Care Medicine 2008, 36:1523-30. 
42. Williams TA, Dobb GJ, Finn JC, Webb SA: Long-term survival from intensive care: a review. Intensive Care Medicine 2005, 31:1306-15.

43. Wunsch H, Guerra C, Barnato AE, Angus DC, Li G, Linde-Zwirble WT: Three-year outcomes for Medicare beneficiaries who survive intensive care. JAMA 2010, 303:849-56.

44. Chelluri L, Im KA, Belle SH, Schulz R, Rotondi AJ, Donahoe MP, Sirio C a, Mendelsohn AB, Pinsky MR: Long-term mortality and quality of life after prolonged mechanical ventilation. Critical Care Medicine 2004, 32:61-9.

45. Euteneuer S, Windisch W, Suchi S, Köhler D, Jones PW, Schönhofer B: Health-related quality of life in patients with chronic respiratory failure after long-term mechanical ventilation. Respiratory Medicine 2006, 100:477-86.

46. Pappalardo F, Franco A, Landoni G, Cardano P, Zangrillo A, Alfieri O: Long-term outcome and quality of life of patients requiring prolonged mechanical ventilation after cardiac surgery. European Journal of Cardio-thoracic Surgery 2004, 25:548-52.

47. Needham DM, Dinglas VD, Bienvenu OJ, Colantuoni E, Wozniak a. W, Rice TW, Hopkins RO: One year outcomes in patients with acute lung injury randomised to initial trophic or full enteral feeding: prospective follow-up of EDEN randomised trial. BMJ 2013, 346:f1532f1532.

48. Heyland DK, Dhaliwal R, Jiang X, Day AG: Identifying critically ill patients who benefit the most from nutrition therapy: the development and initial validation of a novel risk assessment tool. Critical Care 2011, 15:R268. 
49. Barr J, Hecht M, Flavin KE, Khorana A, Gould MK: Outcomes in critically ill patients before and after the implementation of an evidence-based nutritional management protocol. Chest 2004, 125:1446-57.

50. Herridge MS, Cheung AM, Tansey CM, Matte-Martyn A, Diaz-Granados N, Al-Saidi F, Cooper AB, Guest CB, Mazer CD, Mehta S, Stewart TE, Barr A, Cook D, Slutsky AS: One-year outcomes in survivors of the acute respiratory distress syndrome. The New England Journal of Medicine 2003, 348:683-93.

51. Lam S, Ridley S: Critically ill medical patients, their demographics and outcome. Anaesthesia 1999, 54:845-52.

52. Badia X, Diaz-Prieto a, Gorriz MT, Herdman M, Torrado H, Farrero E, Cavanilles JM: Using the EuroQol-5D to measure changes in quality of life 12 months after discharge from an intensive care unit. Intensive Care Medicine 2001, 27:1901-7.

53. Flancbaum L, Choban PS, Sambucco S, Verducci J, Burge JC: Comparison of indirect calorimetry, the Fick method, and prediction equations in estimating the energy requirements of critically ill patients. The American Journal of Clinical Nutrition 1999, 69:461-6.

54. Volkert D: The role of nutrition in the prevention of sarcopenia. Wiener Medizinische Wochenschrift 2011, 161:409-15.

55. Kasper CE, Talbot LA, Gaines JM: Skeletal muscle damage and recovery. AACN Clinical Issues 2002, 13:237-47. 
56. Puthucheary Z, Montgomery H, Moxham J, Harridge S, Hart N: Structure to function: muscle failure in critically ill patients. The Journal of Physiology 2010, 588:4641-8.

57. Hickson M, Frost G: An investigation into the relationships between quality of life, nutritional status and physical function. Clinical Nutrition 2004, 23:213-21.

58. Needham DM, Davidson J, Cohen H, Hopkins RO, Weinert C, Wunsch H, Zawistowski C, Bemis-Dougherty A, Berney SC, Bienvenu OJ, Brady SL, Brodsky MB, Denehy L, Elliott D, Flatley C, Harabin AL, Jones C, Louis D, Meltzer W, Muldoon SR, Palmer JB, Perme C, Robinson M, Schmidt DM, Scruth E, Spill GR, Storey CP, Render M, Votto J, Harvey MA: Improving long-term outcomes after discharge from intensive care unit: report from a stakeholders' conference. Critical Care Medicine 2012, 40:502-9.

59. Heyland DK, Guyatt G, Cook DJ, Meade M, Juniper E, Cronin L, Gafni A: Frequency and methodologic rigor of quality-of-life assessments in the critical care literature. Critical Care Medicine 1998, 26:591-598. 


\title{
Chapter 4
}

\section{Nutritional Adequacy and Health-related Quality of Life in Critically Ill Patients Requiring Prolonged Mechanical Ventilation}

\begin{abstract}
Introduction: The objective of this study was to examine the association between nutritional adequacy and health-related quality of life (HRQoL) in six-month survivors requiring prolonged mechanical ventilation in the intensive care unit (ICU).

Methods: The study was conducted as a retrospective cohort study on data collected prospectively in the context of a multicenter randomized controlled trial in critically ill patients. Patients survived to six-months follow-up and were mechanically ventilated for more than eight days in the intensive care unit were included. Nutritional adequacy was obtained from the average proportion of prescribed calories received during the first eight days of mechanical ventilation in the ICU. HRQoL was prospectively assessed using Short-Form 36 Health Survey (SF-36) questionnaire at three-months and six-months post ICU admission.

Results: At six-months follow-up, 302 of the 475 patients who were mechanically ventilated and remained in the ICU for $>8$ days, were alive and therefore eligible for inclusion. Among these survivors, the increases in scores for Physical Functioning (PF), Role Physical (RP), and Physical Component Scale (PCS) of the SF-36 from three-months to six-months were statistically significant. At three-months follow-up, a $25 \%$ increase in nutritional adequacy was associated with improvements in PF, RP, and PCS of $7.29(P=0.02), 8.30(P=0.004)$, and $1.82(P=0.07)$ points respectively. At six-months follow-up, a $25 \%$ increase in nutritional adequacy was associated with improvements in PF, RP, and PCS of $4.16(P=0.14), 3.15(P=0.25)$, and 1.33
\end{abstract}


$(P=0.19)$ points respectively. A stronger association with nutritional adequacy was found at three-months compared with results obtained at six-months. Consistent results were obtained after performing multiple imputation on missing values.

Conclusions: Nutritional adequacy is associated with HRQoL in six-month survivors requiring prolonged mechanical ventilation in the ICU. Increasing nutritional intake can help facilitate faster physical recovery. 


\section{Introduction}

Malnutrition is a common problem in hospitalized patients [1], especially in critically ill patients requiring mechanical ventilation $[2,3]$. A patient's nutritional status often further worsens during prolonged ICU stay, due to factors that may be intrinsic to the patient or iatrogenic [4]. In mechanically ventilated patients, nutritional status often becomes deteriorated because of inability of these patients to express hunger and feed orally, or because of the complexity of intensive medical care [2]. Malnutrition in critically ill patients has been associated with impaired immunological function, impaired ventilator drive, and weakened respiratory muscles, leading to prolonged ventilator dependence and increased infectious morbidity and mortality $[5,6]$.

Nutrition therapy is now considered an integral part of standard care in the ICU [7]. The goals of nutrition therapy for critically ill patients are to attenuate loss of lean body mass, alleviate or treat malnutrition, and support the patient nutritionally to prevent physiologic deterioration [8]. Although the benefits of nutrition therapy are recognized and clinical practice guidelines are published worldwide, the optimal amount of nutritional intake in critically ill remains controversial. Some studies have shown that underfeeding or caloric debt is associated with adverse clinical outcomes [9-17]. In contrast, other studies have suggested better clinical outcomes in patients receiving low caloric intake [18-23]. Inconsistent findings could be due to the use of different statistical methodology to account for duration of exposure to nutrition, and failure to consider which patients may benefit the most from artificial nutrition support [24-26]. The duration of exposure to nutrition may be a confounder in evaluating the relationship between nutrition intake and clinical outcomes because short-term ICU patients who have a good outcome often receive few calories while in ICU [24]. Thus, taking a robust approach to account for the 
duration of exposure to nutrition is important in studies of nutrition support in the critical care setting.

There is emerging evidence that not all critically ill patients are the same in terms of nutrition risk or the benefit they receive from artificial nutrition. The patients at high nutrition risk are more likely to benefit from nutrition therapy than others [26]. It is recognized that nutrition risk depends on degrees of severity of disease as well as degrees of undernutrition. This concept was illustrated in studies that showed differential treatment effects of artificial nutrition in different subgroups of ICU patients. Alberda et al., found that the beneficial treatment effects of increased calories intake on 60-day mortality was observed only in critically ill patients whose body mass index (BMI) was under 25 or at least 35 [10]. A study by Faisy et al. demonstrated that in a small group of critically ill patients requiring prolonged mechanical ventilation $(>7$ days), an energy deficit of approximately $1200 \mathrm{kcal} /$ day was independently associated with ICU mortality [13]. Therefore, consideration of ICU patients at high nutrition risk, potentially those who require prolonged mechanical ventilation or have extreme BMI is needed in future studies of critical care nutrition.

While many studies have documented the impacts of nutritional intake on short-term outcomes such as ICU-acquired infection, and ICU and hospital mortality, relatively little is known about subsequent long-term outcomes. As the number of ICU survivors increases, it has been recognized that survival alone is not the only important outcome after ICU discharge [27]. ICU-acquired weakness following prolonged ICU stay is independently associated with morbidity in survivors of critical illness [28]. As quality patient survival is the primary goal of intensive care medicine, consideration of health-related quality of life (HRQoL) is also important [29]. There is emerging evidence suggesting that nutritional intake may impact muscle mass and muscle function which in turn predicts physical recovery [30-35]. Studies have found that, on 
average, critically ill patients only receive caloric intake between $40 \%$ and $50 \%$ of their prescribed requirements [36-40]. In ICU patients requiring prolonged mechanical ventilation, nutritional status is often further deteriorated due to their critical illness and, coupled with ongoing inadequate caloric intake, these patients may experience ongoing muscle loss and impaired physical function. Although achieving nutrition targets will not always be possible, we believe that optimal nutritional intake in the ICU is clinically relevant and understanding how it impacts patients in the long run and more importantly, in the physical aspects of health-related quality of life (HRQoL), is needed.

Our prior analysis demonstrated that, after adjusting for several potential confounders, increased nutritional adequacy was associated with improved survival up to six months post ICU admission (Wei X, Day A, Ouellette-Kuntz H, Heyland DK, manuscript in preparation). Thus, building on our previous finding of a significant association with survival, the purpose of this study was to examine the relationship between nutritional adequacy and HRQoL post ICU in sixmonth survivors requiring prolonged mechanical ventilation in the ICU. Our a priori hypothesis was that in critically ill patients at high nutrition risk, particularly those who were mechanically ventilated for a long period of time, increased nutritional adequacy is associated with improved physical aspects of HRQoL.

\section{Materials and Methods}

\section{Study design}

This is a retrospective cohort study on data collected prospectively in the context of a randomized controlled trial (RCT) of glutamine and antioxidants supplementation in critically ill patients. The trial was conducted between May 2007 and December 2011 in 40 ICU sites across Canada, the United States, and Europe. Details of the RCT are described elsewhere [41]. This 
study involved secondary analysis of data collected for the RCT as well as additional data collected on the characteristics of ICU sites.

\section{Study population}

Mechanically-ventilated adult patients 18 years of age and older admitted to ICU who had two or more organ failures related to their acute illness were eligible for the parent clinical trial (see Appendix $\mathrm{C}$ for a complete list of the eligibility criteria for the RCT). In the current study, eligible patients were randomized critically ill patients who survived to six months post ICU admission with duration of mechanical ventilation and length of ICU stay $>8$ days. Patients who were overfed (received $\geq 110 \%$ of prescribed energy) were excluded (Figure 4.1 ). The duration of mechanical ventilation and ICU length of stay allowed selection of patients requiring prolonged mechanical ventilation $[12,13,42]$. 
RCT (Parent study):

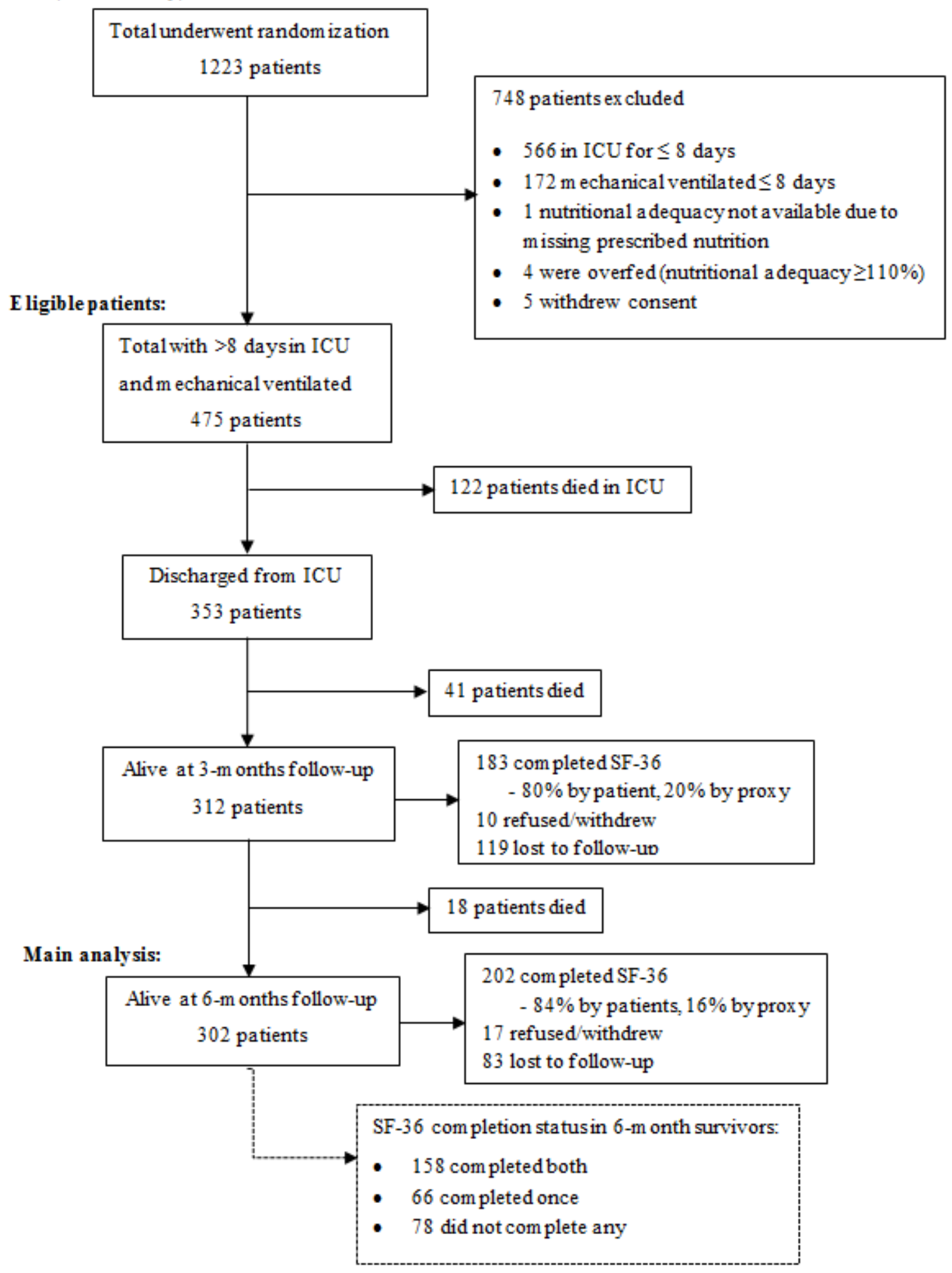

Figure 4.1 Patient flow chart 


\section{Data collection and measurements}

The following data collected at ICU admission were extracted from the database of the RCT: age, sex, admission category (medical or surgical), primary admission diagnosis (cardiovascular, respiratory, gastrointestinal, sepsis, and other), body mass index (BMI), comorbidities, Acute Physical and Chronic Health Evaluation (APACHE) II score to assess the severity of illness [43], and Sequential Organ Failure Assessment (SOFA) score to determine organ dysfunction [44]. The Functional Comorbidity Index was used to describe patients' comorbidities [45]. A survey of ICU characteristics was conducted at each participating site. The ICU characteristics included: ICU type (open or closed), ICU size (number of beds), case mix, region, presence of a medical director, and presence of a dietitian.

The daily total caloric intake from enteral nutrition (EN) and parenteral nutrition (PN) was collected from ICU admission for a maximum of 28 days, unless ICU discharge or death occurred sooner. The optimal amount of energy prescription was determined by indirect calorimetry or a formula that estimates energy requirements. Nutritional adequacy per day was calculated as the amount of calories received from enteral nutrition (EN) or parenteral nutrition (PN) divided by the amount prescribed, and expressed as a percentage. The average nutritional adequacy is then calculated as overall average percentage of prescribed calories received during the pre-specified duration of mechanical ventilation.

In the RCT, randomized patients were followed prospectively for a maximum of six months from the date of ICU admission. At three and six months post ICU admission, patients or next of kin were contacted by telephone to assess their survival status and to administer SF-36 
questionnaire. If the patient was not able to participate, proxy responses by a family member or a health care professional who knew the patient's condition the best were allowed.

SF-36, a short-form health-related quality of life (HRQoL) scoring system, is a generic, general health status survey consisting of eight domains and thirty-six items [46]. All but one of the 36 items are compressed into eight domains: General Health (GH), Physical Functioning (PF), Role Physical (RP), Role Emotional (RE), Social Functioning (SF), Bodily Pain (BP), Vitality (VT), and Mental Health (MH) [47]. The domains of the SF-36 are summarized into two higherorder scales: Physical Component Scale (PCS) and Mental Component Scale (MCS) [46]. Each domain and summary component is scored from 0 (worst score) to 100 (best score). The score of the summary components are weighed averages of the domains based on a factor analysis with orthogonal rotation [48]. The SF-36 is suitable for self-administration, or for administration by a trained interviewer in person or by phone. It has been tested and found both valid and reliable in the ICU setting, and is one of the recommended outcome measures $[49,50]$. A minimum change of five points in the domains and two points change in the summary component scale are considered clinically meaningful [46].

\section{Statistical analysis}

Patients and selected ICU characteristics were described using means with standard deviations for continuous variables and counts with percentages for categorical variables. The Physical Functioning (PF), Role Physical (RP), and Physical Component Scale (PCS) scores of the SF-36 were selected $a$ prior to examine their association with nutritional adequacy based on the biological plausibility presented in the literature [30-35]. PF, RP, and PCS at three- and sixmonths were described using mean scores and presented in bar graphs. We compared the scores at three- and six-months using paired t-test. We used the locally weighted regression scatter plot smoother (LOWESS) procedure to graphically depict the unadjusted univariate relationships 
between nutritional adequacy and each of the PF, RP, and PCS scores. The LOWESS curve is a procedure for drawing a smooth curve through a scatter diagram based on local regression and makes no assumption about the form of the relationship [51]. A linear mixed effects model was used to model the association between nutritional adequacy and SF-36 scores, both as continuous variables. For the ease of interpretation, nutritional adequacy was converted into 'per $25 \%$ increase' scale as it is a reasonable and achievable quality improvement in caloric delivery [21, 52]. The mixed model included random ICU effects to account for the dependence between patients within the same ICU. This approach equates to a two level multi-level model with the HRQoL assessment at level 1 and ICU at level 2. PF, RP, and PCS at each time point (three- and six-months) were modeled separately while adjusting for age, Functional Comorbidity Index, APACHE II score, baseline SOFA, and admission category based on evidence from previous research [53-56]. In addition to these pre-specified covariates, the final model included the site and patient characteristics from Table 4.1 and 4.2 that were selected by backward selection based on a significance of 0.1 . Subgroup analyses by admission category (medical vs. surgical) were performed to explore the interactions between admission category and nutritional adequacy. The significance of the interaction term was tested in the final model.

The missing data at three- and six-months were described by frequency to help understand the pattern of missing data. The baseline characteristics for three groups of patients: completed SF-36 at both time points, only at one time point, and not completed at any time point were described respectively. Multiple imputation was used to explore the robustness of the results. Because of the arbitrary missing pattern in all three sets of the SF-36 scores (i.e. a patient (or proxy) did not complete the three-months SF-36 but completed the six-months SF-36), the Markov chain Monte Carlo (MCMC) method was used to impute all the missing values [57]. Each of the PF, RP, and PCS scores across two time points were imputed together. Other 
variables that were used to impute the missing values include: age, gender, APACHE II score, baseline SOFA, Functional Comorbidity Index, region, admission category, BMI, ICU length of stay, hospital length of stay, and nutritional adequacy. Values were imputed only for those missing due to follow-up or dropout, not for those known to be dead at the time point. Multiple imputation reflects missing data uncertainty and results in multiple sets of a complete dataset. Twenty imputations were generated and each was analyzed using the linear mixed model. The estimates were then combined using Rubin's rules, which incorporate both within and betweenimputation variability [58]. This method assumes that the data were missing at random, meaning that the missingness is related to other measured variables in the analysis model, but not to the unobserved values of the incomplete variables [59].

All statistical analyses were performed using SAS version 9.3 (SAS Institute Inc., Cary, NC, USA). Unless otherwise specified, statistical significance was set at $P=0.05$ (two-sided) for all tests.

Research ethics approval was obtained from the Health Sciences Research Ethics Board at Queen's University in Kingston, Ontario, Canada. The need for informed patient consent was waived given the observational nature and deidentified data capture of this study.

\section{Results}

\section{Study population}

Figure 4.1 shows the number of patients included, reasons for exclusion, and the followup of eligible patients. Of the 1223 patients enrolled in the randomized controlled trial, 475 were mechanically ventilated in the ICU for $>8$ days and were not overfed (received $<110 \%$ of prescribed energy) were eligible for our study. This analysis includes the 302 patients alive and on study at six-months. Among the 302 patients alive at six-months follow-up, 158 patients completed the SF-36 at both time points, 66 patients only completed it at one time point, and 78 
patients did not complete any due to study refusal, withdrawal, or loss to follow-up (Figure 4.1). The characteristics for these three groups of patients with different SF-36 completion status are described in Appendix D (Table D.1). The six-month survivors included were from 34 ICU sites across Canada, Europe, and US. Table 4.1 shows characteristics of participating ICU sites.

\section{Table 4.1 Characteristics of participating ICU sites}

\begin{tabular}{lr}
\hline Site characteristics & All sites (n=34) \\
\hline Region & $22(64.7 \%)$ \\
Canada & $4(11.8 \%)$ \\
Europe & $8(23.5 \%)$ \\
USA & $27(8.0,62.0)$ \\
Size of ICU (beds) & \\
ICU type & $25(73.5 \%)$ \\
Closed & $5(14.7 \%)$ \\
Open & $4(11.8 \%)$ \\
Open/Closed & \\
Case type & $31(91.2 \%)$ \\
Medical & $33(97.1 \%)$ \\
Surgical & $21(61.8 \%)$ \\
Trauma & $1(2.9 \%)$ \\
Pediatrics & $22(64.7 \%)$ \\
Neurological & $11(32.4 \%)$ \\
Cardiac surgery & $9(26.5 \%)$ \\
Burns & $5(14.7 \%)$ \\
Others & \\
Presence of medical director & $32(94.1 \%)$ \\
Yes & $2(5.9 \%)$ \\
Yesence of dietitian & \\
No & \\
\hline Des & \\
\hline
\end{tabular}

Data are reported as number (\%) or median (range). ICU, Intensive Care Unit. 
Table 4.2 describes the baseline and clinical characteristics of patients included in the main analysis. The patient cohort had a mean age of 60.5 years, $41.4 \%$ were female, $74.5 \%$ were admitted for medical indications, had a mean BMI of 30.7, and an average APACHE II score of 26.9. The average length of stay and duration of mechanical ventilation were 26 and 23 days, respectively.

\section{Table 4.2 Patient baseline and clinical characteristics in 6-month survivors}

\begin{tabular}{|c|c|}
\hline Variables & Overall \\
\hline Number of patients & 302 \\
\hline Age, yrs & $60.5 \pm 14.3$ \\
\hline Female & $125(41.4 \%)$ \\
\hline APACHE II score & $26.9(7.2 \%)$ \\
\hline Functional Comorbidity Index & $1.2 \pm 1.3$ \\
\hline Baseline SOFA & $8.6 \pm 3.0$ \\
\hline \multicolumn{2}{|l|}{ Admission Category } \\
\hline Medical & $225(74.5 \%)$ \\
\hline Surgical & $77(25.5 \%)$ \\
\hline \multicolumn{2}{|l|}{ Primary ICU Diagnosis } \\
\hline Cardiovascular & $47(15.6 \%)$ \\
\hline Respiratory & $87(28.8 \%)$ \\
\hline Gastrointestinal & $29(9.6 \%)$ \\
\hline Sepsis & $96(31.8 \%)$ \\
\hline Other & $43(14.2 \%)$ \\
\hline \multicolumn{2}{|l|}{ Treatment Arm } \\
\hline Antioxidants & $77(25.5 \%)$ \\
\hline Glutamine & $78(25.8 \%)$ \\
\hline Glutamine + Antioxidants & $70(23.2 \%)$ \\
\hline Placebo & $77(25.5 \%)$ \\
\hline \multicolumn{2}{|l|}{ Body Mass Index, $\mathrm{kg} / \mathrm{m}^{2}$} \\
\hline Overall mean & $30.7 \pm 8.5$ \\
\hline Underweight $(<18.5)$ & $3(0.4 \%)$ \\
\hline Normal weight $(18.5-<25)$ & $79(26.2 \%)$ \\
\hline Overweight $(25-<30)$ & $90(29.8 \%)$ \\
\hline Obese I $(30-<35)$ & $60(19.9 \%)$ \\
\hline Obese II $(35-<40)$ & $30(9.9 \%)$ \\
\hline Obese III $(>-40)$ & $40(13.2 \%)$ \\
\hline \multicolumn{2}{|l|}{ Region } \\
\hline Canada & $256(84.8 \%)$ \\
\hline Europe & $9(3.0 \%)$ \\
\hline USA & $37(12.9 \%)$ \\
\hline ICU length of stay, median (interquartile) & $26.0 \pm 18.3$ \\
\hline Mechanical ventilation duration, median (interquartile) & $22.9 \pm 34.2$ \\
\hline
\end{tabular}




\section{HRQoL in 6-month survivors}

Figure 4.2 shows the mean SF-36 scores for Physical Functioning (PF), Role Physical (RP), and Physical Component Scale (PCS) at three- and six-months in completed cases among six-month survivors. The increases in scores for PF, RP, and PCS from three-months to sixmonths were statistically significant and clinically relevant; that is, greater than five for the PF and RP domains, and greater than two points in PCS.

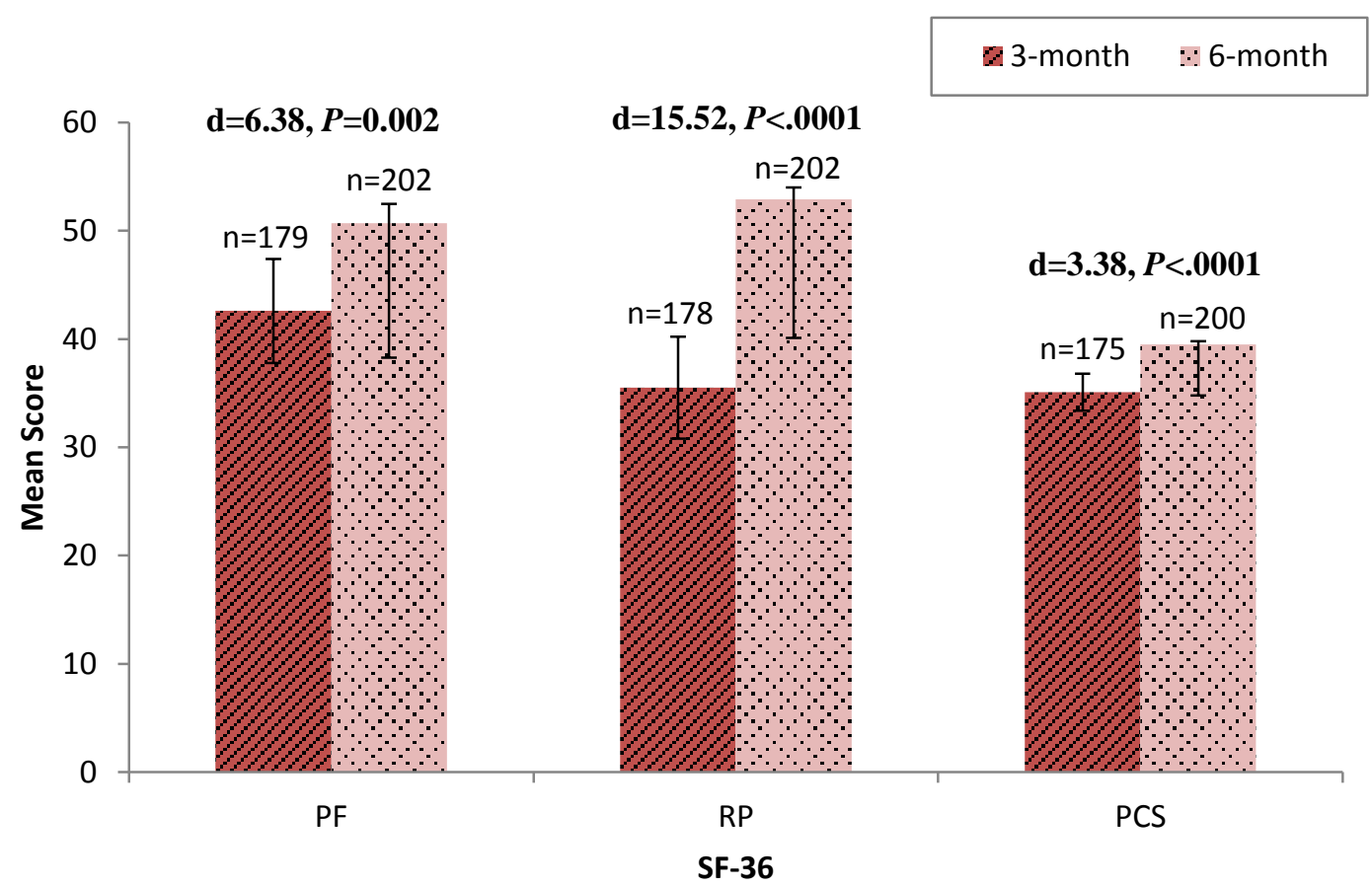

Figure 4.2 Three-month and six-month mean scores for PF, RP, and PCS of SF-36

(Error bars indicate 95\% confidence intervals of the mean score; $d$ is the mean difference between three-month and six-month mean score and p-values were calculated by paired t-test.)

\section{The relationship between nutritional adequacy and SF-36 scores}

Figure 4.3 shows the unadjusted relationships between nutritional adequacy and SF-36 scores at three- and six-months based on locally weighted regression and smoothing scatterplots (LOWESS). The smoothing curves revealed positive and linear relationships between nutritional 
adequacy and each of the PF, RP, and PCS score on the SF-36. Higher scores were observed at six-months in PF, RP, and PCS compared to 3-months (Figure 4.3). In panel A (PF) and B (RP), the slopes of the '6-month' LOWESS lines were steeper than the slopes of the ' 3 -month' LOWESS lines. No difference in slopes of the ' 3 -month' and '6-month' LOWESS lines was seen in panel C (PCS).

Results of the linear mixed model are presented in Table 4.3. At three-months follow-up, the unadjusted relationship between nutritional adequacy and the PF score showed that for every $25 \%$ increase in nutritional adequacy or energy prescription received over the first eight days of mechanical ventilation, $\mathrm{PF}$ score increased by 7.71 points $(P=0.006)$. After adjusting for important covariates including age, APACHE II score, baseline SOFA, Functional Comorbidity Index, admission category, primary ICU diagnosis, body mass index, and geographic region, the expected increase in PF score for every $25 \%$ increase in nutritional adequacy remained similar and statistically significant (adjusted estimate $=7.29, P=0.02$ ). At six-months follow-up, both unadjusted and adjusted increase in PF score for every $25 \%$ decrease in nutrition adequacy became smaller and were no longer statistically significant compared to the increase at threemonths follow-up (adjusted estimate $=4.16, P=0.14$ ). 

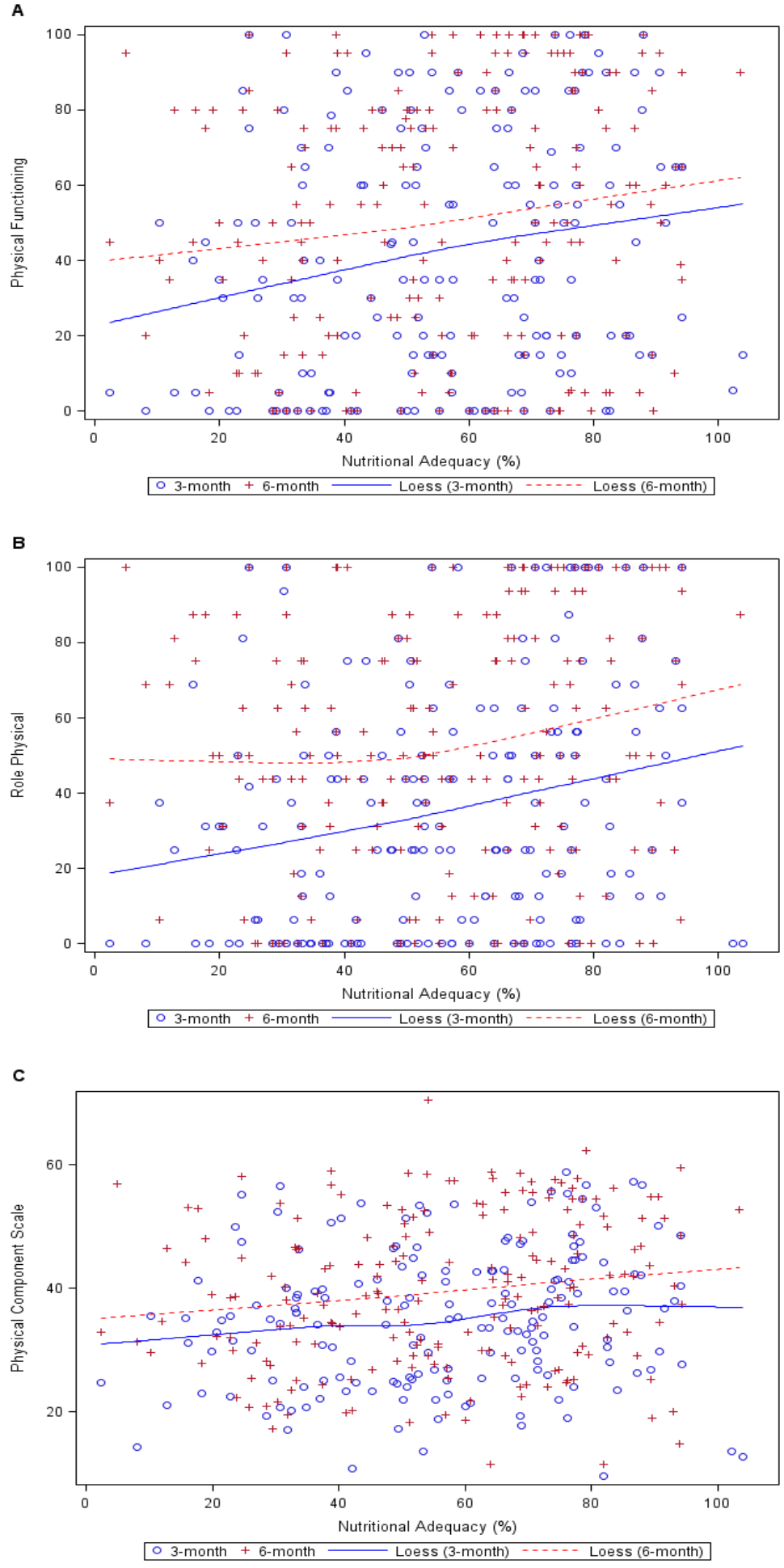

Figure 4.3 Unadjusted relationship between nutritional adequacy and SF-36 scores 
Table 4.3 Parameter estimates of the effect of nutritional adequacy on SF-36 scores

\begin{tabular}{|c|c|c|c|c|c|}
\hline \multirow[t]{2}{*}{ SF-36 } & & \multicolumn{4}{|c|}{ Nutritional Adequacy $^{\mathrm{a}}$ per $25 \%$ increase } \\
\hline & & $\begin{array}{c}\text { Crude Estimate }^{b} \\
(95 \% \text { CI })\end{array}$ & p-value & $\begin{array}{c}\text { Adjusted } \\
\text { Estimate }^{\text {b,c }}(95 \% \\
\text { CI })\end{array}$ & p-value \\
\hline \multirow[t]{2}{*}{$\begin{array}{l}\text { Physical } \\
\text { Functioning }\end{array}$} & $\begin{array}{l}\text { 3-month } \\
(n=179)^{d}\end{array}$ & $7.71(2.29,13.14)$ & 0.006 & $7.29(1.43,13.15)$ & 0.02 \\
\hline & $\begin{array}{l}\text { 6-month } \\
(n=202)^{d}\end{array}$ & $5.25(0.03,10.47)$ & 0.05 & $4.16(-1.32,9.64)$ & 0.14 \\
\hline \multirow[t]{2}{*}{$\begin{array}{l}\text { Role } \\
\text { Physical }\end{array}$} & $\begin{array}{l}\text { 3-month } \\
(n=178)^{d}\end{array}$ & $8.27(3.03,13.52)$ & 0.002 & $8.30(2.65,13.95)$ & 0.004 \\
\hline & $\begin{array}{l}\text { 6-month } \\
(n=202)^{d}\end{array}$ & $5.00(-0.16,10.16)$ & 0.06 & $3.15(-2.25,8.54)$ & 0.25 \\
\hline $\begin{array}{l}\text { Physical } \\
\text { Component }\end{array}$ & $\begin{array}{l}\text { 3-month } \\
(\mathrm{n}=175)^{\mathrm{d}}\end{array}$ & $1.82(-0.07,3.70)$ & 0.06 & $1.82(-0.18,3.81)$ & 0.07 \\
\hline Scale & $\begin{array}{l}\text { 6-month } \\
(n=200)^{d}\end{array}$ & $1.77(-0.15,3.69)$ & 0.07 & $1.33(-0.65,3.31)$ & 0.19 \\
\hline
\end{tabular}

At three-months follow-up, the unadjusted association between nutritional adequacy and the RP score was statistically significant (crude estimate $=8.27, P=0.002$ ). After adjusting for important covariates, the expected increase in RP score for every $25 \%$ increase in nutritional adequacy remained similar and statistically significant (adjusted estimate $=8.30, P=0.004)$. At six-months follow-up, both unadjusted and adjusted increase in RP score for every $25 \%$ increase 
in nutrition adequacy became smaller and were no longer statistically significant compared to the increase at three-months follow-up (adjusted estimate $=3.15, P=0.25$ ).

The association between nutritional adequacy and the PCS score was not statistically significant at three-months follow-up after adjusting for important covariates (adjusted estimate $=$ $1.82, P=0.07)$. At six-months follow-up, both unadjusted and adjusted estimates of increase in PCS score for every $25 \%$ increase in nutritional adequacy became smaller and were not statistically significant (adjusted estimate $=1.33, P=0.19$ ).

In summary, we observed a greater increase in SF-36 scores for every $25 \%$ increase in nutritional adequacy and a stronger association between nutritional adequacy and the PF and RP scores at three-months compared to six-months. We did not find any statistical significance in the association between nutritional adequacy and the PCS at three- or six-months.

\section{Subgroup analysis by admission category}

Subgroup analysis by admission category showed significant and clinically meaningful associations between nutritional adequacy and each of the PF, RP, and PCS scores at three- and six-months in medical patients, but not in surgical patients (Table 4.4). Compared to the findings at six-months, more clinically meaningful and statistical significant increases in PF, RP, and PCS scores for every $25 \%$ increase in nutritional adequacy were observed at three-months. The interaction between admission category and nutritional adequacy was tested in each model and found not to be statistically significant (Table 4.4). 
Table 4.4 Subgroup analysis of the effect of nutritional adequacy on SF-36 scores by admission category

\begin{tabular}{|c|c|c|c|c|c|c|c|}
\hline \multicolumn{8}{|c|}{ Nutritional Adequacy $^{\text {a }}$ per $25 \%$ increase } \\
\hline & \multicolumn{3}{|c|}{ Medical Patients } & \multicolumn{3}{|c|}{ Surgical Patients } & \multirow{2}{*}{$\begin{array}{c}\text { Interaction } \\
P\end{array}$} \\
\hline SF-36 & $\mathbf{N}^{\mathbf{b}}$ & $\begin{array}{c}\text { Adjusted Estimate }{ }^{c, d} \\
(95 \% \text { CI })\end{array}$ & $\boldsymbol{P}$ & $\mathbf{N}^{\mathbf{b}}$ & $\begin{array}{c}\text { Adjusted Estimate }^{c, d} \\
(95 \% \text { CI })\end{array}$ & $\boldsymbol{P}$ & \\
\hline PF: 3-mo & 128 & $10.94(4.33,17.56)$ & 0.001 & 51 & $-1.22(-13.74,11.30)$ & 0.84 & 0.10 \\
\hline PF: 6-mo & 144 & $6.70(0.19,13.21)$ & 0.04 & 58 & $-0.25(-11.78,11.28)$ & 0.97 & 0.22 \\
\hline RP: 3-mo & 127 & $13.13(6.66,19.59)$ & 0.0001 & 51 & $-2.95(-15.17,9.26)$ & 0.63 & 0.07 \\
\hline RP: 6-mo & 144 & $7.15(0.87,13.44)$ & 0.03 & 58 & $-3.37(-15.44,8.72)$ & 0.58 & 0.11 \\
\hline PCS: 3-mo & 125 & $3.48(1.19,5.77)$ & 0.003 & 50 & $-1.55(-5.90,2.81)$ & 0.47 & 0.06 \\
\hline PCS: 6-mo & 142 & $2.53(0.19,4.87)$ & 0.03 & 58 & $-0.36(-4.38,3.66)$ & 0.86 & 0.14 \\
\hline \multicolumn{8}{|c|}{$\begin{array}{l}{ }^{a} \text { Proportion of caloric prescription received by enteral nutriti } \\
\text { ventilation and intensive care unit stay; } \\
{ }^{b} \mathrm{~N} \text { provides the number of responders for each SF- } 36 \text { score; } \\
{ }^{c} \text { The estimate provides the change in SF- } 36 \text { scores for every }\end{array}$} \\
\hline
\end{tabular}

\section{Evaluation of the effect of missing data on study outcomes}

Multiple imputation was used to adjust for potential non-response bias due to missing data. As shown in the Appendix D (Table D.2), the mean PF, RP, and PCS scores in the imputed datasets were about 1 point lower than the mean scores in the completed cases. Multiple imputation yielded results that were similar to those of the main analysis; that is, significant association between $25 \%$ increase in nutritional adequacy and increase in each of $\mathrm{PF}$ and $\mathrm{RP}$ scores at 3-months (Appendix D Table D.3). No significant association between nutritional adequacy and PCS was observed following imputation. 


\section{Discussion}

This retrospective cohort study evaluated the impact of short-term nutritional adequacy (percentage of prescribed energy patients received) on the physical components of HRQoL in critically ill patients who required mechanical ventilation in ICU for $>8$ days and survived up to six months following ICU admission. We hypothesized that adequate nutritional intake would improve physical aspects of HRQoL post ICU discharge in six-month survivors with prolonged mechanical ventilation in the ICU.

Consistent with the finding of previous studies of ICU survivors, our study showed substantially lower scores in PF, RP, and PCS domains of SF-36 at three-months and six-months post ICU admission in the six-month survivors compared to the age and sex matched general population sample [60-65]. The reported mean age- and sex-standardized scores for the PF, RP, and PCS of SF-36 for Canadians in age group 54-64 are 82.3 (95\% CI: 81.5-83.0), 81.3 (95\% CI: 80.0-82.7), and 49.0 (95\% CI: 48.6-49.3), respectively [66]. Also consistent with previous studies, we observed clinically meaningful improvements in the physical components of the SF36 over three to six months of follow-up [53, 54, 67].

The main finding of our study was that reducing nutritional intake is independently associated with reduction in scores of PF and RP at three-months. The association was weaker and not statistically significant at six-months. There is limited clinical research investigating the effect of nutrition therapy on HRQoL post ICU discharge in critically ill patients. In a recently published follow-up evaluation of a large randomized controlled trial (EDEN trial) [68], Needham et al. compared the long-term effects of trophic feeding (for the first six days, 25\% of energy target) versus full energy feeding (80\% of energy target) in 525 patients with acute lung injury. The study found physical outcomes including those measured by the PF and PCS scores on the SF-36 at 12-months significantly improved from the assessment at six months. The 
investigators reported no difference between trophic vs. full feeding in mean SF-36 PF (55 (SD: $33)$ vs. 55 (SD: 31$), P=0.54)$ and PCS (39 (SD: 14) vs. 40 (SD: 13), $P=0.76)$ scores at twelvemonths follow-up. The study also indicated that the treatment effects at the six- and twelvemonths follow-up did not significantly differ.

Our findings are similar to those of the EDEN trial in that the physical outcomes improved over time after ICU discharge and that there was no significant difference in treatment effects at six-months. However, in contrast to the EDEN trial, we found a significant association between nutritional intake and physical outcomes at three months. We observed a clinically meaningful change of about 8 points decrease in scores of PF and RP at three-months for every $25 \%$ decrease in nutritional adequacy. As studies have documented that impaired physical domains of HRQoL in ICU survivors generally improve within six to twelve months after ICU discharge $[53,54,67,69,70]$, our finding implies that improving nutritional intake may help to facilitate a faster physical recovery in these ICU survivors.

In addition to the HRQoL assessments at different times, it is important to note that all EDEN patients received the benefits of early enteral nutrition and the trophic feeding group eventually received full feeding after the six-day period. It is possible that the overall duration of differences in feeding strategies was not long enough to contribute to differences in physical outcomes. It is also important to recognize that the patients in the EDEN trial are different from our patient population. The EDEN patients were younger (average 52 years), had a much shorter duration of mechanical ventilation (average 5 days), and had a smaller proportion of medical patients (62\%). Our patient population is relatively older (mean 60.5 years), had much longer average duration of mechanical ventilation (23 days), and had higher proportion of medical patients $(74.5 \%)$. Thus, a key difference between our study and the EDEN trial is that our study targeted more severely ill patients or 'high-risk' patients. An emerging body of evidence suggests 
that not all critically ill patients are the same in terms of their nutrition risk [26, 71]. The patients at high nutrition risk are more likely to benefit from nutrition therapy than others. It has been well recognized that severity of illness can further impair patients' nutritional status, and these patients need more nutritional intake due to their increased stress-metabolism [26]. Thus, our study only focused on the 'high-risk' patients, who are those who were very sick and required prolonged mechanical ventilation.

Another finding of our study is that nutritional adequacy improved physical function at three- and six-months in medical patients with no evidence of an effect in surgical patients. Although the interaction between admission category and nutritional adequacy did not reach statistical significance, possibly because of inadequate power, the observed difference in medical and surgical patients is consistent with the findings of previous studies. Compared to surgical patients, medical patients have more underlying comorbidities, suffer from more decompensation of chronic underlying disease, and have poorer short-term survival. This finding may again explain the different results we have seen in heterogeneous patient population with varied nutrition risk. Medical patients are more severely ill or at higher nutrition risk, thus more likely to benefit from artificial nutrition than surgical patients.

The major strength of this study is the assessment of longer-term outcomes in critically ill patients as compared to previous studies examining the effect of nutrition therapy. The study is novel in that it is the first observational study that evaluated the impact of nutrition therapy on HRQoL post ICU discharge and focused on 'high-risk' patients. Another strength of our study is that we used the most robust sample restriction approach by only including patients with a minimum duration of mechanical ventilation in the ICU, which has been shown to be appropriate to account for the confounding effect of duration of exposure to nutrition in estimating the association between nutritional adequacy and clinical outcomes. In addition, nutritional data were 
extracted from an original RCT conducted in multiple intensive care units across different countries thus enhancing the generalizability of the findings.

There are several limitations to this study. First, although the study provides evidence for temporality, the causal association between nutritional adequacy and physical function aspects of HRQoL post ICU discharge cannot be definitively established due to the observational nature of the study and possible remaining unknown confounding. However, we did use sample restriction and statistical adjustment techniques to account for variability in duration of exposure to nutrition and key patient demographics that relate to exposure and outcome.

Second, the study has a small sample size and a relatively large proportion of patients were lost to follow-up, with as many as $26 \%$ of patients not completing any assessments. The reasons for loss to follow-up were not systematically recorded and it is possible that the patients who were lost to follow-up did so because of poorer physical quality of life. However, it is also possible that patients who were fully recovered may have been more likely to be lost to follow-up because they may have perceived the research as irrelevant to them. We used multiple imputation to explore the robustness of the results. Consistent results were obtained after imputation, meaning that the missing data did not significantly impact the results.

Third, proxies were used when patients were not available or unable to answer the questionnaire. Family or caregiver completed $20 \%$ and $16 \%$ of SF-36 assessments at threemonths and six-months follow-up respectively (Figure 4.1). Rogers et al. have tested the reliability and validity of proxy respondents using SF-36 six months following ICU discharge and concluded that the next of kin are able to give a good proxy assessment of functional aspects of quality of life [72].

Fourth, the method used for caloric prescription for individual patients is not standardized across ICU sites because there is lack of evidence to determine the best method for estimating 
energy requirements [73]. In the RCT, the prescribed calories were left to clinical judgment of the dietitians in selecting the appropriate method to estimate energy requirement. Therefore, depending on the method used, there may be measurement error in estimating the amount of energy prescription for individual study patient, which would have led to over and under estimation of nutritional adequacy. The variation in method used to estimate energy requirement may reduce the precision of our exposure measurements, but it is unlikely to lead to significant systematic bias in estimates of the effect.

Fifth, many exclusion criteria of the RCT were applied to only include patients who are likely to benefit from the therapeutic intervention for the purpose of the clinical trial. Thus, the generalizability of the study findings is restricted. However, the study targeted the most severely ill ICU patients, which have been projected as the patient population that will benefit the most from artificial nutrition.

Finally, this analysis only included six-month survivors. Thus, this study provides an inference that is conditional on survival. Such a conditional inference requires cautious interpretation, which is only meaningful after the association with survival is carefully considered. Our prior analysis demonstrated that, after adjusting for several potential confounders, increased nutritional adequacy was associated with improved survival (Wei X, Day A, Ouellette-Kuntz H, Heyland DK, manuscript in preparation). Therefore, we can conclude that increased nutritional adequacy is associated with both improved survival and increased HRQoL among survivors. From a nutrition practice perspective, our findings provide the rationale for initiating quality improvement in nutrition therapy that may help with faster physical recovery post ICU discharge, particularly in the high nutrition risk patients such as those who require prolonged mechanical ventilation. It is necessary for future clinical research evaluating outcome 
of critical care nutrition to incorporate quality of life assessment post ICU discharge, and to consider those 'high-risk' patients.

\section{Conclusion}

Our study has suggested an important relationship between insufficient nutritional intake and impairment in physical function aspects of quality of life post ICU discharge in survivors of critical illness with prolonged mechanical ventilation in the ICU. Receiving adequate energy as early as the first week of ICU stay may help facilitate faster physical recovery post ICU discharge only in medical patients as opposed to surgical patients. Randomized controlled trials are needed to provide stronger assessment of the causal impact of nutrition therapy on HRQoL post ICU discharge. 


\section{References}

1. McWhirter JP, Pennington CR: Incidence and recognition of malnutrition in hospital. $B M J$ 1994, 308:945-8.

2. Driver AG, Lebrun M: latrogenic Malnutrition in Patients Receiving Ventilatory Support. JAMA 1980, 244:2195-2196.

3. Bassili H, Deitel M: Effect of nutritional support on weaning patients off mechanical ventilators. Journal of Parenteral and Enteral Nutrition 1981, 5:161-163.

4. Cerra FB, Benitez MR, Blackburn GL, Irwin RS, Jeejeebhoy K, Katz DP, Pingleton SK, Pomposelli J, Rombeau L, Shronts E, Robert R, Zaloga GP: Applied Nutrition in ICU Patients. A Consensus Statement of the American of Chest Physicians. Chest 1997, 111:769-778.

5. Dardaine V, Dequin PF, Ripault H, Constans T, Giniès G: Outcome of older patients requiring ventilatory support in intensive care: impact of nutritional status. Journal of the American Geriatrics Society 2001, 49:564-70.

6. Dempsey, DT Mullen, JL Buzby G: The link be- tween nutritional status and clinical outcome: can nutritional intervention modify it? The American Journal of Clinical Nutritrion $1988,47: 352-356$.

7. Jones NE, Dhaliwal R, Day AG, Ouellette-Kuntz H, Heyland DK: Factors predicting adherence to the Canadian Clinical Practice Guidelines for nutrition support in mechanically ventilated, critically ill adult patients. Journal of Critical Care 2008, 23:301-7. 
8. Martindale RG, Mcclave SA, Vanek VW, Mccarthy M, Roberts P, Taylor B, Ochoa JB, Napolitano L, Cresci G, College A, Medicine C, Board ASPEN: Guidelines for the provision and assessment of nutrition support therapy in the adult critically ill patient : Society of Critical Care Medicine and American Society for Parenteral and Enteral Nutrition. Critical Care Medicine 2009, 37:1-30.

9. Villet S, Chiolero RL, Bollmann MD, Revelly J-P, Cayeux R N M-C, Delarue J, Berger MM: Negative impact of hypocaloric feeding and energy balance on clinical outcome in ICU patients. Clinical Nutrition Edinburgh Scotland 2005, 24:502-9.

10. Alberda C, Gramlich L, Jones N, Jeejeebhoy K, Day AG, Dhaliwal R, Heyland DK: The relationship between nutritional intake and clinical outcomes in critically ill patients: results of an international multicenter observational study. Intensive Care Medicine 2009, 35: $1728-37$.

11. Rubinson L, Diette GB, Song X, Brower RG, Krishnan JA: Low caloric intake is associated with nosocomial bloodstream infections in patients in the medical intensive care unit. Critical Care Medicine 2004, 32:350-7.

12. Strack Van Schijndel RJ, Weijs PJ, Koopmans RH, Sauerwein HP, Beishuizen A, Girbes AR: Optimal nutrition during the period of mechanical ventilation decreases mortality in critically ill, long-term acute female patients: a prospective observational cohort study. Critical Care 2009, 13:R132. 
13. Faisy C, Lerolle N, Dachraoui F, Savard J-F, Abboud I, Tadie J-M, Fagon J-Y: Impact of energy deficit calculated by a predictive method on outcome in medical patients requiring prolonged acute mechanical ventilation. The British Journal of Nutrition 2009, 101:1079-87.

14. Taylor S, Fettes S, Jewkes C, Nelson RJ: Prospective, randomized, controlled trial to determine the effect of early enhanced enteral nutrition on clinical outcome in mechanically ventilated patients suffering head injury. Critical Care Medicine 1999, 27:2525-2531.

15. Martin CM, Doig GS, Heyland DK, Morrison T, Sibbald WJ: Multicentre, clusterrandomized clinical trial of algorithms for critical-care enteral and parenteral therapy (ACCEPT). CMAJ 2004, 170:197-204.

16. Singer P, Anbar R, Cohen J, Shapiro H, Shalita-Chesner M, Lev S, Grozovski E, Theilla M, Frishman S, Madar Z: The tight calorie control study (TICACOS): a prospective, randomized, controlled pilot study of nutritional support in critically ill patients. Intensive Care Medicine 2011, 37:601-9.

17. Heyland DK, Stephens KE, Day AG, McClave SA: The success of enteral nutrition and ICU-acquired infections: a multicenter observational study. Clinical Nutrition 2011, 30:14855.

18. Krishnan JA, Parce PB, Martinez A, Diette GB, Brower RG: Caloric intake in medical ICU patients: consistency of care with guidelines and relationship to clinical outcomes. Chest 2003, 124:297-305. 
19. Arabi YM, Haddad SH, Tamim HM, Rishu AH, Sakkijha MH, Kahoul SH, Britts RJ: Neartarget caloric intake in critically ill medical-surgical patients is associated with adverse outcomes. Journal of Parenteral and Enteral Nutrition 2010, 34:280-8.

20. Dickerson RN, Boschert KJ, Kudsk KA, Brown RO: Hypocaloric enteral tube feeding in critically ill obese patients. Nutrition 2002, 18:241-6.

21. Ibrahim E, Mehringer L, Prentice D, Sherman G, Schaiff R, Fraser V, Kollef M: Early versus late enteral feeding of mechanically ventilated patients: results of a clinical trial. Journal of Parenteral and Enteral Nutrition 2002, 26:174-181.

22. Rice TW, Mogan S, Hays MA, Bernard GR, Jensen GL, Wheeler AP: Randomized trial of initial trophic versus full-energy enteral nutrition in mechanically ventilated patients with acute respiratory failure. Critical Care Medicine 2011, 39:967-74.

23. Rice TW, Wheeler AP, Thompson BT, Steingrub J, Hite RD, Moss M, Morris A, Dong N, Rock P: Initial trophic vs full enteral feeding in patients with acute lung injury: the EDEN randomized trial. JAMA 2012, 307:795-803.

24. Heyland DK, Cahill N, Day AG: Optimal amount of calories for critically ill patients: depends on how you slice the cake! Critical Care Medicine 2011, 39:2619-26.

25. Heyland DK: Critical care nutrition support research: lessons learned from recent trials. Current Opinion in Clinical Nutrition and Metabolic Care 2013, 16:176-81.

26. Kondrup J: Nutritional risk screening (NRS 2002): a new method based on an analysis of controlled clinical trials. Clinical Nutrition 2003, 22:321-336. 
27. Needham DM, Davidson J, Cohen H, Hopkins RO, Weinert C, Wunsch H, Zawistowski C, Bemis-Dougherty A, Berney SC, Bienvenu OJ, Brady SL, Brodsky MB, Denehy L, Elliott D, Flatley C, Harabin AL, Jones C, Louis D, Meltzer W, Muldoon SR, Palmer JB, Perme C, Robinson M, Schmidt DM, Scruth E, Spill GR, Storey CP, Render M, Votto J, Harvey MA: Improving long-term outcomes after discharge from intensive care unit: report from a stakeholders' conference. Critical Care Medicine 2012, 40:502-9.

28. Ali N a, O’Brien JM, Hoffmann SP, Phillips G, Garland A, Finley JCW, Almoosa K, Hejal R, Wolf KM, Lemeshow S, Connors AF, Marsh CB: Acquired weakness, handgrip strength, and mortality in critically ill patients. American Journal of Respiratory and Critical Care Medicine 2008, 178:261-8.

29. Keenan SP, Dodek P, Chan K, Hogg RS, Craib KJP, Anis AH, Spinelli JJ: Intensive care unit admission has minimal impact on long-term mortality. Critical Care Medicine 2002, 30:501-7.

30. Volkert D: The role of nutrition in the prevention of sarcopenia. Wiener Medizinische Wochenschrift 2011, 161:409-15.

31. Kasper CE, Talbot LA, Gaines JM: Skeletal muscle damage and recovery. AACN Clinical Issues 2002, 13:237-47.

32. Gruther W, Benesch T, Zorn C, Paternostro-Sluga T, Quittan M, Fialka-Moser V, Spiss C, Kainberger F, Crevenna R: Muscle wasting in intensive care patients: ultrasound observation of the M. quadriceps femoris muscle layer. Journal of Rehabilitation Medicine 2008, 40:185-9. 
33. Puthucheary Z, Montgomery H, Moxham J, Harridge S, Hart N: Structure to function: muscle failure in critically ill patients. The Journal of Physiology 2010, 588:4641-8.

34. Hickson M, Frost G: An investigation into the relationships between quality of life, nutritional status and physical function. Clinical Nutrition 2004, 23:213-21.

35. Faisy C, Rabbat a, Kouchakji B, Laaban JP: Bioelectrical impedance analysis in estimating nutritional status and outcome of patients with chronic obstructive pulmonary disease and acute respiratory failure. Intensive Care Medicine 2000, 26:518-25.

36. Barr J, Hecht M, Flavin KE, Khorana A, Gould MK: Outcomes in critically ill patients before and after the implementation of an evidence-based nutritional management protocol. Chest 2004, 125:1446-57.

37. Binnekade JM, Tepaske R, Bruynzeel P, Mathus-Vliegen EMH, de Hann RJ: Daily enteral feeding practice on the ICU: attainment of goals and interfering factors. Critical Care 2005, 9:R218-25.

38. De Jonghe B, Appere-De-Vechi C, Fournier M, Tran B, Merrer J, Melchior JC, Outin H: A prospective survey of nutritional support practices in intensive care unit patients: what is prescribed? What is delivered? Critical Care Medicine 2001, 29:8-12.

39. Heyland D, Schroter-Noppe D, Drover J, Jain M, Keefe L, Dhaliwal R, Day a: Nutrition support in the critical care setting: current practice in canadian ICUs--opportunities for improvement? Journal of Parenteral and Enteral Nutrition 2003, 27:74-83. 
40. McClave S, Sexton L, Spain D: Enteral tube feeding in the intensive care unit: factors impeding adequate delivery. Critical Care Medicine 1999, 27:1252-1256.

41. Heyland DK, Dhaliwal R, Day AG, Muscedere J, Drover J, Suchner U, Cook D: REducing Deaths due to OXidative Stress (The REDOXS $\odot$ Study): rationale and study design for a randomized trial of glutamine and antioxidant supplementation in critically-ill patients. Proceedings of the Nutrition Society 2007, 65:250-263.

42. Tsai J-R, Chang W-T, Sheu C-C, Wu Y-J, Sheu Y-H, Liu P-L, Ker C-G, Huang M-C: Inadequate energy delivery during early critical illness correlates with increased risk of mortality in patients who survive at least seven days: a retrospective study. Clinical Nutrition 2011, 30:209-14.

43. Knaus W, Draper E: APACHE II: a severity of disease classification system. Critical Care 1985, 13:819-29.

44. Vincent JL, Moreno R, Takala J, Willatts S, Mendonca AD, Bruining H, Reinhart CK, Suter PM, , Thijs LG: The SOFA ( Sepsis-related Organ Failure Assessment ) score to describe organ dysfunction/failure. Intensive Care Medicine 1996, 22:707-710.

45. Groll DL, To T, Bombardier C, Wright JG: The development of a comorbidity index with physical function as the outcome. Journal of clinical epidemiology 2005, 58:595-602.

46. Ware J, Kosinski M, Dewey J, Gandek B: SF-36 Health Survey: Manual and Interpretation Guide. Boston: The Health Institute, New England Medical Center; 2000. 
47. McHorney CA, Ware JE, Raczek AE: The MOS 36-Item Short-Form Health Survey (SF36): II. Psychometric and clinical tests of validity in measuring physical and mental health constructs. Medical Care 1993, 31:247-63.

48. Ware J, Kosinski M: SF-36 physical \& mental health summary scales: a manual for users of version 1. 2001.

49. Heyland D, Hopman W, Coo H: Long-term health-related quality of life in survivors of sepsis. Short Form 36: a valid and reliable measure of health-related quality of life. Critical Care Medicine 2000, 28:3599-3605.

50. Chrispin PS, Scotton H, Rogers J, Lloyd D, Ridley S a: Short Form 36 in the intensive care unit: assessment of acceptability, reliability and validity of the questionnaire. Anaesthesia 1997, 52:15-23.

51. Cleveland WS: Robust Locally and Smoothing Weighted Regression Scatterplots. Journal of the Americal Statistical Association 1979, 74:829-836.

52. Soguel L, Revelly J-P, Schaller M-D, Longchamp C, Berger MM: Energy deficit and length of hospital stay can be reduced by a two-step quality improvement of nutrition therapy: the intensive care unit dietitian can make the difference. Critical Care Medicine 2012, 40:412-9.

53. Heyland DK, Groll D, Caeser M: Survivors of acute respiratory distress syndrome: Relationship between pulmonary dysfunction and long-term health-related quality of life. Critical Care Medicine 2005, 33:1549-1556. 
54. Dowdy DW, Eid MP, Sedrakyan A, Mendez-Tellez PA, Pronovost PJ, Herridge MS, Needham DM: Quality of life in adult survivors of critical illness: a systematic review of the literature. Intensive Care Medicine 2005, 31:611-20.

55. Parker CM, Heyland DK, Groll D, Caeser M: Mechanism of injury influences quality of life in survivors of acute respiratory distress syndrome. Intensive Care Medicine 2006, 32:1895-900.

56. Orwelius L, Nordlund A, Nordlund P, Simonsson E, Bäckman C, Samuelsson A, Sjöberg F: Pre-existing disease: the most important factor for health related quality of life long-term after critical illness: a prospective, longitudinal, multicentre trial. Critical Care 2010, 14:R67.

57. Schafer J: Analysis of Incomplete Multivariate Data. London, U.K.: Chapman \& Hal; 1997.

58. Rubin D: Multiple Imputation for Nonresponse in Surveys. Hoboken, NJ; 2004.

59. Baraldi AN, Enders CK: An introduction to modern missing data analyses. Journal of School Psychology 2010, 48:5-37.

60. Kvåle R, Ulvik A, Flaatten H: Follow-up after intensive care: a single center study. Intensive Care Medicine 2003, 29:2149-56.

61. Eddleston JM, White P, Guthrie E: Survival, morbidity, and quality of life after discharge from intensive care. Critical Care Medicine 2000, 28:2293-9. 
62. Orwelius L, Nordlund A, Edell-Gustafsson U, Simonsson E, Nordlund P, Kristenson M, Bendtsen P, Sjoberg F: Role of preexisting disease in patients' perceptions of health-related quality of life after intensive care. Critical Care Medicine 2005, 33:1557-1564.

63. Pettilä V, Kaarlola A, Mäkeläinen A: Health-related quality of life of multiple organ dysfunction patients one year after intensive care. Intensive Care Medicine 2000, 26:14731479 .

64. Graf J, Koch M, Dujardin R, Kersten A, Janssens U: Health-related quality of life before, 1 month after, and 9 months after intensive care in medical cardiovascular and pulmonary patients. Critical Care Medicine 2003, 31:2163-9.

65. Ridley SA, Chrispin PS, Scotton H, Rogers J, Lloyd D: Changes in quality of life after intensive care: comparison with normal data. Anaesthesia 1997, 52:195-202.

66. Hopman WM, Towheed T, Anastassiades T, Tenenhouse A, Poliquin S, Berger C, Joseph L, Brown JP, Murray TM, Adachi JD, Hanley DA, Papadimitropoulos E, Lilly E: Canadian normative data for the SF-36 health survey. 2000, 163:265-271.

67. Winters BD, Eberlein M, Leung J, Needham DM, Pronovost PJ, Sevransky JE: Long-term mortality and quality of life in sepsis: a systematic review. Critical Care Medicine 2010, 38: $1276-83$.

68. Needham DM, Dinglas VD, Bienvenu OJ, Colantuoni E, Wozniak a. W, Rice TW, Hopkins RO: One year outcomes in patients with acute lung injury randomised to initial trophic or full enteral feeding: prospective follow-up of EDEN randomised trial. BMJ 2013, 346:f1532f1532. 
69. Van der Schaaf M, Beelen A, Dongelmans DA, Vroom MB, Nollet F: Functional status after intensive care: a challenge for rehabilitation professionals to improve outcome. Journal of Rehabilitation Medicine 2009, 41:360-6.

70. Sukantarat K, Greer S, Brett S, Williamson R: Physical and psychological sequelae of critical illness. British Journal of Health Psychology 2007, 12:65-74.

71. Heyland DK, Dhaliwal R, Jiang X, Day AG: Identifying critically ill patients who benefit the most from nutrition therapy: the development and initial validation of a novel risk assessment tool. Critical Care 2011, 15:R268.

72. Rogers J, Ridley S, Chrispin P, Scotton H, Lloyd D: Reliability of the next of kins' estimates of critically ill patients' quality of life. Anaesthesia 1997, 52:1137-43.

73. Flancbaum L, Choban PS, Sambucco S, Verducci J, Burge JC: Comparison of indirect calorimetry, the Fick method, and prediction equations in estimating the energy requirements of critically ill patients. The American Journal of Clinical nutrition 1999, 69:461-6. 


\section{Chapter 5}

\section{General Discussion}

\subsection{Summary of Study}

Underfeeding occurs systematically in intensive care units (ICUs) around the world [1]. In patients requiring prolonged mechanical ventilation, nutritional status is often deteriorated due to their critical illness and, coupled with ongoing inadequate caloric intake, these patients may experience ongoing muscle loss and impaired muscle function which may be associated with survival and physical outcomes post ICU discharge [2-7]. The overall purpose of this thesis was to examine the effect of short-term nutritional adequacy received while in the ICU on long-term outcomes post ICU discharge in critically ill patients requiring prolonged mechanical ventilation.

The aim of Manuscript 1 was to examine the association between nutritional adequacy and six-month survival in critically ill patients who were mechanically ventilated in the ICU for more than eight days. The main conclusion of the first manuscript was that after adjusting for important covariates, receiving adequate caloric prescription (particularly $>80 \%$ of prescribed calories) as early as the first week of ICU stay is associated with improved six-month survival of critically patients with prolonged mechanical ventilation compared to patients receiving less nutritional intake.

As the number of ICU survivors increases, it has been recognized that survival alone is not the only important outcome, health-related quality of life (HRQoL) needs to be incorporated in the outcome evaluation of critical care nutrition to develop guidelines for the use of scarce ICU resources that reflect the values of individual patients $[8,9]$. Thus, building on the first manuscript, Manuscript 2 examined how short-term nutritional adequacy received while in the ICU could impact HRQoL post ICU discharge in the survivors of critical illness. The main 
conclusion was that after adjusting for important covariates, receiving adequate energy in the first week of ICU stay is associated with improved functional aspects of HRQoL at three-months follow-up in survivors of critical illness who required prolonged mechanical ventilation.

In both manuscripts, we took a further step in examining how the relationship of interest may be different in medical patients versus surgical patients. By subgroup analyses, we found that the increased intake of energy appears to be associated with improved long-term outcomes only in medical patients as opposed to surgical patients. Although the interaction between admission category and nutritional adequacy was not statistically significant, possibly because of inadequate power, the observed difference in medical and surgical patients is consistent with the findings of previous studies [10-12].

Our findings suggest that provision of adequate energy as early as the first week of ICU stay is beneficial to long-term outcomes of critically ill patients who require prolonged mechanical ventilation.

\subsection{Additional Results of Manuscript 2}

An exploratory analysis was performed by categorizing nutritional adequacy into three groups (low, $<50 \%$; moderate, $\geq 50$ and $<80 \%$; and high, $\geq 80 \%$ ) to examine the association between nutritional adequacy and physical components of HRQoL in six-month survivors. This analysis was conducted for two reasons: 1) Since the most discrepancies in the optimal amount of caloric intake have been whether achieving full feeding (about $70-100 \%$ of caloric goal) is beneficial compared to trophic feeding ( $<30 \%$ of caloric goal) and achieving $80 \%$ of caloric goal has been shown to be clinically relevant [13-15], it would be meaningful for us to explore the effect of full feeding on HRQoL in the survivors of critical illness; 2) This analysis also serves to 
justify our decision of treating nutritional adequacy as continuous in the main analysis of Manuscript 2.

The results of this exploratory analysis are shown in Appendix E. The study population for Manuscript 2 was in six-month survivors only and there was a large amount of study participants who were lost to follow-up and hence the study sample size is small. After categorizing the patients by nutritional adequacy groups, the number of patients in the high nutritional adequacy group $(n=41,13.6 \%)$ was much smaller than the number of patients in the low and moderate groups (Appendix E Table E.1), thus the analysis may not have enough statistical power to detect a significant effect.

As shown in Appendix E Figure E.1, the mean SF-36 scores for Physical Functioning (PF), Role Physical (RP), and Physical Component Scale (PCS) in each nutritional adequacy group increased from three-months to six-months. The increase in scores for PF from threemonths to six-months was only statistically significant in the high nutritional adequacy group. The increases in scores for RP and PCS from three-months to six-months were statistically significant in all three nutritional adequacy groups.

The results of the linear mixed model with nutritional adequacy treated as a categorical predictor are shown in Appendix E Table E.2. At three-months follow-up, there was no significant difference in SF-36 scores between low and high nutritional adequacy groups except for RP domain. However, the differences between low and high groups in scores for PF and RP domains are much greater than 5 , which is clinically meaningful. The conclusion remains the same after adjusting for confounders. No statistically significant differences between moderate and high nutritional adequacy groups were observed at three-months follow-up. At six-months follow-up, no statistical significant differences in SF-36 scores were observed in any of the group comparisons. 
Although not statistically significant, the differences in SF-36 scores consistently trended toward the benefit from high over moderate nutritional adequacy, as well as over low nutritional adequacy. Hence, this consistent trend, in addition to the approximate linearity demonstrated by the non-parametric LOWESS smoother (Figure 4.3) helped us to justify our use of nutritional adequacy as a continuous predictor in examining the relationship of interest in Manuscript 2.

\subsection{General Strengths and Limitations}

This is the first observational study that evaluated the impacts of nutrition therapy on long-term outcomes post ICU discharge of critically ill patients, whereas most of the previous studies in critical care nutrition only examined the short-term clinical outcomes in the ICU. As

the primary goal of intensive care is quality survival [16], our study looked at long-term survival as well as HRQoL, which are both important outcomes for making clinical and policy decisions about the most effective utilization of critical care nutrition.

There is an emerging body of evidence suggesting that not all critically ill patients are the same in terms of their nutrition risk. The patients at high nutrition risk are more likely to benefit from nutrition therapy than others $[17,18]$. Inclusion of heterogeneous patient populations with some at high nutrition risk and some at low nutrition risk likely contributes to inconsistent results in the studies of nutrition therapy. Thus, our study is strong in that we only targeted more severely ill patients or 'high-risk' patients, who are those who required prolonged mechanical ventilation. Our finding from sub-group analysis (i.e. medical vs. surgical patients) also helped to explain the inconsistent results we have seen in heterogeneous patient populations with different nutrition risk.

Another potential problem in the field of critical nutrition research is the use of different statistical methodologies to account for duration of exposure to nutrition. As most feeding 
protocols recommend the gradual increase of nutrition over the first several days of ICU stay, with little or none given on the first few days, patients with short-term stays often receive few calories while in the ICU [13]. Thus, if the duration of nutrition is not properly adjusted, patients with short stays would have had very little feeds, but had a "good outcome"[13]. To avoid this problem, our study used the most robust sample restriction approach by only including patients with a minimum duration of mechanical ventilation in the ICU, which has been shown to be appropriate to account for the confounding effect of duration of exposure to nutrition [13]. Moreover, data were extracted from a randomized controlled trial conducted in multiple intensive care units across different countries thus enhancing the generalizability of the findings.

Our study is not without limitations. The most important limitation is that the causal association between nutritional adequacy and long-term survival cannot be definitively established due to the observational nature of the study and possible residual confounding. However, we did use sample restriction and statistical adjustment techniques to account for the variability in duration of exposure to nutrition and key patient demographics that relate to exposure and outcome. A randomized controlled trial would be the ideal study design to provide stronger evidence in examining the effect of nutrition therapy on long-term outcomes.

Additionally, the method used for caloric prescription was not standardized across ICU sites because there is lack of evidence in determining the best method for estimating energy requirements [19]. In the randomized controlled trial, the method to estimate energy requirement and hence the prescribed calories was left to the clinical judgment of the dietitians. Therefore, depending on the method used, there may be measurement error in estimating the amount of energy prescription for individual study patients, which would have led to over and under estimation of nutritional adequacy. The variation in method used to estimate energy requirement 
may reduce the precision of our exposure measurements, but it is unlikely to lead to significant systematic bias in estimates of the effect.

Many exclusion criteria of the parent study were applied to only include patients who were likely to benefit from the therapeutic intervention for the purpose of the clinical trial. Thus, the generalizability of the study finding is limited. However, our study targeted the most severely ill ICU patients, which have been projected as the patient population that will benefit the most from artificial nutrition.

Another limitation is that there were many patients who were lost to follow-up. In Manuscript 1, 21\% of patients were lost to follow-up by six month; in the survival analysis, these patients were censored at their last date known to be alive. In Manuscript 2, approximately 30\% of six-month survivors did not respond to the SF-36. The reasons for loss to follow-up were not systematically recorded and it is possible that the patients either became too sick to follow-up or they may have fully recovered and may see the research as irrelevant to them. Multiple imputation was used to explore the robustness of the results. Consistent results were obtained after imputation, meaning that the missing data is not likely to have a significant impact on the results.

\subsection{Implications and Future Directions}

Our study has important implications for the planning of nutrition practices as well as future research. From a nutrition practice perspective, more nutritional intake (receiving $25 \%$ more of prescribed energy) may be associated with better long-term outcomes, particularly in the most severely ill patients with prolonged mechanical ventilation. We looked at nutritional adequacy as 'per $25 \%$ increase' because it has been shown to be a reasonable and achievable quality improvement in caloric delivery, thus it helps us to understand the implication of our 
findings in the real world of nutrition practice. In the future development of nutrition practice, special attention should be given to the most severely ill patients such as those who require prolonged mechanical ventilation. Future research in critical care should be more cautious in selecting the appropriate method to account for the confounding effect of duration of exposure to nutrition. Future studies should also recognize that not all critically ill patients are the same in terms of the benefit they receive from nutrition therapy; a focus on 'high-risk' patients is important. The issue of heterogeneous patient populations should be taken into consideration by either including only patients at risk or stratifying the sample studied by nutrition risk. Finally, a randomized clinical trial to evaluate long-term outcomes of nutrition therapy is warranted to provide stronger evidence of the causal association. 


\subsection{References}

1. Cahill NE, Dhaliwal R, Day AG, Jiang X, Heyland DK: Nutrition therapy in the critical care setting: what is "best achievable" practice? An international multicenter observational study. Critical Care Medicine 2010, 38:395-401.

2. Faisy C, Rabbat a, Kouchakji B, Laaban JP: Bioelectrical impedance analysis in estimating nutritional status and outcome of patients with chronic obstructive pulmonary disease and acute respiratory failure. Intensive Care Medicine 2000, 26:518-25.

3. Gruther W, Benesch T, Zorn C, Paternostro-Sluga T, Quittan M, Fialka-Moser V, Spiss C, Kainberger F, Crevenna R: Muscle wasting in intensive care patients: ultrasound observation of the M. quadriceps femoris muscle layer. Journal of Rehabilitation Medicine 2008, 40:185-9.

4. Volkert D: The role of nutrition in the prevention of sarcopenia. Wiener Medizinische Wochenschrift 2011, 161:409-15.

5. Kasper CE, Talbot LA, Gaines JM: Skeletal muscle damage and recovery. AACN Clinical Issues 2002, 13:237-47.

6. Puthucheary Z, Montgomery H, Moxham J, Harridge S, Hart N: Structure to function: muscle failure in critically ill patients. The Journal of Physiology 2010, 588:4641-8.

7. Hickson M, Frost G: An investigation into the relationships between quality of life, nutritional status and physical function. Clinical Nutrition 2004, 23:213-21.

8. Needham DM, Davidson J, Cohen H, Hopkins RO, Weinert C, Wunsch H, Zawistowski C, Bemis-Dougherty A, Berney SC, Bienvenu OJ, Brady SL, Brodsky MB, Denehy L, Elliott D, 
Flatley C, Harabin AL, Jones C, Louis D, Meltzer W, Muldoon SR, Palmer JB, Perme C, Robinson M, Schmidt DM, Scruth E, Spill GR, Storey CP, Render M, Votto J, Harvey MA: Improving long-term outcomes after discharge from intensive care unit: report from a stakeholders' conference. Critical Care Medicine 2012, 40:502-9.

9. Suter P, Armaganidis A, Beaufils F, Bonfill X, Burchardi H, Cook D: Predicting outcome in ICU patients. Intensive Care Medicine 1994, 20:390-397.

10. Rubinson L, Diette GB, Song X, Brower RG, Krishnan JA: Low caloric intake is associated with nosocomial bloodstream infections in patients in the medical intensive care unit. Critical Care Medicine 2004, 32:350-7.

11. Faisy C, Lerolle N, Dachraoui F, Savard J-F, Abboud I, Tadie J-M, Fagon J-Y: Impact of energy deficit calculated by a predictive method on outcome in medical patients requiring prolonged acute mechanical ventilation. The British Journal of Nutrition 2009, 101:1079-87.

12. Barr J, Hecht M, Flavin KE, Khorana A, Gould MK: Outcomes in critically ill patients before and after the implementation of an evidence-based nutritional management protocol. Chest 2004, 125:1446-57.

13. Heyland DK, Cahill N, Day AG: Optimal amount of calories for critically ill patients: depends on how you slice the cake! Critical Care Medicine 2011, 39:2619-26.

14. Arabi YM, Tamim HM, Dhar GS, Al-dawood A, Al-sultan M, Sakkijha MH, Kahoul SH, Brits R: Permissive underfeeding and intensive insulin therapy in critically ill patients : a randomized controlled trial. The American Journal of Clinical Nutritrion 2011, 93:569-77. 
15. Needham DM, Dinglas VD, Bienvenu OJ, Colantuoni E, Wozniak a. W, Rice TW, Hopkins RO: One year outcomes in patients with acute lung injury randomised to initial trophic or full enteral feeding: prospective follow-up of EDEN randomised trial. BMJ 2013, 346:f1532f1532.

16. Kvale R, Flaatten H: Changes in health-related quality of life from 6 months to 2 years after discharge from intensive care. Health and Quality of Life Outcomes 2003, 1:2.

17. Heyland DK, Dhaliwal R, Jiang X, Day AG: Identifying critically ill patients who benefit the most from nutrition therapy: the development and initial validation of a novel risk assessment tool. Critical Care 2011, 15:R268.

18. Kondrup J: Incidence of nutritional risk and causes of inadequate nutritional care in hospitals. Clinical Nutrition 2002, 21:461-468.

19. Flancbaum L, Choban PS, Sambucco S, Verducci J, Burge JC: Comparison of indirect calorimetry, the Fick method, and prediction equations in estimating the energy requirements of critically ill patients. The American Journal of Clinical Nutrition 1999, 69:461-6. 
Appendix A Short-Form 36 Health Survey (SF-36)

\section{Your Health and Well-Being}

This survey asks for your views about your health. This information will help keep track of how you feel and how well you are able to do your usual activities. Thank you for completing this survey!

For each of the following questions, please mark an $\bigotimes$ in the one box that best describes your answer.

1. In general, would you say your health is:

\begin{tabular}{|lllll|}
\hline Excellent & Very good & Good & Fair & Poor \\
$\square_{1}$ & $\square_{2}$ & $\square_{3}$ & $\square_{4}$ & $\square$ 5
\end{tabular}

2. Compared to one year ago, how would you rate your health in general now?

$\begin{array}{|ccccc|}\begin{array}{c}\text { Much better } \\ \text { now than one } \\ \text { year ago }\end{array} & \begin{array}{c}\text { Somewhat } \\ \text { better } \\ \text { now than one } \\ \text { year ago }\end{array} & \begin{array}{c}\text { About the } \\ \text { same as } \\ \text { one year ago }\end{array} & \begin{array}{c}\text { Somewhat } \\ \text { worse } \\ \text { now than one } \\ \text { year ago }\end{array} & \begin{array}{c}\text { Much worse } \\ \text { now than one } \\ \text { year ago }\end{array} \\ \square_{1} & \square_{2} & \square_{3} & \square_{4} & \square\end{array}$

\begin{tabular}{l}
\hline SF-36v2 $\mathrm{TM}$ Health Survey $(1992-2002$ by Health Assessment Lab, Medical Outcomes Trust and QualityMetric Incorporated. All rights reserved. \\
SF-36® is a registered trademark of Medical Outcomes Trust.
\end{tabular}

SF-36® is a registered trademark of Medical Outcomes Trust.

(IQOLA SF-36v2 Standard, English (Canada) 
3. The following questions are about activities you might do during a typical day. Does your health now limit you in these activities? If so, how much?

a Vigorous activities, such as running, lifting heavy objects, participating in strenuous sports

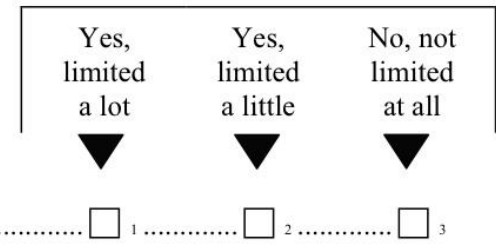

b Moderate activities, such as moving a table, pushing a vacuum cleaner, bowling, or playing golf.

Lifting or carrying groceries

d Climbing several flights of stairs

e Climbing one flight of stairs.

f Bending, kneeling, or stooping.

g Walking more than a kilometre

h Walking several hundred metres

i Walking one hundred metres.

; Bathing or dressing yourself.

4. During the past 4 weeks, how much of the time have you had any of the following problems with your work or other regular daily activities as a result of your physical health?

a Cut down on the amount of time you spent on work or other activities

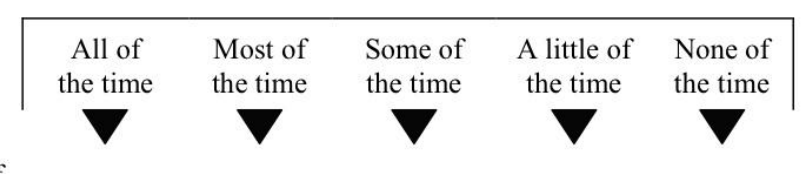

Accomplished less than you would like.

c Were limited in the kind of work or other activities.

d Had difficulty performing the the work or other activities (for example, it took extra effort)

Page 2 
5. During the past 4 weeks, how much of the time have you had any of the following problems with your work or other regular daily activities as a result of any emotional problems (such as feeling depressed or anxious)?

Cut down on the amount of time you spent on work or other activities

$\begin{array}{ccccc}\begin{array}{c}\text { All of } \\ \text { the time }\end{array} & \begin{array}{c}\text { Most of } \\ \text { the time }\end{array} & \begin{array}{l}\text { Some of } \\ \text { the time }\end{array} & \begin{array}{c}\text { A little of } \\ \text { the time }\end{array}\end{array}$

Accomplished less than you would like.....
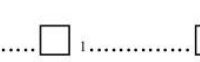

Did work or other activities

less carefully than usual.

6. During the past 4 weeks, to what extent has your physical health or emotional problems interfered with your normal social activities with family, friends, neighbors, or groups?

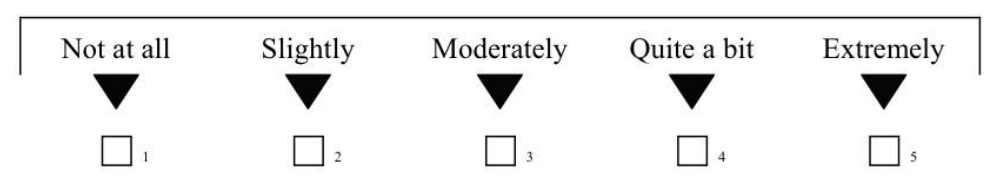

7. How much bodily pain have you had during the past 4 weeks?

\begin{tabular}{|lccccc|}
\hline None & Very mild & Mild & Moderate & Severe & Very severe \\
$\square_{1}$ & $\square_{2}$ & $\square_{3}$ & $\square_{4}$ & $\square_{5}$ & $\square_{6}$
\end{tabular}

Page 3 
8. During the past 4 weeks, how much did pain interfere with your normal work (including both work outside the home and housework)?

\begin{tabular}{|c|c|c|c|c|}
\hline Not at all & A little bit & Moderately & Quite a bit & Extremely \\
\hline
\end{tabular}

9. These questions are about how you feel and how things have been with you during the past 4 weeks. For each question, please give the one answer that comes closest to the way you have been feeling. How much of the time during the past 4 weeks...

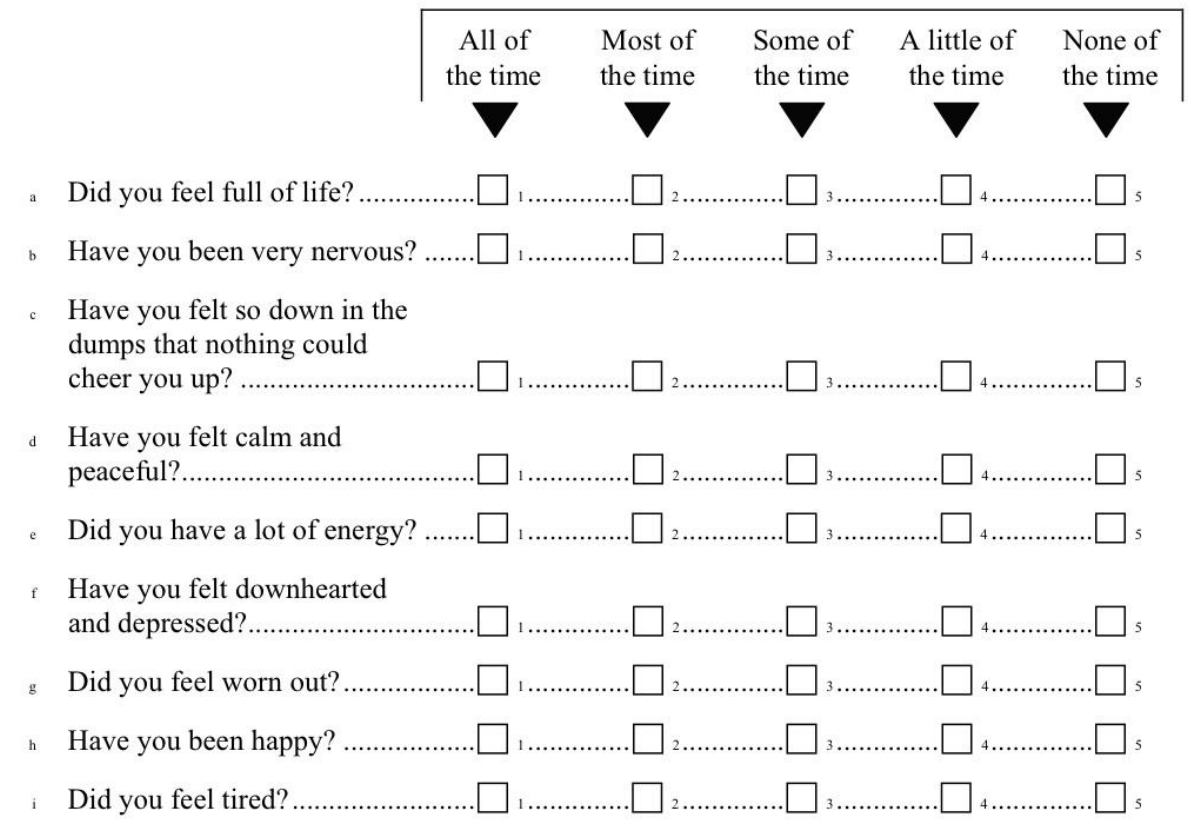

Page 4 
10. During the past 4 weeks, how much of the time has your physical health or emotional problems interfered with your social activities (like visiting with friends, relatives, etc.)?

$\begin{array}{|cccc|}\begin{array}{c}\text { All of } \\ \text { the time }\end{array} & \begin{array}{l}\text { Most of } \\ \text { the time }\end{array} & \begin{array}{l}\text { Some of } \\ \text { the time }\end{array}\end{array}$

11. How TRUE or FALSE is each of the following statements for you?

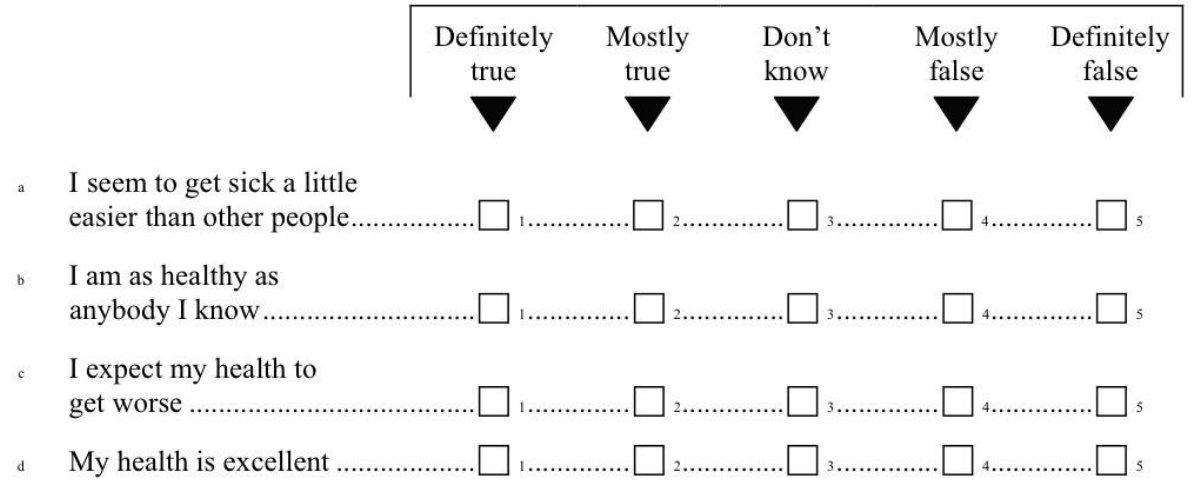

Thank you for completing these questions!

Page 5 


\section{Appendix B SF-36 Scoring System}
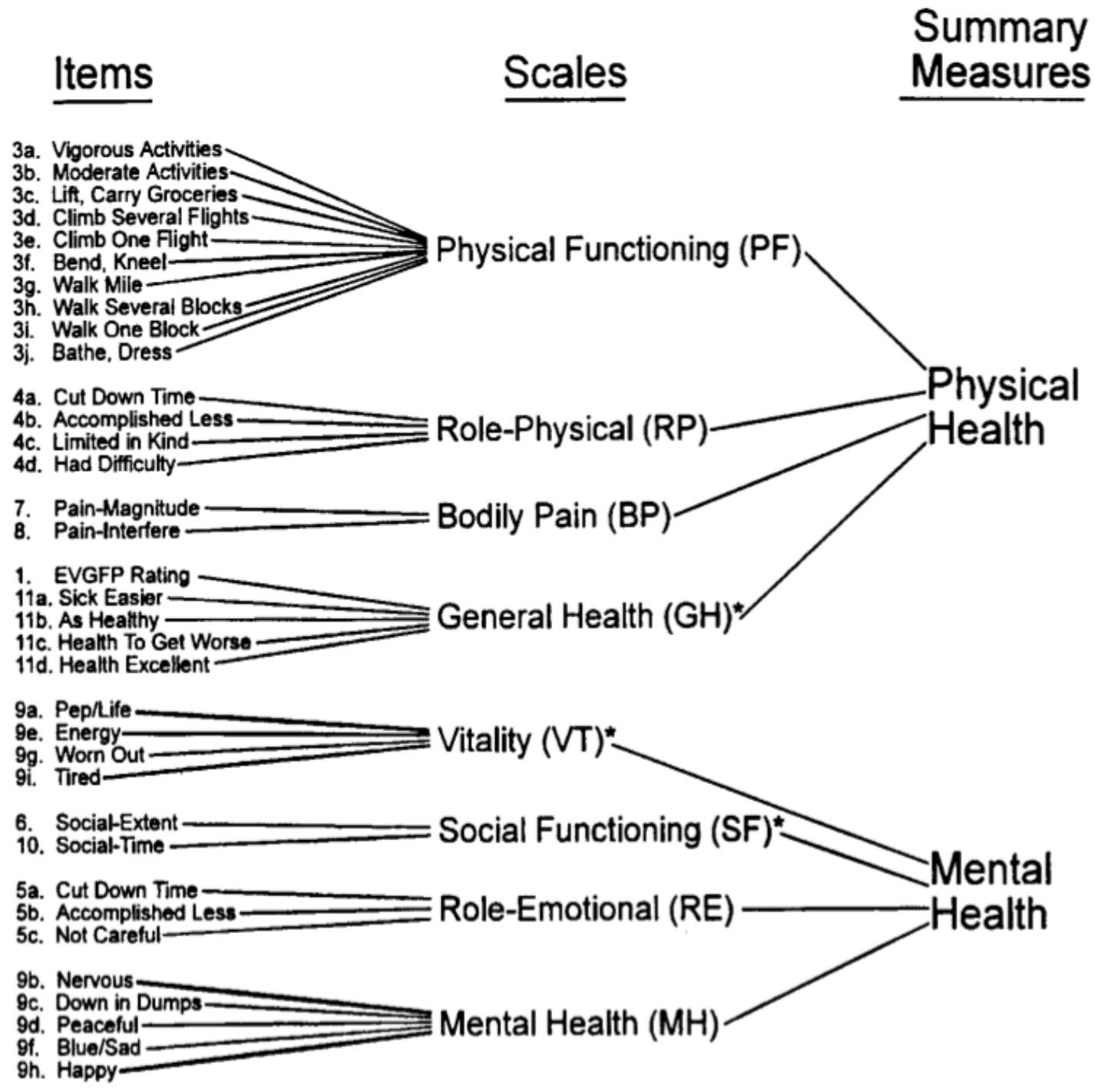


\section{Appendix C Inclusion and Exclusion Criteria for the RCT}

\section{Inclusion criteria:}

Mechanically ventilated adult patients ( $\geq 18$ years old) admitted to ICU will be considered eligible if they have 2 or more of the following organ failures related to their acute illness:

i. $\mathrm{A} \mathrm{PaO} 2 / \mathrm{FiO} 2$ ratio of $\leq 300$;

ii. Clinical evidence of hypoperfusion defined as the need for vasopressor agents (norepinephrine, epinephrine, vasopressin, $\geq 5 \mu \mathrm{g} / \mathrm{kg} / \mathrm{min}$ of dopamine, or $\geq 50 \mu \mathrm{g} / \mathrm{min}$ phenylephrine) for greater than or equal to 2 hours;

iii. In patients without known renal disease, renal dysfunction defined as a serum creatinine $\geq 171$ $\mu \mathrm{mol} / \mathrm{L}$ or a urine output of less than $500 \mathrm{ml} /$ last 24 hours (or $80 \mathrm{ml} /$ last 4 hours if a 24 hour period of observation not available). In patients with acute on chronic renal failure (pre-dialysis), an absolute increase of $\geq 80 \mu \mathrm{mol} / \mathrm{L}$ from baseline or pre-admission creatinine or a urine output of $<500 \mathrm{ml} /$ last 24 hours (or $80 \mathrm{ml} /$ last 4 hours) will be required;

iv. A platelet count of $\leq 50 \times 10^{9} / \mathrm{L}$.

\section{Exclusion criteria:}

1) $>24$ hours from admission to ICU

2) Patients who are moribund (not expected to be in ICU for more than 48 hours due to imminent death)

3) A lack of commitment to full aggressive care (anticipated withholding or withdrawing treatments in the first week)

4) Absolute contraindication to enteral nutrients (e.g., GI perforation, obstruction or no GI tract access for any reason)

5) Patients with severe acquired brain injury

a) Significant head trauma (defined as an injury, in the opinion of the investigator, that represents a severe, disabling, or fatal brain injury)

b) Grade 4 or 5 subarachnoid haemorrhage

c) Stroke resulting in coma and intubation

d) Post-cardiac arrest with suspected significant anoxic brain injury

6) Seizure disorder requiring anticonvulsant medication

7) Cirrhosis - Child's class C liver disease

8) Metastatic cancer or Stage IV Lymphoma with life expectancy $<6$ months

9) Routine elective cardiac surgery (patients with complicated peri-operative course requiring pressors, IABP, ventricular assist devices can be included)

10) Patients with primary admission diagnosis of burns ( $\geq 30 \%$ BSA)

11) Weight less than $50 \mathrm{~kg}$ or greater than $200 \mathrm{~kg}$

12) Pregnant patients or lactating with the intent to breastfeed

13) Previous randomization in this study

14) Enrollment in a related ICU interventional study 


\section{Appendix D Results of Multiple Imputation for Manuscript 2}

Table D.1 Patient characteristics according to SF-36 completion status

\begin{tabular}{|c|c|c|c|}
\hline \multirow[b]{2}{*}{ Patient Characteristics } & \multicolumn{3}{|c|}{ SF-36 Completion Status } \\
\hline & $\begin{array}{l}\text { Completed at both } \\
\text { time points }\end{array}$ & $\begin{array}{l}\text { Missing at one } \\
\text { time point }\end{array}$ & $\begin{array}{l}\text { Missing at both } \\
\text { time points }\end{array}$ \\
\hline Number of patients & $158(52.3 \%)$ & $66(21.9 \%)$ & $78(25.8 \%)$ \\
\hline Age, yrs & $61.2 \pm 14.4$ & $58.9 \pm 14.0$ & $58.4 \pm 16.2$ \\
\hline Female & $63(39.9 \%)$ & $26(39.4 \%)$ & $36(46.2 \%)$ \\
\hline APACHE II score & $26.7 \pm 6.8$ & $27.3 \pm 8.1$ & $25.6 \pm 7.6$ \\
\hline Functional Comorbidity Index & $1.2 \pm 1.2$ & $1.3 \pm 1.4$ & $1.3 \pm 1.5$ \\
\hline Baseline SOFA & $8.4 \pm 2.9$ & $9.1 \pm 3.1$ & $8.6 \pm 2.9$ \\
\hline \multicolumn{4}{|l|}{ Admission Category } \\
\hline Medical & $110(69.6 \%)$ & $53(80.3 \%)$ & $62(79.5 \%)$ \\
\hline Surgical & $48(30.4 \%)$ & $13(19.7 \%)$ & $16(19.9 \%)$ \\
\hline \multicolumn{4}{|l|}{ Primary ICU Diagnosis } \\
\hline Cardiovascular & $32(20.3 \%)$ & $8(12.1 \%)$ & $7(9.0 \%)$ \\
\hline Respiratory & $40(25.3 \%)$ & $19(28.8 \%)$ & $28(35.9 \%)$ \\
\hline Gastrointestinal & $18(11.4 \%)$ & $4(6.1 \%)$ & $7(9.0 \%)$ \\
\hline Sepsis & $44(27.9 \%)$ & $28(42.4 \%)$ & $24(30.8 \%)$ \\
\hline Other & $24(15.2 \%)$ & $7(10.6 \%)$ & $12(15.4 \%)$ \\
\hline \multicolumn{4}{|l|}{ Treatment Arm } \\
\hline Antioxidants & $39(24.7 \%)$ & $16(24.2 \%)$ & $22(28.2 \%)$ \\
\hline Glutamine & $40(25.3 \%)$ & $21(31.8 \%)$ & $17(21.8 \%)$ \\
\hline Glutamine + Antioxidants & $37(23.4 \%)$ & $15(22.7 \%)$ & $18(23.1 \%)$ \\
\hline Placebo & $42(26.6 \%)$ & $14(21.2 \%)$ & $21(26.9 \%)$ \\
\hline \multicolumn{4}{|l|}{ Body Mass Index, $\mathrm{kg} / \mathrm{m}^{2}$} \\
\hline Underweight $(<18.5)$ & $1(0.6 \%)$ & $0(0.0 \%)$ & $2(2.6 \%)$ \\
\hline Normal weight $(18.5-<25)$ & $41(26.0 \%)$ & $20(30.3 \%)$ & $18(23.1 \%)$ \\
\hline Overweight $(25-<30)$ & $44(27.9 \%)$ & $21(31.8 \%)$ & $25(32.1 \%)$ \\
\hline Obese I $(30-<35)$ & $31(19.6 \%)$ & $14(21.2 \%)$ & $15(19.2 \%)$ \\
\hline Obese II $(35-<40)$ & $17(10.8 \%)$ & $8(12.1 \%)$ & $5(6.4 \%)$ \\
\hline Obese III $(>-40)$ & $24(15.2 \%)$ & $3(4.6 \%)$ & $13(16.7 \%)$ \\
\hline \multicolumn{4}{|l|}{ Region } \\
\hline Canada & $131(82.9 \%)$ & $53(89.4 \%)$ & $66(84.6 \%)$ \\
\hline Europe & $3(1.9 \%)$ & $4(3.0 \%)$ & $4(5.1 \%)$ \\
\hline USA & $24(15.2 \%)$ & $9(7.6 \%)$ & $8(10.3 \%)$ \\
\hline
\end{tabular}

Data are reported as number $(\%)$ or mean \pm SD. 
Table D.2 Mean scores of physical components of SF-36 in before and after imputation

\begin{tabular}{llll}
\hline \multicolumn{2}{c}{ SF-36 } & \multicolumn{2}{c}{ Mean Scores of SF-36 } \\
\cline { 3 - 4 } & & Before Imputation & After Imputation (n=302) \\
\hline Physical Functioning & 3-month & $42.6 \pm 32.8$ & $41.6 \pm 39.3$ \\
& 6-month & $50.7 \pm 33.7$ & $49.2 \pm 36.6$ \\
\hline Role Physical & 3-month & $35.5 \pm 31.8$ & $33.3 \pm 35.5$ \\
& 6-month & $52.9 \pm 33.1$ & $51.9 \pm 34.7$ \\
\hline Physical Component & 3-month & $35.1 \pm 11.1$ & $34.9 \pm 12.3$ \\
\hline Scale & 6-month & $39.5 \pm 12.2$ & $38.8 \pm 12.8$ \\
\hline
\end{tabular}

Data are reported as mean \pm SD.

Table D.3 Adjusted parameter estimates of the effect of nutritional adequacy on SF-36 scores in 6-month survivors before and after imputation

\begin{tabular}{|c|c|c|c|c|c|}
\hline \multirow[t]{3}{*}{ SF-36 } & & \multicolumn{4}{|c|}{ Nutritional Adequacy per $25 \%$ increase } \\
\hline & & \multicolumn{2}{|c|}{ Before Imputation } & \multicolumn{2}{|c|}{ After Imputation $(\mathrm{n}=302)$} \\
\hline & & $\begin{array}{c}\text { Adjusted Estimate }^{\mathrm{a}, \mathrm{b}} \\
(95 \% \mathrm{CI})\end{array}$ & p-value & $\begin{array}{c}\text { Adjusted Estimate }^{a} \\
{ }^{b}(95 \% \text { CI })\end{array}$ & p-value \\
\hline \multirow{3}{*}{$\begin{array}{l}\text { Physical } \\
\text { Functioni }\end{array}$} & 3-month & $7.29(1.43,13.15)$ & 0.02 & $6.38(0.69,12.06)$ & 0.03 \\
\hline & & & & & \\
\hline & 6-month & $4.16(-1.32,9.64)$ & 0.14 & $4.68(-1.29,10.65)$ & 0.12 \\
\hline \multirow{3}{*}{$\begin{array}{l}\text { Role } \\
\text { Physical }\end{array}$} & 3-month & $8.30(2.65,13.95)$ & 0.004 & $7.89(2.57,13.20)$ & 0.004 \\
\hline & & & & & \\
\hline & 6-month & $3.15(-2.25,8.54)$ & 0.25 & $4.28(-1.39,9.94)$ & 0.14 \\
\hline Physical & 3-month & $1.82(-0.18,3.81)$ & 0.07 & $1.37(-0.7,3.46)$ & 0.19 \\
\hline \multicolumn{6}{|c|}{ Component } \\
\hline Scale & 6-month & $1.33(-0.65,3.31)$ & 0.19 & $1.62(-0.41,3.65)$ & 0.12 \\
\hline
\end{tabular}


Appendix E Additional Results for Manuscript 2 
Table E.1 Patient baseline and clinical characteristics according to nutritional adequacy groups in 6-month survivors

\begin{tabular}{|c|c|c|c|c|c|}
\hline \multirow[b]{2}{*}{ Variable } & \multirow[b]{2}{*}{ Overall } & \multicolumn{3}{|c|}{ Nutritional Adequacy $^{\mathrm{a}}$} & \multirow[b]{2}{*}{$\begin{array}{c}\text { p- } \\
\text { value }^{b}\end{array}$} \\
\hline & & $\begin{array}{c}\text { Low } \\
(0-<50 \%)\end{array}$ & $\begin{array}{l}\text { Moderate } \\
(50-<80 \%)\end{array}$ & $\begin{array}{c}\text { High } \\
(>-80 \%)\end{array}$ & \\
\hline Number of patients & 302 & $113(37.4 \%)$ & $148(49.0 \%)$ & $41(13.6 \%)$ & \\
\hline Age, yrs & $60.5 \pm 14.3$ & $59.4 \pm 15.2$ & $59.7 \pm 14.8$ & $62.4 \pm 13.8$ & 0.42 \\
\hline Female & $125(41.4 \%)$ & $35(31.0 \%)$ & $69(46.6 \%)$ & $21(51.2 \%)$ & 0.0005 \\
\hline APACHE II score & $26.9(7.2 \%)$ & $26.6 \pm 7.5$ & $26.8 \pm 7.1$ & $25.5 \pm 7.5$ & 0.66 \\
\hline Functional Comorbidity Index & $1.2 \pm 1.3$ & $1.2 \pm 1.3$ & $1.3 \pm 1.3$ & $1.3 \pm 1.5$ & 0.92 \\
\hline Baseline SOFA & $8.6 \pm 3.0$ & $8.6 \pm 3.2$ & $8.6 \pm 3.0$ & $8.6 \pm 2.4$ & 0.19 \\
\hline Admission Category & & & & & 0.0007 \\
\hline Medical & $225(74.5 \%)$ & $64(56.6 \%)$ & $125(84.5 \%)$ & $36(87.8 \%)$ & \\
\hline Surgical & $77(25.5 \%)$ & $49(43.4 \%)$ & $23(15.5 \%)$ & $5(12.2 \%)$ & \\
\hline Primary ICU Diagnosis & & & & & 0.007 \\
\hline Cardiovascular & $47(15.6 \%)$ & $26(23.0 \%)$ & $15(10.1 \%)$ & $6(14.6 \%)$ & \\
\hline Respiratory & $87(28.8 \%)$ & $18(15.9 \%)$ & $50(33.8 \%)$ & $19(46.3 \%)$ & \\
\hline Gastrointestinal & $29(9.6 \%)$ & $16(14.2 \%)$ & $10(6.7 \%)$ & $3(7.3 \%)$ & \\
\hline Sepsis & $96(31.8 \%)$ & $36(31.9 \%)$ & $49(33.1 \%)$ & $11(26.8 \%)$ & \\
\hline Other & $43(14.2 \%)$ & $17(15.0 \%)$ & $24(16.2 \%)$ & $2(4.9 \%)$ & \\
\hline Treatment Arm & & & & & 0.10 \\
\hline Antioxidants & $77(25.5 \%)$ & $22(19.4 \%)$ & $45(30.4 \%)$ & $10(24.4 \%)$ & \\
\hline Glutamine & $78(25.8 \%)$ & $28(24.8 \%)$ & $41(27.7 \%)$ & $9(22.0 \%)$ & \\
\hline Glutamine + Antioxidants & $70(23.2 \%)$ & $30(26.5 \%)$ & $34(23.0 \%)$ & $6(14.6 \%)$ & \\
\hline Placebo & $77(25.5 \%)$ & $33(29.2 \%)$ & $28(19.0 \%)$ & $16(39.0 \%)$ & \\
\hline Body Mass Index, $\mathrm{kg} / \mathrm{m}^{2}$ & & & & & $0.04^{\mathrm{c}}$ \\
\hline Overall mean & $30.7 \pm 8.5$ & $30.7 \pm 8.0$ & $31.3 \pm 9.3$ & $28.5 \pm 6.3$ & \\
\hline Underweight $(<18.5)$ & $3(0.4 \%)$ & $0(0.0 \%)$ & $2(1.4 \%)$ & $1(2.4 \%)$ & \\
\hline Normal weight $(18.5-<25)$ & $79(26.2 \%)$ & $27(23.9 \%)$ & $41(27.7 \%)$ & $11(26.8 \%)$ & \\
\hline Overweight $(25-<30)$ & $90(29.8 \%)$ & $36(31.9 \%)$ & $36(24.3 \%)$ & $18(43.9 \%)$ & \\
\hline Obese I $(30-<35)$ & $60(19.9 \%)$ & $28(24.8 \%)$ & $27(18.2 \%)$ & $5(12.2 \%)$ & \\
\hline Obese II $(35-<40)$ & $30(9.9 \%)$ & $9(8.0 \%)$ & $17(11.5 \%)$ & $4(9.8 \%)$ & \\
\hline Obese III $(>-40)$ & $40(13.2 \%)$ & $13(11.5 \%)$ & $25(16.9 \%)$ & $2(4.9 \%)$ & \\
\hline Region & & & & & $0.12^{\mathrm{c}}$ \\
\hline Canada & $256(84.8 \%)$ & $88(77.9 \%)$ & $130(87.8 \%)$ & $38(92.7 \%)$ & \\
\hline Europe & $9(3.0 \%)$ & $4(3.5 \%)$ & $5(3.4 \%)$ & $0(0.0 \%)$ & \\
\hline USA & $37(12.9 \%)$ & $15(17.9 \%)$ & $11(10.2 \%)$ & $3(9.4 \%)$ & \\
\hline ICU length of stay & $26.0 \pm 18.3$ & $31.4 \pm 46.1$ & $28.0 \pm 34.9$ & $23.8 \pm 14.5$ & 0.16 \\
\hline $\begin{array}{l}\text { Mechanical ventilation } \\
\text { duration }\end{array}$ & $22.9 \pm 34.2$ & $23.8 \pm 39.2$ & $23.0 \pm 34.2$ & $20.4 \pm 14.0$ & 0.04 \\
\hline
\end{tabular}

Data are reported as number $(\%)$ or mean \pm SD. ${ }^{a}$ Proportion of caloric prescription received by enteral nutrition and parenteral nutrition over first 8 days of mechanical ventilation and intensive care unit stay; ${ }^{b}$ to account for intensive care unit level clustering, p-values were calculated by Rao-Scott adjusted chi-squared method for categorical variables and the linear generalized estimating equations for continuous variable; ${ }^{\mathrm{c} C a t e g o r y}$ with cell count $=0$ was removed from the group comparison. 

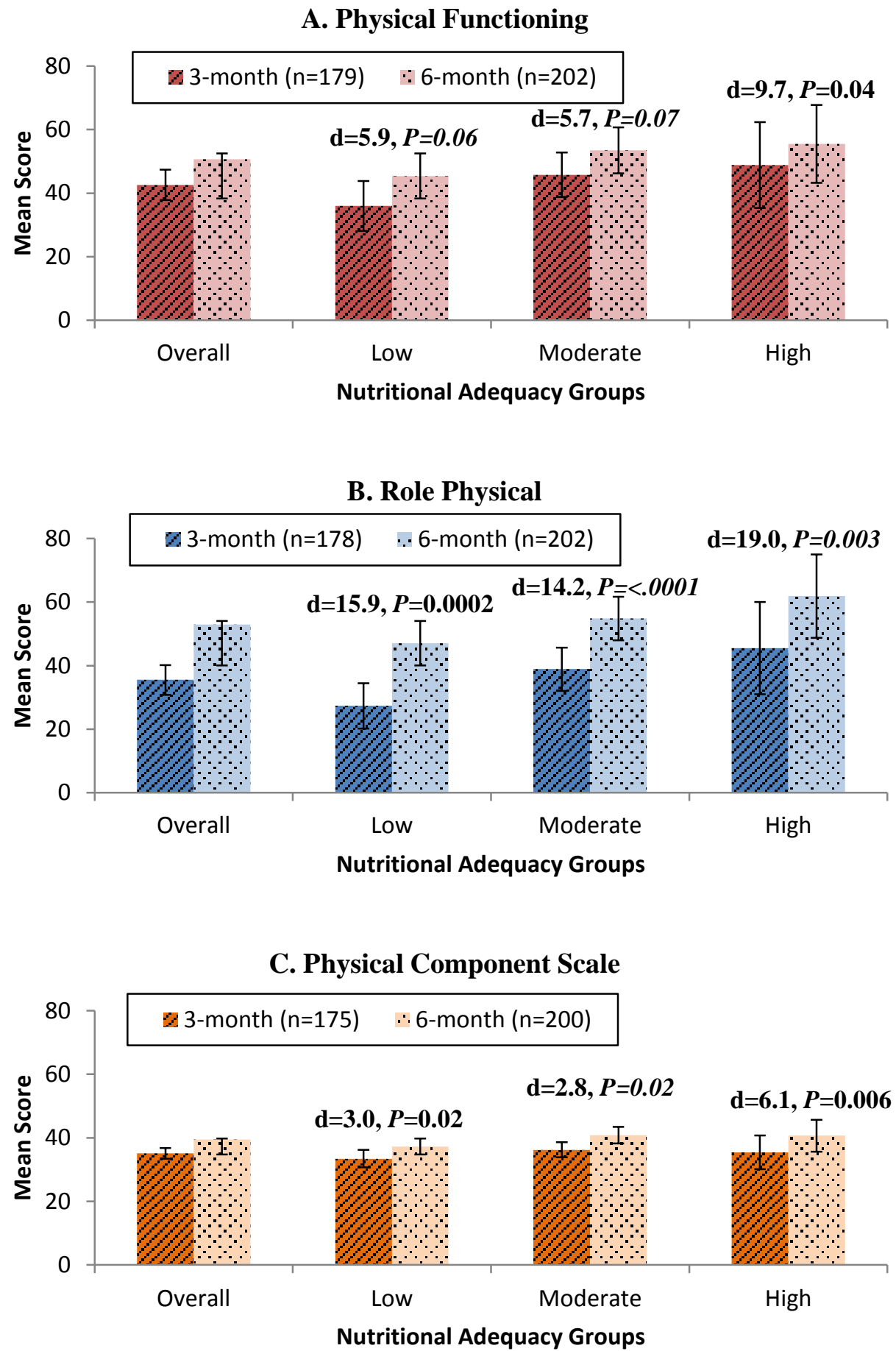

Figure E.1 (A) Mean score for PF according to nutritional adequacy groups in 6-month survivors. (B) Mean score for RP according to nutritional adequacy groups in 6-month survivors. (C) Mean score for PCS according to nutritional adequacy groups in 6-month survivors. (Error bars indicate $95 \%$ confidence intervals of the mean score; $d$ is the mean difference between three-month and six-month mean score and p-values were calculated by paired t-test.) 


\section{Table E.2 Parameter estimates of the effect of nutritional adequacy groups on SF-36 scores in 6-month survivors}

\begin{tabular}{|c|c|c|c|c|c|c|c|c|c|}
\hline \multirow[t]{2}{*}{ SF-36 } & & \multicolumn{4}{|c|}{$\begin{array}{c}\text { Low vs. High } \\
(0=<50 \% \text { vs. }>=\mathbf{8 0 \%})\end{array}$} & \multicolumn{4}{|c|}{$\begin{array}{c}\text { Moderate vs. High } \\
(\mathbf{5 0}=<\mathbf{8 0 \%} \text { vs. }>=\mathbf{8 0 \%}))\end{array}$} \\
\hline & & $\begin{array}{c}\text { Crude Estimate }^{\mathrm{a}} \\
(95 \% \mathrm{CI})\end{array}$ & $p$ & $\begin{array}{c}\text { Adjusted Estimate }{ }^{\mathrm{a}, \mathrm{b}} \\
(95 \% \mathrm{CI})\end{array}$ & $p$ & $\begin{array}{c}\text { Crude Estimate }^{\mathrm{a}} \\
(95 \% \mathrm{CI})\end{array}$ & $p$ & $\begin{array}{c}\text { Adjusted Estimate }{ }^{\mathrm{a}, \mathrm{b}} \\
(95 \% \mathrm{CI})\end{array}$ & $p$ \\
\hline \multirow[t]{2}{*}{$\begin{array}{l}\text { Physical } \\
\text { Functioning }\end{array}$} & $\begin{array}{l}\text { 3-month } \\
(\mathrm{n}=179)^{\mathrm{c}}\end{array}$ & $-12.57(-27.97,2.23)$ & 0.09 & $-10.76(-26.46,4.94)$ & 0.18 & $-3.04(-17.61,11.53)$ & 0.68 & $-2.25(-16.81,12.31)$ & 0.76 \\
\hline & $\begin{array}{l}\text { 6-month } \\
(\mathrm{n}=202)^{\mathrm{c}}\end{array}$ & $-10.05(-24.53,4.44)$ & 0.17 & $-7.34(-22.24,7.55)$ & 0.33 & $-2.02(-16.06,12.03)$ & 0.78 & $-1.80(-15.78,12.18)$ & 0.80 \\
\hline \multirow[t]{2}{*}{ Role Physical } & $\begin{array}{l}\text { 3-month } \\
(\mathrm{n}=178)^{\mathrm{c}}\end{array}$ & $-17.98(-32.53,-3.43)$ & 0.02 & $-16.94(-32.31,-1.57)$ & 0.03 & $-6.38(-20.43,7.68)$ & 0.37 & $-5.66(-19.94,8.62)$ & 0.43 \\
\hline & $\begin{array}{l}\text { 6-month } \\
(n=202)^{c}\end{array}$ & $-14.58(-28.83,-0.33)$ & 0.05 & $-10.07(-24.73,4.59)$ & 0.18 & $-6.83(-20.57,6.91)$ & 0.33 & $-5.88(-19.62,7.86)$ & 0.40 \\
\hline \multirow{2}{*}{$\begin{array}{l}\text { Physical } \\
\text { Component } \\
\text { Scale }\end{array}$} & $\begin{array}{l}\text { 3-month } \\
(\mathrm{n}=175)^{\mathrm{c}}\end{array}$ & $-1.94(-7.14,3.26)$ & 0.46 & $-1.51(-6.92,3.90)$ & 0.58 & $-0.88(-4.13,5.88)$ & 0.73 & $-1.05(-3.96,6.05)$ & 0.68 \\
\hline & $\begin{array}{l}\text { 6-month } \\
(\mathrm{n}=200)^{\mathrm{c}}\end{array}$ & $-3.22(-8.50,2.07)$ & 0.23 & $-1.84(-7.23,3.55)$ & 0.50 & $-0.36(-4.70,5.42)$ & 0.89 & $-0.81(-4.21,5.84)$ & 0.75 \\
\hline
\end{tabular}

${ }^{\mathrm{a}}$ The estimate provides the difference in SF-36 scores between the nutritional adequacy groups; ${ }^{\mathrm{b}}$ Adjusted for age, APACHE II score, baseline SOFA, Functional Comorbidity Index, admission category, and region; ${ }^{c}$ provides the number of responders for each SF-36 score. 


\section{Appendix F Ethics Approval}

\section{Queens}

QUEEN'S UNIVERSITY HEALTH SCIENCES \& AFFILIATED TEACHING HOSPITALS RESEARCH ETHICS BOARD-DELEGATED REVIEW

November 23, 2012

Ms. Xuejiao Wei

Department of Community Health and Epidemiology

Queen's University

Dear Ms. Wei

Study Title: EPID-403-12 The association between nutritional adequacy and long-term outcomes in critically ill patients: an international multicenter longitudinal study

File \# 6007550

Co-Investigators: Dr. D. Heyland, Mrs. H. Ouellette-Kuntz

I am writing to acknowledge receipt of your recent ethics submission. We have examined the protocol and the (REDOX study protocol, survey and consent form) for your project (as stated above) and consider it to be ethically acceptable. This approval is valid for one year from the date of the Chair's signature below. This approval will be reported to the Research Ethics Board. Please attend carefully to the following listing of ethics requirements you must fulfill over the course of your study:

Reporting of Amendments: If there are any changes to your study (e.g. consent, protocol, study procedures, etc.), you must submit an amendment to the Research Ethics Board for approval. Please use event form: HSREB MultiUse Amendment/Full Board Renewal Form associated with your post review file \# $\mathbf{6 0 0 7 5 5 0}$ in your Researcher Portal (https://eservices.queensu.ca/romeo_researcher/)

Reporting of Serious Adverse Events: Any unexpected serious adverse event occurring locally must be reported within 2 working days or earlier if required by the study sponsor. All other serious adverse events must be reported within 15 days after becoming aware of the information. Serious Adverse Event forms are located with your postreview file 6007550 in your Researcher Portal (https://eservices.queensu.ca/romeo_researcher)

Reporting of Complaints: Any complaints made by participants or persons acting on behalf of participants must be reported to the Research Ethics Board within 7 days of becoming aware of the complaint. Note: All documents supplied to participants must have the contact information for the Research Ethics Board.

Annual Renewal: Prior to the expiration of your approval (which is one year from the date of the Chair's signature below), you will be reminded to submit your renewal form along with any new changes or amendments you wish to make to your study. If there have been no major changes to your protocol, your approval may be renewed for another year.

Yours sincerely,

$$
\text { Quent } 7 \text {. Clate. }
$$

Chair, Research Ethics Board November 23, 2012

Investigators please note that if your trial is registered by the sponsor, you must take responsibility to ensure that the registration information is accurate and complete 